\title{
Morphological structure can escape reduction effects from mass admixture of second language speakers: evidence from Sino-Tibetan
}

\author{
M. Widmer, M. Jenny, W. Behr \& B. Bickel \\ University of Zurich
}

Morphological complexity is expected to decrease under mass admixture from adult second language speakers. While this has been chiefly shown for morphological richness, an unresolved question is whether the effect extends to aspects of morphological boundedness. Here we report a case study of Sino-Tibetan verbs, contrasting verbal expressions of two languages with very large (Chinese, Burmese) and of two languages with very small (Bunan, Chintang) numbers of second language speakers. We find that while the amount of second language speakers accounts for differences in the range and number of inflectional categories (degrees of synthesis), it does not affect the way in which morphological constituents are bound together, reflecting fortification through a mix of diachronically stable and universally preferred patterns. This calls for theoretical models that narrow down the range of changes that are driven by second language speaker admixture, and for extensive empirical testing on a global scale.

\section{Introduction}

It has often been hypothesized that mass admixture of adult second language (L2) speakers causes a reduction of morphological complexity in languages (Trudgill 2001, 2011; McWhorter 2007; Wray \& Grace 2007). Empirical support for this hypothesis has chiefly come from data on morphological richness, operationalized either by word form variation in corpora (Bentz \& Winter 2013) or by databases registering the morphological vs. syntactic coding of various categories (Lupyan \& Dale 2010). Here we examine the extent to which effects from L2 admixture extends to structural dimensions of morphological complexity in verbal expressions, specifically to the various dimensions of phonological and syntactic boundedness that elements can have and thereby enter various wordlike domains. These dimensions are crucially involved in making morphemes more vs. less transparently and consistently identifiable for adult L2 learners. Some examples of such oppositions are: (i) tightly bound affixes with boundaries blurred by morphophonological alternations vs. phonologically isolated and formally stable morphemes; (ii) affixes whose occurrence depends on the simultaneous occurrence of related affixes in other slots vs. simple linear sequences; (iii) consistently positioned, "framed" affixes vs. "hard-to-catch", free-floating clitics without a well-defined host; (iv) lengthy combinations under a single stress domain vs. separately stressed morphemes. Any of these, and many more dimensions, can be expected to be affected by L2 admixture, but the presence of such effects has remained largely unexplored.

Unfortunately, current databases do not yet resolve data to a sufficient level for worldwide assessment. We therefore report here a small-scale case study instead. With this study, we aim at refining our understanding of the L2 effect on morphology and thereby at paving the way for more specific models of the effect and for larger test arrays. 
Our study focuses on Sino-Tibetan. ${ }^{1}$ This large and far-flung family provides an ideal test case because it comprises languages with large-scale and sustained admixture of L2 speakers as well as languages spoken by small minority communities with hardly any L2 speakers. Consistent with the hypothesized correlation between L2 admixture and morphological complexity, DeLancey (2013, 2015) has proposed a morphological divide in Sino-Tibetan, with morphologically rich languages as preserving ancestral patterns and morphologically poor languages as resulting from more recent L2 admixture and creolization effects. The divide also corresponds to some extent to traditional stereotypes associated with the better-known Southeast and East Asian languages as lacking morphology and being of the isolating type.

As representative of languages with large L2 admixture we choose Mandarin Chinese ${ }^{2}$ (Glottocode mand1415) and Burmese (nucl1310). Mandarin Chinese and Burmese have approximately 20\% L2 speakers (out of $1.1 \mathrm{bn}$ and $52 \mathrm{~m}$ total speakers, respectively) and have had substantial numbers of L2 speakers throughout their documented history, and probably also for much of their undocumented history (Behr 2004, 2010). As languages with small L2 admixture we choose Chintang (chhi1245) and Bunan (gahr1239). In Chintang and Bunan we estimate at most a dozen or two of L2 speakers each, out of about 6,000 and 4,000 speakers, respectively. There is no evidence that either Chintang and Bunan had a substantial number of L2 speakers in their history. ${ }^{3}$ The contrast between the languages is visualized in the map in Figure 1.

We choose these languages as representative of large vs. small L2 admixture cases because we have fieldwork access to data and because the languages come from different phylogenetic clades. Current estimates put the age of the last common ancestor between 5,900 and 7,400 years before present

\footnotetext{
${ }^{1}$ Also known as Trans-Himalayan or Tibeto-Burman. These labels are associated with debates on the family's phylogeny that are orthogonal to our present purposes. We use the Glottolog name for the family and follow Sagart et al. (2019) for the phylogeny.
}

2 As Mandarin is spoken across a vast territory by hundreds of millions of speakers, there is a considerable amount of regional variation within the language. Throughout this paper, "Mandarin Chinese" is understood as the Northern Mandarin official standard known as pǔtōnghuà 普通话 in the People's Republic of China, which is historically based on - though in many respects different - from the city dialect of Bějīng (Bějinghuà 北京 话). We acknowledge that many other Mandarin varieties, including the standard known as Taiwan Mandarin (guóyŭ 國語) propagated in the Republic of China, Taiwan, differ from pǔtōnghuà in various lexical and phonological dimensions such as tonal reduction, stress patterning etc. For our description of the verbal morphology of pǔtōnghuà we primarily draw on the grammars by Li \& Thompson (1981) and Wiedenhof (2015)

${ }^{3}$ There is evidence that Bunan is closely affiliated with the language of Zhangzhung, a polity that dominated the western half of the Tibetan Plateau in the $6^{\text {th }}$ century CE (Sharma 1989: 10-12; van Driem 2001b; Widmer 2017: 52-53). Since Zhangzhung was a major political power in its time, it is possible that the Zhangzhung language had a wider distribution and presumably also a certain amount of L2 speakers (DeLancey 2013: 60). Together, these facts give rise to the question of whether Bunan (or more precisely its ancestor) could not have had a considerable number of L2 speakers. There are several reasons to doubt this. First, it is not clear whether Zhangzhung is the direct ancestor of Bunan. It is equally possible that Zhangzhung and the language ancestral to Bunan already existed as distinct languages by the $6^{\text {th }}$ century $\mathrm{CE}$ and subsequently developed independently. Second, the Zhangzhung polity seems to have been the dominating political power on the plateau for only little more than a century (Aldenderfer \& Zhang 2004: 42). Even if the Zhangzhung language would have acted as a lingua franca on the plateau during that time, this would leave a comparatively short time period of a few speaker generations during which the language could have absorbed larger populations of L2 speakers. This cannot be directly compared to the repeated and sustained L2 admixture that Mandarin Chinese and Burmese saw throughout their history. 


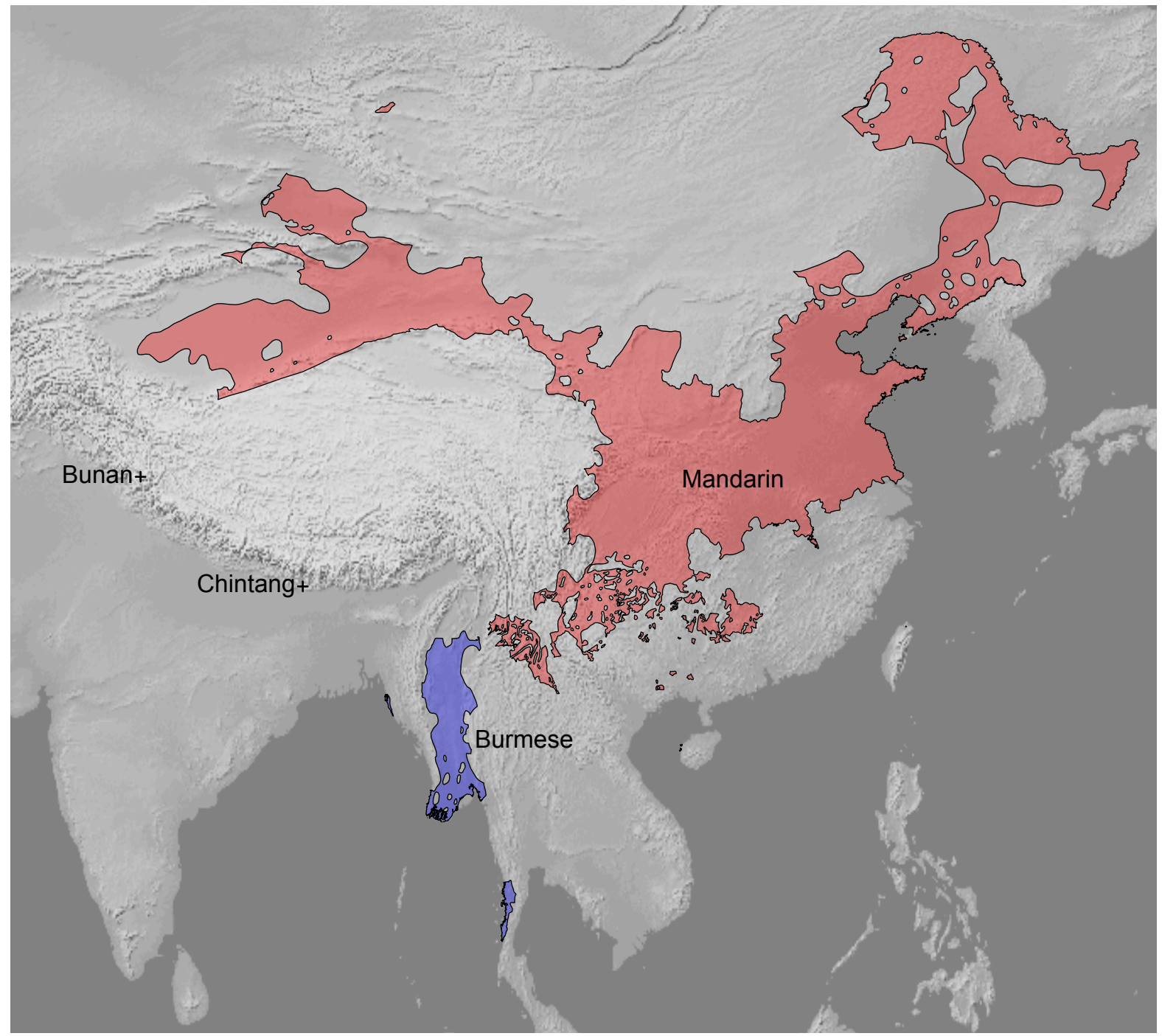

Figure 1. Areas covered by the languages in the sample according to the 16th edition of the Ethnologue (Lewis 2009). Base map from http://naturalearthdata. com.

(Sagart et al. 2019; Zhang et al. 2019). ${ }^{4}$ This divergence time is long enough to minimize the risk of masking L2 admixture effects through strong phylogenetic autocorrelation (where related languages remain similar by default).

In what follows, we explain our methods for comparing phonological and grammatical boundedness in Section 2. In Section 3 we apply these methods to our data and extract morphological structures in each language. Section 4 summarizes and quantifies the findings of our survey and Section 5 discusses the distribution of morphological structures across the two degrees of L2 admixture in our sample. Section 6 concludes the paper with implications for general theories of the relationship between morphology and L2 admixture.

\footnotetext{
${ }^{4}$ This is also largely consistent with traditional topologies (Bradley 1997; van Driem 2001a; Thurgood 2017). Chintang and Bunan are sometimes placed in the same top-level group, but even then it is uncontroversial that they belong to highly distinct clades within such a group.
} 


\section{Methods}

While the difference between phonological and grammatical dimensions of morphological boundedness is well-established (Dixon 1977; Hall \& Kleinhenz 1999; Dixon \& Aikhenvald 2002; Anderson 2005; Hall et al. 2008, etc.), research over the past decade has documented additional variation in how elements can be bound together within phonology and within grammar (Hyman 2008; Bickel et al. 2009; Post 2009; Schiering et al. 2010; Hildebrandt 2007; Haspelmath 2011). Morphemes 5 enter a multitude of cohesion domains (i.e. various kinds of phonological or grammatical "words"), depending on which rule or constraint one looks at.

To capture this variation, we adopt a multivariate approach to boundedness and the domains that are defined by bound elements. Following Bickel \& Zúñiga (2017), we distinguish three ways in which morphemes can be bound, each spanning multiple dimensions of variation:

(1) a. SELECTION: $\mathrm{X}$ requires $\mathrm{Y}$ in any context

b. INFLECTION: $\mathrm{X}$ requires $\mathrm{Y}$ in a specific grammatical context

c. COHESION: $\mathrm{X}$ and $\mathrm{Y}$ behave as a unit with respect to (syntactic or phonological) constraint or rule $^{6} \mathrm{Z}$

The SELECTION and INFLECTION variables identify the types of morphemes that a language has, while the COHESION variables define how these types are combined into larger, word-like structures. In what follows, we explain and illustrate these variables in more detail.

The SELECTION variable captures the observation that some elements, e.g. expressions like English ed, the or former, require a host for their appearance. This is independent of whether they are phonologically independent (cf. phonologically dependent the and ed vs independent former), and also independent of whether they need to be directly adjacent to the host (adjacent ed vs not necessarily adjacent the and former). Thus, SELECTION only captures the specific combinatorial requirements of an element, and we keep this distinct from independent pronounceability and from the syntactic behavior in terms of adjacency, linear order, or position. Indeed, an element can select a host even when it is uttered on its own. This is the case for example with English auxiliaries which select a verbal host, but can be uttered alone when their host can be fully reconstructed from the context, i.e. in cases of elliptical answers (have you read this? - I have.). The possible values of the SELECTION variable are defined by what is selected, both in terms of its complexity (a single morpheme, a phrase, a sentence) and its category (a verb morpheme vs. a noun morpheme, a verb phrase vs. a noun phrase etc.)

The INFLECTION variable specifies whether a given morpheme requires the presence of additional morphemes in order to occur in a specific grammatical context (Bickel \& Nichols 2007). A verb may, for example, require tense, aspect, and agreement markers to occur in a specific clause context (e.g. a main clause), but only aspect in another context (e.g. a referentially controlled infinitival clause).

While both INFLECTION and SELECTION specify co-occurrence requirements, they differ in the scope of this requirement. SELECTION is general boundedness, i.e. the selecting element simply cannot occur

\footnotetext{
5 We use the term "morpheme" as a cover term for any kind of identifiable phonological exponent of some semantic or syntactic function with well-defined combinatorial possibilities. We consider it to be an orthogonal question how combinations of morphemes are best modeled in formal representations, e.g. in terms of derivations, paradigm functions, constructions etc.

${ }^{6}$ In the remainder we talk about "constraints", but nothing in our analyses depends on whether patterns are formulated as rules or constraints. Also, we remain neutral as to whether the patterns are best captured in a generative or constraint-based system of representations.
} 
without its host (or at least not without cognitive access to the host, as in cases of ellipsis). INFLECTION is restricted boundedness, i.e. the inflecting element requires the inflection only in a given context (e.g. only in main clauses). Often, SELECTION and INFLECTION are mutually exclusive. For example, most English verb stems do not select anything, but they inflect (albeit with only very few forms). As we will see, however, the Sino-Tibetan languages in our sample have an important class of verbs - often called "secondary verbs" or "V2" in the specialist literature - that select other verbs, and at the same time inflect. This means that they are doubly bound: once to the verbal host that they select, and once to the inflectional morphemes that they require, minimally in terms of aspect and/or polarity markers, but often including also categories of agreement, tense, and various notions of evidentiality and mirativity. The choice of these categories defines the values of the INFLECTION variable, specific to given syntactic contexts.

Like SELECTION, INFLECTION is completely independent of phonological and syntactic behavior in such terms as phonological fusion or linear adjacency. Some exponents of English inflection, for example, are auxiliaries, and these are independent from the verb stems whose inflection they realize, both phonologically (when they cliticize, they do so with other elements, e.g. a pronoun as in we'll go) and syntactically (they don't need to be adjacent to the verb, e.g. will you go?)

The SELECTION and INFLECTION variables together allow determining the types of morphemes that a language has available for generating morphological structures. For example, English distinguishes, among others: "verb stems", defined as morphemes requiring tense, aspect and mood as well as limited person inflection (TAM); or "nominal phrasal affixes", defined as elements selecting an NP host $(' s, t o)$. In our analysis below we use the INFLECTION and SELECTION variables to determine the range of morpheme types that each language has in its verbal expressions.

The morpheme types so defined may or may not be bound together into coherent structures. This notion of "bound" is captured by variables of COHESION. Phonological COHESION approximates one of the most prominent senses of "bound": the observation that some elements (English ed or 's) form a phonological domain together with some other element (their phonological host), as witnessed by the application of phonological constraints (e.g. stress-induced vowel reduction). Phonological COHESION domains differ from smaller phonological units like syllable or feet in that they reference morpheme structure, although the constraints are not tied to individual, lexically specified morphemes, but hold in a general way (Nespor \& Vogel 2007; Schiering et al. 2010; Hildebrandt 2014). In other words, phonological COHESION domains are properties only of what is sometimes referred to as postlexical rules and constraints.

Grammatical COHESION captures ways in which grammatical, rather than phonological, constraints can bind morphemes together. For example, in compounding, two (non-selecting) morphemes are bound together so that neither element can be extracted anymore (compare: the sentence we studied the structure of _, with a syntactic dependency pointing to the non-coherent expression the structure of [the sentence] vs. *the sentence we studied the _ structure, with a dependency pointing to the coherent expression the [sentence] structure). Like phonological COHESION domains, grammatical COHESION domains reference morpheme structure, i.e. the types defined by selection and inflection. In this, they differ from larger syntactic units which also reference phrases and entire clauses.

A particularly important type of grammatical COHESION is imposed by linear order constraints, and the relevant cohesion domains often differ between phonology and grammar. The English reduced auxiliaries ' $l l$ or 've for example, follow their phonological host while they do not at the same time form a grammatical domain with their syntactically selected host (the verb stem). In our analysis below we assess linear order principles only when they are fixed by specific COHESION domains. Note 
that this also entails that SELECTION is a purely combinatorial notion, independent of linearization into surface strings; we see linearization as an effect of COHESION domain formation.

Coherent phonological and grammatical domains are often called phonological and grammatical "words" respectively. We avoid this terminology for two reasons. First, the terminology invites the expectation that a language has only one phonological and only one grammatical cohesion domain, whereas many languages define several non-isomorphic domains (Schiering et al. 2010). Second, the label "word" is associated with lexicality, while we consider questions of lexical storage or the existence of a dedicated lexical word-formation "module" in the language faculty as orthogonal to the definition of domains and therefore outside our purview. Another terminology uses $\mathrm{X}^{0}$ for grammatical cohesion domains (e.g. Bruening 2018), but this again invites expectations of convergence which may or may not be warranted. Also, the $\mathrm{X}^{0}$ concept is commonly associated with specific proposals for analyzing phrase structure (e.g. binary branching and strict endocentricity) that go far beyond our methodological needs.

Some approaches to cohesion also recruit semantic patterns such as lexical collocation and conventionalization (Dixon \& Aikhenvald 2002). We do not include such patterns because collocations also encompass phrasal or even sentential units (as in idioms like kick the bucket or once a cheater always a cheater), and this casts doubt on their relevance for defining cohesion domains on a par with those established by phonological and grammatical rules or constraints.

Similarly, we exclude from our analysis any assessment of whether morpheme meanings are "lexical" or "grammatical" (siding with Construction Grammar approaches; Booij 2010). The boundary between lexical and grammatical is notoriously difficult to maintain. Consider the case of the Bunan V2 pay, which expresses the speaker's fear that the event described by the main verb might occur in the future (see Section 3.1.1 for examples). Speakers of Bunan do not assign any lexical meaning to this morpheme in isolation and can only interpret it in combination with an accompanying main verb. Based on these facts, one might argue that pay expresses grammatical meaning and should thus be glossed as APPR (for 'apprehensive'). At the same time, pay clearly behaves like a verb from a structural point of view, and speakers usually assign it the meaning '(to) fear' when asked to translate an utterance containing pay. Accordingly, one might as well argue that pay has the lexical meaning '(to) fear', but can only express this meaning in combination with an accompanying main verb. These considerations, which could be repeated ad libitum in many languages worldwide (Bickel \& Zúñiga 2017), suggest that the grammatical vs lexical distinction is not particularly helpful for understanding morphological structure. ${ }^{7}$

Along the same lines, we do not expect any strict correlation between specific morphological structures and specific grammatical functions. Accordingly, we have no expectations about the morphological realization of grammatical categories, e.g. whether negation is expressed as a V2 (as is partly the case in Chintang) or as a phrasal affix (as is the case in Mandarin).

We restrict our attention to main clause contexts with maximum inflectional requirements. This allows us to compare our findings directly with the measurement of synthesis in the World Atlas of Language Structure (Bickel \& Nichols 2005) and the AUTOTYP database (Bickel et al. 2020), where synthesis captures the maximum number of inflectional categories that can be expressed in a verb form.

\footnotetext{
${ }^{7}$ In our data, we gloss V2s with grammatical abbreviations if there is a well-known and established label for the relevant function (such as APPR for 'apprehensive' in the case of the Bunan V2 pay). Otherwise, we will give a lexical translation.
} 


\section{Analysis}

In what follows we apply the analytical methods described above to the four languages in our sample. In each of them we recruit the SELECTION and INFLECTION variables to identify types of morphemes and the COHESION variables to determine the domains in which these types are bound together. We limit our purview to verbal morphology, defined here as any structure that contains at least one morpheme that selects a verbal host (a verb stem or a verb phrase). Often, however, morphemes that do not select verbal hosts (e.g. focus clitics) interact with selecting morphemes, for example, they may be included into a single stress domain together with selecting morphemes. To round off our analyses, we include such non-selecting morphemes if they show any such interaction.

In order to study COHESION domains, we first set up a maximally complex morphological template of the verbal complex for each language. This template exhaustively lists all slots for morphemes that select verbs (i.e. V2, preverbs, affixes) or verb phrases (i.e. verbal phrasal affixes). Morphemes that do not exclusively select verbs (i.e. clitics, free phrasal affixes, sentential affixes) are then added to this template according to their preferred position of placement. The resulting template is used to identify cohesion domains. Less complex morphological templates are only taken into consideration if a given cohesion domain does not manifest itself in the maximally complex morphological template.

\subsection{Bunan}

Bunan is a West Himalayish language spoken by approximately 4,000 speakers in the North Indian state of Himachal Pradesh. Using the criteria defined in Section 2, we can identify the following morpheme types for Bunan:

Table 1. Bunan morpheme types.

\begin{tabular}{llll}
\hline Morpheme type & SELECTION & INFLECTION & Example \\
\hline verb (V) & - & TAMEP, AGR, VOICE, VAL & $d z a$ 'eat' \\
secondary verb (V2) & $\mathrm{V}$ & TAMEP, AGR, VOICE, VAL & $\mathrm{pay}$ 'APPR' \\
affix (AFF) & $\mathrm{V}(2)$ & - & $\mathrm{ma}$ 'NEG' \\
preverb (PV) & $\mathrm{V}$ & - & ha: 'understand' (with go) \\
free phrasal affix (FPA) & $\mathrm{XP}$ & - & tok 'DAT' \\
sentential affix (SA) & $\mathrm{S}$ & - & $l a$ 'Q' \\
\hline
\end{tabular}

Verbs can inflect for S, A and P agreement (AGR), tense/aspect, mood, evidentiality, polarity (TAMEP). In addition, they code valency (VAL) depending on the syntactic argument-structure context (continuing what is sometimes referred to as coronal augments in Sino-Tibetan studies). Independently of this, they signal voice alternations.

The morpheme type V2 comprises a number of secondary verbs, which express a range of different aspectual notions. Bunan secondary verbs select main verbs in the sense that they cannot support their own arguments, but rather adopt the argument structure of the main verb. At the same time, they are clearly verbs in the sense that they inflect for various grammatical categories, albeit to different degrees. The apprehensive secondary verb pay, for example, inflects for tense, valency, and agreement, while the resultative secondary verb el, on the other hand, inflects for tense, mood, evidentiality, egophoricity, agreement, and polarity.

The class of affixes comprises a number of morphemes expressing various grammatical categories such as tense, aspect, egophoricity, person, or polarity and these attach to V or V2 morphemes. 
Examples of affixes are the preverbal negation affix ma or the postverbal egophoric past tense affix et. The class of preverbs consists of morphemes that form a so-called "bipartite stem" (Jacobson 1980; DeLancey 1996; Bickel \& Nichols 2007) together with the main verb. Preverbs select main verbs but never secondary verbs. Also, they do not inflect. Examples of Bunan preverbs are aks, which together with the verb root tak expresses the meaning 'invite', or ha:, which together with the verb root go expresses the meaning 'understand'. The class of free phrasal affixes comprises a number of case markers with converbial function (e.g. the dative marker $t o k^{8}$ ) as well as information-structure markers (e.g. the additive marker $r e$ ), while the class of sentential affixes contains some markers with discourse-related functions (e.g. the question marker la).

\subsubsection{Grammatical cohesion in Bunan}

Insertion and displacement potential: [PV-V-AFF-AFF-V2-AFF-FPA-SA]. The largest grammatical domain in the Bunan verb comprises the entire string of morpheme types that make up the verb complex, i.e. [PV-V-AFF-AFF-V2-AFF-FPA-SA]. This domain is evidenced by its lack of insertion and displacement potential. That is to say, extraneous constituents cannot be inserted into the relevant morpheme string (unless of course they are not extraneous and instead select the verb or the verb phrase). At the same time, it is not possible to displace any morpheme of the verbal string independently of other morphemes. Consider:

\begin{tabular}{|c|c|c|c|c|c|c|}
\hline \multirow[t]{2}{*}{ a. $\left[k^{h} O t \in i\right]$} & [mundak] & {$[k j a$} & $d e$ & pay & $\varnothing$ & kata]. \\
\hline & & & $\mathrm{AFF}$ & V2 & $\mathrm{AFF}$ & AFF] \\
\hline later & dark & become & SUP & APPR & TR & FUT.NON1SG \\
\hline 'It migh & comp & ater.' & & & & \\
\hline
\end{tabular}

Ordering: [PV-V-AFF] vs. [AFF-V2-AFF-FPA-SA]. Two further grammatical domains, [PV-V-AFF] vs. [AFF-V2-AFF-FPA-SA], are evidenced by the ordering of morpheme types in a verbal expression. The ordering of preverbs, affixes, free phrasal affixes, and sentential affixes in relation to verbs and secondary verbs is fixed. The ordering of verbs and secondary verbs, by contrast, is driven by the meaning of the relevant verbs.

Cross-slot dependency I: [AFF-V-AFF]. There is a cross-slot dependency that references a domain [AFF-V-AFF]. The relevant cross-slot dependency holds between the preverbal prohibitive affix $t^{\text {h }} a$ and the postverbal imperative affix $a(\mathrm{SG}) / n i(\mathrm{PL})$. The dependency arises from the fact that the prohibitive marker $t^{h} a$ necessarily has to co-occur with an imperative suffix, while imperative suffixes may otherwise appear in isolation. This is illustrated by the following examples.

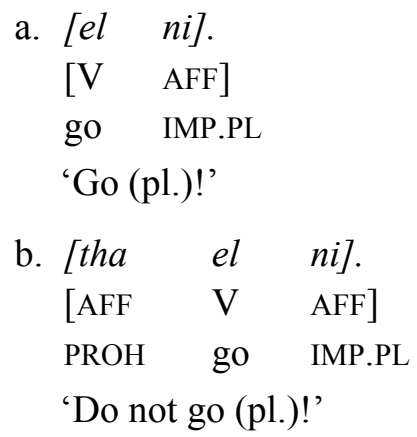

\footnotetext{
${ }^{8}$ The dative case marker tok attaches to active participle forms and gives them the status of subordinate clause heads. The resulting adverbial clause expresses circumstantial semantics, e.g. mar ma ni i tok [butter NEG EX PTCP DAT] 'Without there being butter, ...' (Widmer 2017: 690).
} 
Note that this cross-slot dependency is only attested for main verbs but not secondary verbs, as Bunan does not display secondary verbs that can occur in prohibitive contexts. As a consequence, we cannot test whether the constraint also holds for secondary verbs.

Cross-slot dependency II: [AFF]. An additional cross-slot dependency references the domain [AFF]. The relevant dependency holds between the postverbal egophoric undergoer affix $k u$ and the postverbal direct evidential past tense affix $d z a(\mathrm{SG}) / t s^{h} a(\mathrm{PL})$. The egophoric undergoer affix is optional and can only occur in combination with the direct evidential past tense affix, while the direct evidential past tense affix can occur irrespectively of whether the affix $k u$ is absent or present. ${ }^{9}$ Consider:

$$
\begin{aligned}
& \text { a. } k^{h} e t \varnothing \quad d z a \text {. } \\
& \mathrm{V} \quad \mathrm{AFF} \text { AFF } \\
& \text { beat TR PST.DIR.ALLO.SG } \\
& \text { '(S/he) beat (me).' } \\
& \text { b. } k^{h} \text { et } \varnothing \quad[k u \quad d z a] \text {. } \\
& \mathrm{V} \quad \mathrm{AFF} \quad[\mathrm{AFF} \quad \mathrm{AFF}] \\
& \text { beat TR UND.EGO PST.DIR.ALLO.SG } \\
& \text { '(S/he) beat (me).' } \\
& \text { c. }{ }^{*} k^{h} e t \varnothing k u \text {. }
\end{aligned}
$$

\begin{tabular}{|c|c|c|c|c|c|}
\hline [lwat & $s$ & $d z i$ & $e l$ & $d z i]$ & ['lwas(i)elzi] \\
\hline$[\mathrm{V}$ & AFF & AFF & V2 & $\mathrm{AFF}]$ & \\
\hline forget & DETR & PCVB & RESUL & PST.INFER.ALLO.SG & \\
\hline
\end{tabular}

\subsection{Phonological cohesion domains in Bunan}

Stress anchoring: [PV] vs. [V-AFF-AFF-V2-AFF-FPA-SA] vs. [V-AFF] vs. [AFF-V2-AFF-FPA-SA]. The largest phonological domain [V-AFF-AFF-V2-AFF-FPA-SA] comprises all morpheme types of the verbal complex expect for preverbs and is referenced by stress anchoring. Within this domain, there is only one main stress, which falls on the verb stem. ${ }^{10}$ If there are two (nongrammatical) syllables, stress follows an iambic pattern and falls on the second syllable (Widmer 2017). Consider:

The smaller domains [V-AFF] and [AFF-V2-AFF-FPA-SA] are referenced in V2 constructions in which the main verb and the secondary verb constitute separate stress domains. An example is given below:
(6)

$\begin{array}{lllll}{[\text { dat }} & \text { de }] & {[\text { pay }} & \varnothing & \text { kata }] . \\ {[\mathrm{V}} & \mathrm{AFF}] & {[\mathrm{V} 2} & \mathrm{AFF} & \mathrm{AFF}] \\ \text { fall } & \text { SUP } & \text { APPR } & \text { TR } & \text { FUT.NON1SG }\end{array}$
['da?de 'paygata]

'S/he might fall.'

\footnotetext{
9 The egophoric undergoer affix $k u$ is frequently attested in the speech of the oldest speaker generation, but is only rarely found in the speech of younger speakers. It thus has to be considered as an archaic grammatical feature that is on the verge of becoming obsolete (Widmer 2017: 471-474).

${ }^{10}$ Bunan stress follows a trochaic pattern when words are uttered in isolation. This trochaic pattern is masked by a iambic stress pattern when words are uttered in the context of phrases. Since only lexical syllables can attract stress, the iambic pattern only manifests itself in contexts in which lexical roots consists of more than one syllable. We here take the trochaic pattern as the basic one. See Widmer (2017) for a more detailed discussion of Bunan stress.
} 
Preverbs always carry their own stress and, accordingly, constitute a stress domain [PV-AFF] of their own. Consider:

\begin{tabular}{|c|c|c|c|c|c|c|}
\hline [ha: & $m a]$ & {$[g o$} & $s$ & 6 & $d z a]$ & ['ha:ma 'gosa] \\
\hline$[\mathrm{PV}$ & $\mathrm{AFF}]$ & {$[\mathrm{V}$} & $\mathrm{AFF}$ & $\mathrm{AFF}$ & $\mathrm{AFF}]$ & \\
\hline understand & NEG & understand & DETR & MID & PST & \\
\hline
\end{tabular}

Onset requirement: [PV-V-AFF-V2-AFF-FPA]. The phonological domain [PV-V-AFF-V2-AFF-FPA] is referenced by the constraint of onset requirement. According to this constraint, the relevant domain has to begin with a consonantal onset. If no consonant is present in the underlying representation, a glottal stop is inserted. Consider:

$$
\begin{array}{lllll}
{[\text { tal }} & 6 i] & {[i p t} & 6 & \left.t_{6}{ }^{h}\right] \\
{[\mathrm{N}} & \mathrm{AFF}] & {[\mathrm{V}} & \text { AFF } & \text { AFF }] \\
3 & \text { PL } & \text { sleep } & \text { MID } & \text { PCVB.PL }
\end{array}
$$

$\left[\right.$ talæi Pipt $\left.^{h} i\right]$

'They slept and ....'

We cannot establish whether preverbal affixes and postverbal sentential affixes are part of this domain, as there are no vowel-initial instances of the relevant morpheme types in Bunan.

Voicing: [V(2)-AFF-FPA]. The phonological domain [V(2)-AFF-FPA] is referenced by a voicing constraint. The constraint affects voiceless unaspirated obstruents that occur in intervocalic position at a morpheme boundary between verb stems, suffixes, and free phrasal suffixes and turns them into voiced sounds. The alveo-dental plosive / $\mathrm{t} /$ additionally undergoes lenition to [r]. Prefixes are explicitly excluded from this domain. The status of sentential suffixes cannot be established as they do not display the appropriate phonological shape to be affected by this constraint. Relevant examples include the following.

$\left[\begin{array}{ll}\mathrm{V} & \mathrm{AFF}\end{array}\right]$

stumble PTCP

'stumbling.'

b. $\left[\begin{array}{lll}d z a & k & e k\end{array}\right]$

[ $\left.\begin{array}{lll}\mathrm{V} & \mathrm{AFF} & \mathrm{AFF}\end{array}\right]$

$\left[d z a \mathbf{g} \varepsilon^{2} k{ }^{\top}\right]$

drink INTR PRS.EGO.SG

'(I) am eating.'

c. $\left[\begin{array}{lll}d z a & d e & t o k\end{array}\right]$

[ [ AFF FPA]

[dzarero? $\left.{ }^{2}\right]$

eat SUP DAT

'in order to eat'

d. tha [ $\left.\begin{array}{ll}k a n & a\end{array}\right]$

AFF [V AFF $]$

[bubi]

PROH look IMP.SG

'Do not look (at it)!'

Intervocalic deletion: [V(2)-AFF]. The phonological domain $[\mathrm{V}(2)-\mathrm{AFF}]$ is evidenced by the intervocalic deletion of velar nasals $/ \mathrm{V \eta V} />[\tilde{\mathrm{V}} \tilde{\mathrm{V}}]$. If the two vowels have different qualities, they merge into a nasalized diphthong. If they have the same quality, they merge into a nasalized long 
vowel. The constraint only holds between verb stems and suffixes but does not affect prefixes. The status of free phrasal and sentential suffixes cannot be established. The relevant morphemes do not contain syllable-initial or syllable-final velar nasals and, accordingly, cannot be affected by this constraint.

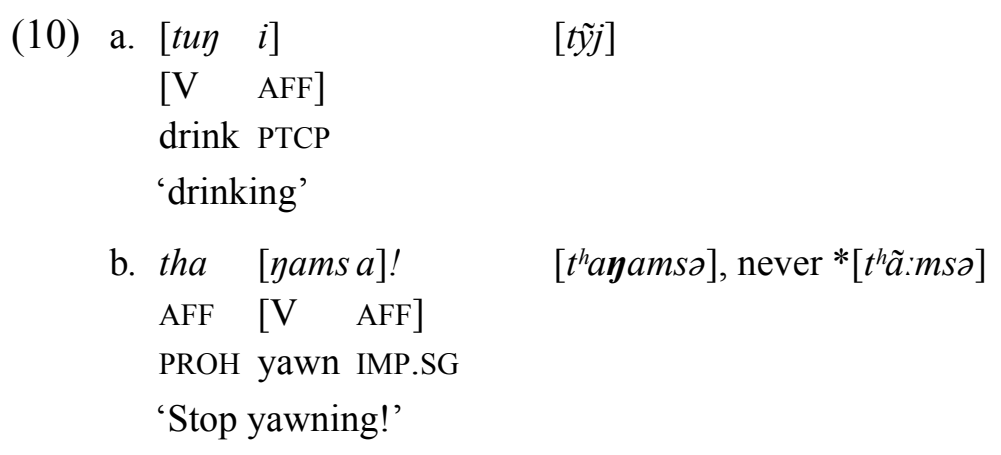

Voicing: [V(2)-AFF]. The phonological domain [V(2)-AFF] is also evidenced by progressive and regressive voicing assimilation. Progressive voicing assimilation affects almost all suffixes with obstruent initials, which assimilate to the voicedness/voicelessness of the preceding consonant. Again, if the verb complex consists of a main verb and a secondary verb, each verb begins its own domain.

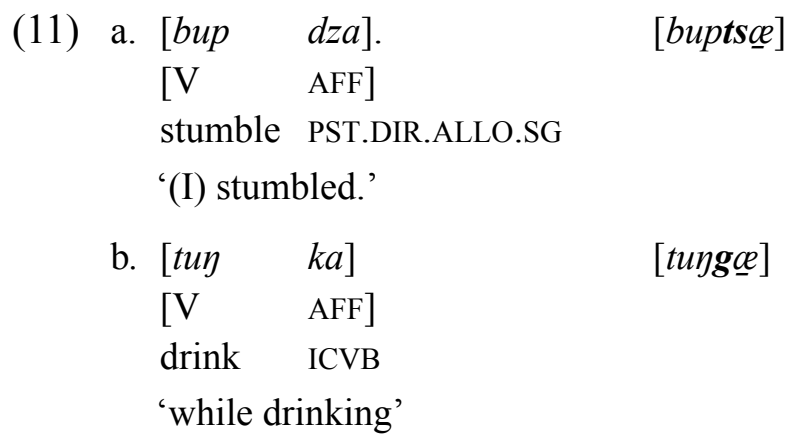

The intransitive supine suffix $d e$ is not affected by progressive voicing assimilation, but rather causes regressive voicing assimilation of stem-final consonants. This divergent behavior can be explained as a consequence of the fact that the suffix de was only recently grammaticalized from a verb root *de 'to go' (Widmer 2017: 434).

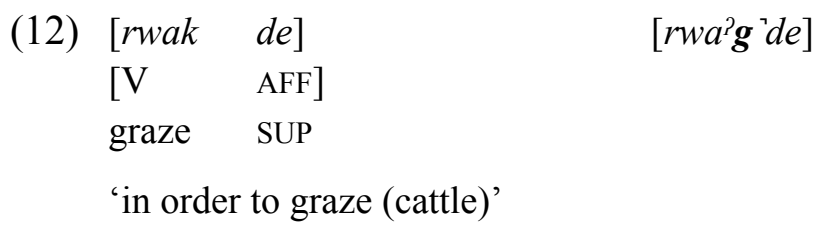

It cannot be established whether prefixes, free phrasal suffixes, and sentential suffixes are part of the relevant phonological domain, as they do not display the phonological shape necessary to be affected by voicing assimilation.

Glottalization: [V(2)-AFF]. Finally, the domain [V(2)-AFF] is also referenced by a glottalization constraint that demands that the syllable-final plosives $/ \mathrm{t} / \mathrm{and} / \mathrm{k} /$ are reduced to a glottalization if they occur between two vowels. A second vowel $/ \mathrm{i} /$ is lowered to [e] if the preceding vowel is $/ \mathrm{a} / \mathrm{or} / \mathrm{o} /$. Consider:
(13) a. [dat i $]$
$\left[\begin{array}{ll}\mathrm{V} & \mathrm{AFF}\end{array}\right]$
[da?e]
fall PTCP
'falling' 


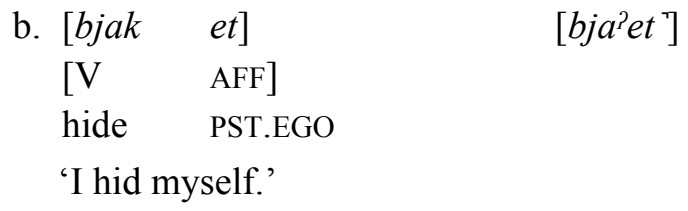

As in the case of intervocalic deletion and voicing assimilation, each verb starts its own domain if the verb complex consists of a main verb and a secondary verb. The behavior of prefixes, free phrasal suffixes, and sentential suffixes with regard to the relevant phonological domain cannot be established, as the morphemes in question do not display the phonological shape necessary to be affected by the relevant constraint.

\subsubsection{Synopsis of Bunan cohesion domains}

Tables 2 and 3 below give an overview of the grammatical and phonological cohesion domains that have been described in the preceding sections.

Table 2. Grammatical cohesion domains in Bunan.

\begin{tabular}{ll}
\hline Domain & Process \\
\hline$[$ PV-V-AFF-AFF-V2-AFF-FPA-SA $]$ & insertion potential, displacement potential \\
{$[$ AFF-V2-AFF-FPA-SA $]$} & ordering \\
{$[\mathrm{PV}-\mathrm{V}-\mathrm{AFF}]$} & ordering \\
{$[\mathrm{AFF}-\mathrm{V}-\mathrm{AFF}]$} & cross-slot dependency \\
{$[\mathrm{AFF}]$} & cross-slot dependency \\
\hline
\end{tabular}

Table 3. Phonological cohesion domains in Bunan.

\begin{tabular}{ll}
\hline Domain & Process \\
\hline$[\mathrm{V}-\mathrm{AFF}-\mathrm{AFF}-\mathrm{V} 2-\mathrm{AFF}-\mathrm{FPA}-\mathrm{SA}]$ & stress anchoring \\
{$[\mathrm{PV}-\mathrm{V}-\mathrm{AFF}-\mathrm{V} 2-\mathrm{AFF}-\mathrm{FPA}-\mathrm{SA}]$} & onset requirement \\
{$[\mathrm{AFF}-\mathrm{V} 2-\mathrm{AFF}-\mathrm{FPA}-\mathrm{SA}]$} & stress anchoring \\
{$[\mathrm{V}(2)-\mathrm{AFF}-\mathrm{FPA}]$} & voicing \\
{$[\mathrm{V}(2)-\mathrm{AFF}]$} & deletion, assimilation, glottalization \\
{$[\mathrm{V} 2-\mathrm{AFF}]$} & stress anchoring \\
{$[\mathrm{PV}]$} & stress anchoring \\
\hline
\end{tabular}

\subsection{Chintang}

Chintang is a Kiranti language that is spoken by 4,000 - 5,000 speakers in the Kośi zone of Eastern Nepal. Seven morpheme types have been identified in previous work (Bickel et al. 2007; Bickel \& Zúñiga 2017). They are summarized in Table 4.

Verbs can inflect for S, A and P agreement (AGR), tense, aspect, mood, and polarity (TAMP). Like Bunan, valency (VAL) markers register syntactic argument structure context with coronal stem augments and independently of this, they signal voice alternations. Connectives (CONN) include 
Table 4. Chintang morpheme types.

\begin{tabular}{llll}
\hline Morpheme type & SELECTION & INFLECTION & Example \\
\hline VERB (V) & - & TAMP, TR, VOICE, CONN, AGR & num 'do' \\
SECONDARY VERB (V2) & $\mathrm{V}$ & TMP, TR, AGR & pid 'BEN' \\
AFFIX (AFF) & $\mathrm{V}(2)$ & - & $m a$ 'NEG', $u$ '3O' \\
PREVERB (PV) & $\mathrm{V}$ & - & $l a k$ 'dance' (with lus) \\
CLITIC (CL) & $\mathrm{X}(\mathrm{P})$ & - & $\mathrm{ta}$ 'FOC' \\
VERBAL PHRASAL AFFIX (VPA) & $\mathrm{VP}$ & - & $n e$ 'OPT' \\
FREE PHRASAL AFFIX (FPA) & $\mathrm{XP}$ & - & $k i$ 'SEQ' \\
\hline
\end{tabular}

nominalization and clause linkage markers that respond to their syntactic environment (and are thus inflection in the sense of Bickel \& Nichols 2007).

The morpheme type V2 comprises a number of secondary verbs, which express a rich array of event notions (e.g. thi 'move down', pid 'do in favor of', $c a$ 'enjoy', yakt 'imperfective aspect') and select verb stems with specific valency and/or Aktionsart structures (e.g. thi 'move down' selects intransitive, thand 'move down' transitive verb stems, loĩs 'move out' either transitive or intransitive stems; Bickel \& Zúñiga 2017: 176-177).

Preverbs (PV) select specific verb (V) stems with which they form bipartite stems, e.g. nam selects nud to form a bipartite stem namnud 'to smell (good)'. Although some of them (indeed nam for example) have a verbal origin, they do not inflect. Selection of verbs and lack of inflection is a property that preverbs share with affixes (AFF) but preverbs differ from affixes in that they never select V2 stems. Affixes express a number of verbal categories like tense, person, number, polarity, etc., and attach to either V or V2 elements. Examples are the preverbal negation affix $m a$ or the postverbal 3rd person object affix $u$. The morpheme type "clitics" comprises a number of information structure markers (e.g. the focus marker $t a$ or the additive marker $y a \eta$ ) and these can attach to individual affixes, affix complexes, phrases and sentences alike (Bickel et al. 2007 and examples in 17 and 21 below). The morpheme type "verbal phrasal affix" includes morphemes such as the optative marker $n e$ and the insisting marker $n a$, while the morpheme type "free phrasal suffix", finally, includes various information structure markers and conjunctions (e.g. the coordinator $k i$ ) that attach to larger domains, but not to individual affixes (unlike clitics).

\subsubsection{Grammatical cohesion domains in Chintang}

Insertion potential and displacement: [AFF-PV-AFF-V-AFF-AFF-V2-AFF-CL-VPA-FPA]. The largest grammatical domain comprises all seven morpheme types in Table 4, and it is the domain that bans insertions of adverbs or noun phrases, or extractions of elements:

$$
\begin{aligned}
& \text { a. }\left[\begin{array}{ll}
n u & l o
\end{array}\right] \quad\left[\begin{array}{lllll}
a & m a & \text { phey yokt } & e
\end{array}\right] \text {. } \\
& \text { [AFF AFF } \mathrm{V} \quad \text { AFF AFF] } \\
& \text { good SIM } 2 \text { NEG plow NEG PST } \\
& \text { 'You didn't plow nicely.' (Bickel et al. 2007: 54) } \\
& \text { b. *a ma nu lo phey yokt e. }
\end{aligned}
$$

This contrasts with sequences of other morphemes: 
(15)

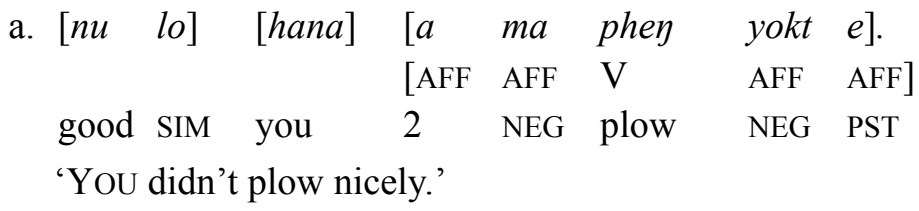

b. hana nu lo a ma phey yokt e

Ordering: [AFF] vs. [PV-V-AFF] vs. [V2-AFF-VPA-FPA] vs. [CL]. The grammatical domains [AFF], [PV-V-AFF], [V2-AFF-VPA-FPA], and [CL] are referenced by constraints on morpheme order. The position of preverbal affixes and enclitics is not fixed. Accordingly, the relevant morpheme types constitute their own grammatical domains. Note, however, that preverbal affixes and clitics cannot occur just anywhere in the verb complex; instead, they subcategorize for specific phonological domains to which they can attach (see Section 3.2.2 below). The variable ordering of preverbal affixes is illustrated in the following example, in which the three preverbal affixes $u$ ' 3 NSG.A', $k h a$ ' 1 NSG.P', and $m a$ 'NEG' can occur in any possible order.

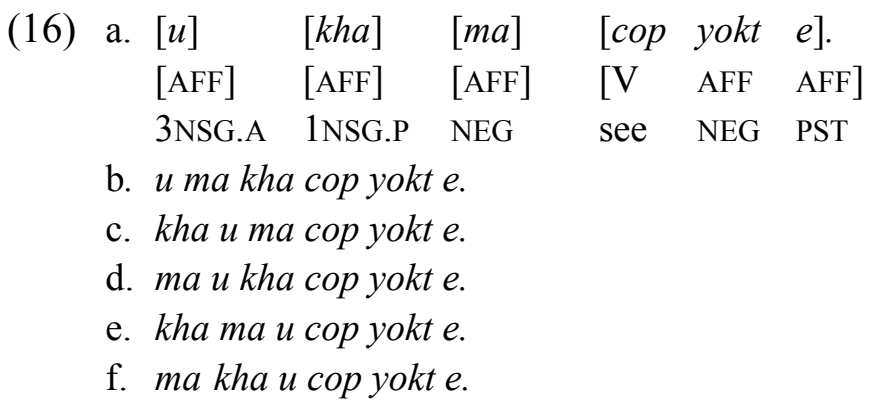

All: 'They did not see us.' (Bickel et al. 2007: 44)

The variable ordering of clitics is illustrated in the following examples. In (17a), the additive clitic $y a y$ and the focus clitic $t a$ attach to a suffix, while in (17b) and (17c) the focus clitic attaches to an affix and the first syllable of a bipartite verb stem, respectively.

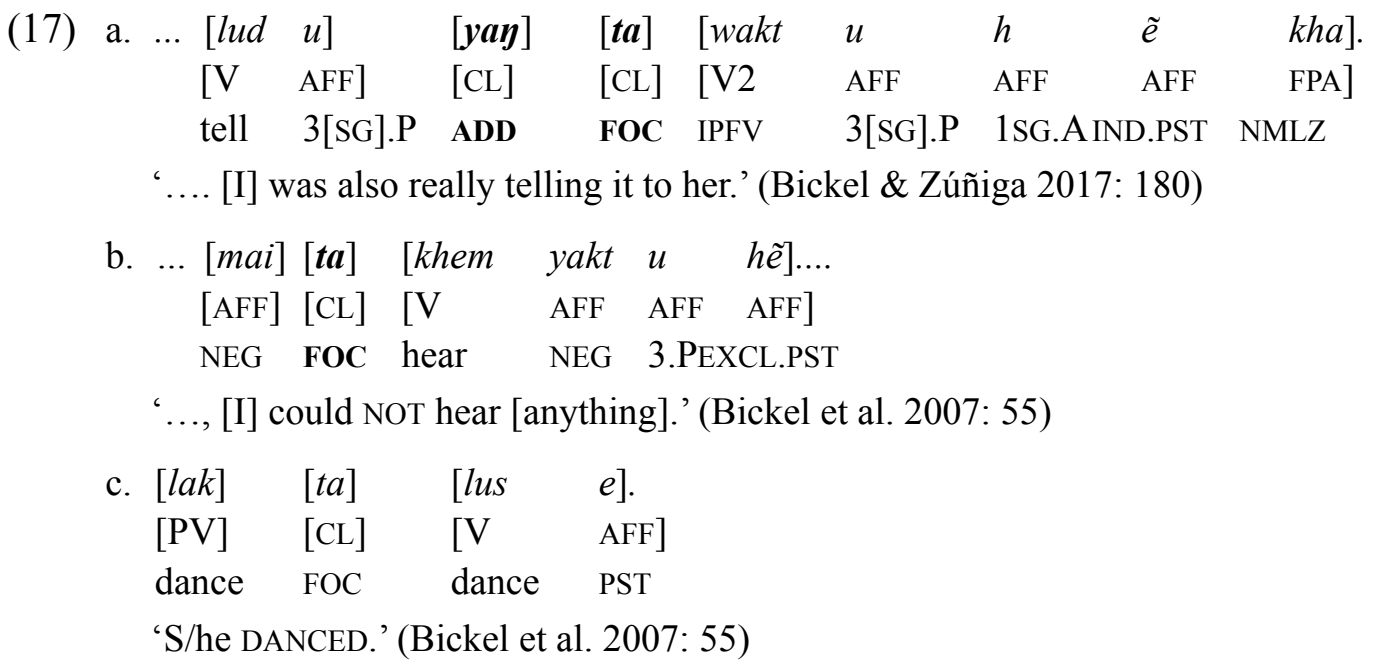

Cross-slot dependencies: [AFF-V-AFF-AFF-V2-AFF]. The grammatical domain [AFF-V-AFF-AFF-V2$\mathrm{AFF}]$ is evidenced by various cross-slot dependencies between pre- and postverbal affixes. Consider the following example, where the preverbal negation marker mai requires the simultaneous presence of the postverbal affix $t$ and vice-versa (this does not preclude mai to be free in its position, as noted above). 
(18)

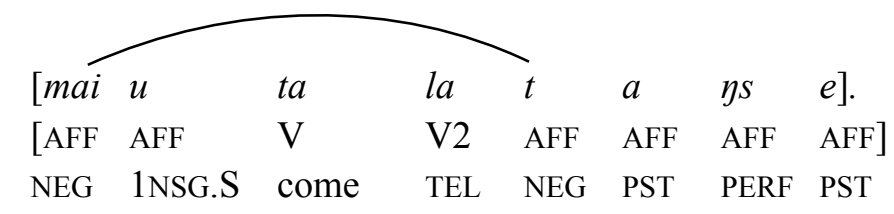

'They have not come yet.' (Paudyal 2015: 187)

\subsubsection{Phonological cohesion domains in Chintang}

Stress anchoring: [AFF-PV-AFF-V-AFF-AFF-V2-AFF-CL-VPA(-FPA)] vs. [FPA]. The phonological domains [AFF-PV-AFF-V-AFF-AFF-V2-AFF-CL-VPA(-FPA)] and [FPA] are domains for stress anchoring. Single main stress is generally anchored on the verb stem and may be followed by an optional dactylic secondary stress pattern (Bickel \& Zúñiga 2017).

Onset requirement: [PV] vs. [AFF] vs. [V(2)-AFF] vs. [CL-VPA-FPA]. The domains [PV], [AFF], [V(2)$\mathrm{AFF}$, and [CL-VPA-FPA] are evidenced by the phonological constraint of onset requirement. This constraint stipulates that all relevant phonological domains must begin with a consonantal onset. If a domain does not display an initial consonant, a glottal stop is inserted, at least in slow articulation. An example is given in the following.

\begin{tabular}{|c|c|c|c|c|c|}
\hline (19) $\left[\begin{array}{ll}\text { (mai }] \\
\text { (1) }\end{array}\right.$ & & {$[e p$} & $t$ & $e]$. & [mairarepte] \\
\hline$[\mathrm{AFF}$ & {$[\mathrm{AFF}]$} & {$[\mathrm{V}$} & $\mathrm{AFF}$ & AFF]. & \\
\hline NEG & 2 & get.u & NEG & PST & \\
\hline
\end{tabular}

'You didn’t get up.' (Bickel \& Zúñiga 2017: 180)

In fast speech, however, glottal stops are often elided in intervocalic positions, so that (18) could also be realized as [maiaepte]. However, even in the absence of glottal stops, the relevant domains can still be identified, as hiatus is resolved by vowel coalescence or diphthongization inside the relevant domains (Bickel \& Zúñiga 2017) but never between domains. Consider the following example.

\begin{tabular}{|c|c|c|c|c|c|}
\hline 0) $[u]$ & {$[$ tup } & $a$ & $u$ & $c e]$. & [?utubuce], never *[?utuba?uce] or *[?utubauce] \\
\hline $\mathrm{AFF}]$ & {$[\mathrm{V}$} & AFF & AFF & $\mathrm{AFF}]$ & \\
\hline 3NSG.A & meet & PST & 3.P3 & NSG.P & \\
\hline
\end{tabular}

'They met them.' (Bickel et al. 2007: 57)

Prosodic subcategorization: [PV] vs. [AFF] vs. [V(2)-AFF] vs. [CL-VPA-FPA]. The sequences [PV], [AFF], [V(2)-AFF], and [CL-VPA-FPA] also define the domains that can phonologically host preverbal affixes and clitics, i.e. the domains which preverbal affixes and clitics subcategorize for (Bickel et al. 2007). Preverbal affixes attach to the left edge of the relevant domains, while clitics attach to their right edge. In (21) below, for example, the affix $a$ and the clitic $t a$ attach to the left and right of a VAFF (a) and a V2-AFF domain (b) (attachment direction is marked here by ' $=$ '):

$$
\begin{aligned}
& \text { a. } \left.a=\left[\begin{array}{ll}
\text { pid } & u
\end{array}\right]=t a \text { wakt } e\right] \text {. } \\
& \mathrm{AFF}=\left[\begin{array}{ll}
\mathrm{V} & \mathrm{AFF}
\end{array}\right]=\mathrm{CL} \quad\left[\begin{array}{ll}
\mathrm{V} 2 & \mathrm{AFF}
\end{array}\right] \\
& 2 \text { give } 3 \mathrm{P} \text { FOC IPFV PST } \\
& \text { b. [pid u }] \quad a=\left[\begin{array}{ll}
\text { wakt } & e
\end{array}\right]=t a \text {. } \\
& {\left[\begin{array}{ll}
\mathrm{V} & \mathrm{AFF}
\end{array} \quad \mathrm{AFF}=\left[\begin{array}{ll}
\mathrm{V} 2 & \mathrm{AFF}
\end{array}=\mathrm{CL}\right.\right.} \\
& \text { give } 3 P \quad 2 \quad \text { IPFV } \quad \text { PST FOC }
\end{aligned}
$$

Voicing: [PV] vs. [AFF] vs. [V-AFF-V2-AFF]. These domains define where voicing applies: inside them, single voiceless stops become voiced if they occur between vowels or between a nasal and a vowel. 


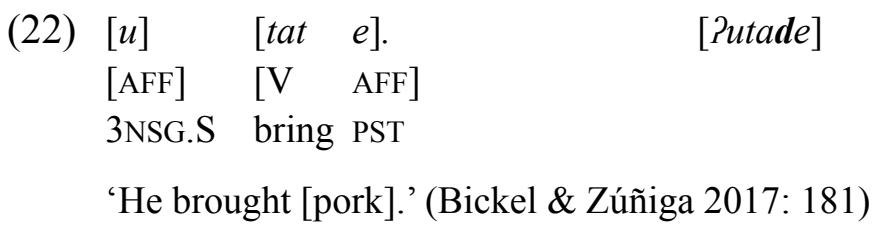

While the constraint holds generally across the lexicon, a few V2 and affixes escape voicing even inside the domain, mostly because of historically geminate environments (e.g. the nonpast marker $k V$ never voices). Clitics and phrasal affixes are not part of the voicing domain, with a couple of illunderstood exceptions (Bickel \& Zúñiga 2017).

\subsubsection{Synopsis of Chintang cohesion domains}

Table 5 and Table 6 below give an overview of the grammatical and phonological cohesion domains that have been described in the preceding sections.

Table 5. Grammatical cohesion domains in Chintang.

\begin{tabular}{ll}
\hline Domain & Process \\
\hline$[$ AFF-PV-AFF-V-AFF-AFF-V2-AFF-CL-VPA-FPA $]$ & insertion potential, displacement potential \\
{$[$ AFF-V-AFF-AFF-V2-AFF $]$} & cross-slot dependency \\
{$[\mathrm{V} 2-\mathrm{AFF}-\mathrm{VPA}-\mathrm{FPA}]$} & ordering \\
{$[\mathrm{PV}-\mathrm{V}-\mathrm{AFF}]$} & ordering \\
{$[\mathrm{AFF}]$} & ordering \\
{$[\mathrm{CL}]$} & ordering \\
\hline
\end{tabular}

Table 6. Phonological cohesion domains in Chintang.

\begin{tabular}{ll}
\hline Domain & Process \\
\hline$[$ AFF-PV-AFF-V-AFF-AFF-V2-AFF-CL-VPA(-FPA) $]$ & stress anchoring \\
{$[$ V-AFF-V2-AFF $]$} & voicing \\
{$[\mathrm{CL}-\mathrm{VPA}-\mathrm{FPA}]$} & onset requirement, prosodic subcat. \\
{$[\mathrm{V}-\mathrm{AFF}]$} & onset requirement, prosodic subcat. \\
{$[\mathrm{V} 2-\mathrm{AFF}]$} & onset requirement, prosodic subcat. \\
{$[\mathrm{PV}]$} & onset requirement, prosodic subcat., voicing \\
{$[\mathrm{AFF}]$} & onset requirement, prosodic subcat., voicing \\
{$[\mathrm{FPA}]$} & stress anchoring \\
\hline
\end{tabular}

\subsubsection{Burmese}

Burmese is the national language of Myanmar and is spoken by approximately 52 million speakers either as a first or second language (Jenny \& Hnin Tun 2016: 1). We identify the morpheme types in Table 7. 
Table 7. Burmese morpheme types.

\begin{tabular}{llll}
\hline Morpheme type & SELECTION & INFLECTION & Example \\
\hline VERB (V) & - & AMP, AGR & $n e$ 'stay' \\
SECONDARY VERB (V2) & $\mathrm{V}$ & AMP, AGR & $n e$ 'PROG' \\
AFFIX (AFF) & $\mathrm{V}(2)$ & - & $m ə$ 'NEG', tcá / dzá 'S/A.PL' \\
CLITIC (CL) & $\mathrm{X}(\mathrm{P})$ & - & $t \dot{ } / d \dot{~ ' C O N T R '}$ \\
VERBAL PHRASAL SUFFIX (VPA) & $\mathrm{VP}$ & - & $p^{h} \grave{u} / b \grave{u}$ 'NEG' \\
SENTENTIAL SUFFIX (SA) & $\mathrm{XP}$ & - & $l o ́$ 'REP' \\
\hline
\end{tabular}

Burmese verbs inflect only for aspect, mood and polarity (AMP). In addition, they can inflect for plural number of the subject argument (Jenny \& Hnin Tun 2016: 217). "V2" comprises a wide range of preverbal and postverbal secondary verbs that express different temporal-aspectual notions or serve

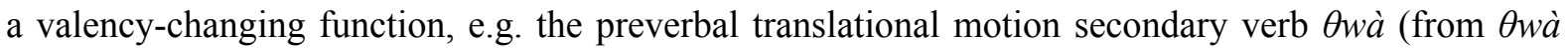
'go') and the postverbal progressive secondary verb ne (from $n e$ 'stay'). Secondary verbs display a number of properties that makes them recognizable as verbs. Preverbal secondary verbs can be marked for their dependent status with the verbal marker pids (consisting of the sequential marker $p \grave{i}$ - a grammaticalized form of the full verb $p \grave{i}$ 'finish' - and the contrastive marker tó / dó), while postverbal secondary verbs inflect for polarity. Both preverbal and postverbal secondary verbs select the main verb in so far as they do not license arguments directly but rely on their selected verb and its valence structure for this.

The morpheme type "affix" expresses a range of different verbal grammatical categories like aspect, mood, number or polarity, attached to either V or V2 elements. Examples are the preverbal negation affix $m a$ or the postverbal plural subject affix $t \epsilon a \dot{a} / d z \dot{a}$. The morpheme type of clitic contains the importance marker $p a / b a$ and the contrast marker $t j$ / dj. The morpheme type of verbal phrasal suffixes comprises a set of inflectional morphemes that are commonly referred to as "status markers" and express a range of TAM categories as well as polarity. Examples are the non-future / realis marker $t \varepsilon / d \varepsilon$ or the negation marker $p^{h} \grave{u} /$ bù. The morpheme type of sentential suffixes, finally, includes a number of markers with pragmatic function such as the reportative ló or the question marker là.

\subsubsection{Grammatical cohesion domains in Burmese}

Insertion and displacement potential: [V2-VPA-AFF-V-AFF-AFF-V2-AFF-CL-VPA-AFF-SA]. The largest grammatical domain in the Burmese verb comprises the entire verb complex, i.e. [V2-VPAAFF-V-AFF-AFF-V2-AFF-CL-VPA-AFF-SA]. The domain is evidenced by its lack of insertion and displacement potential. In (23), for example, no nouns or adverbs can be inserted anywhere into the verb complex. For example, it is not possible to insert a noun or an adverb between the preverbal V2 $\theta w a ̀$ 'go' and the rest of the verb complex, nor is it possible to move the preverbal V2 away from its position in front of the main verb.

\begin{tabular}{|c|c|c|c|c|c|}
\hline$s^{h}$ ain & $h m a$ & $t^{\text {hymin }}$ & {$[\theta w a ̀$} & $s \grave{a}$ & $m \varepsilon]$. \\
\hline & & $\mathrm{N}$ & {$[\mathrm{V} 2$} & $\mathrm{V}$ & $\mathrm{AFF}$ \\
\hline & LOC & cooked.rice & go & eat & FUT \\
\hline
\end{tabular}

'We'll eat at the restaurant.' 


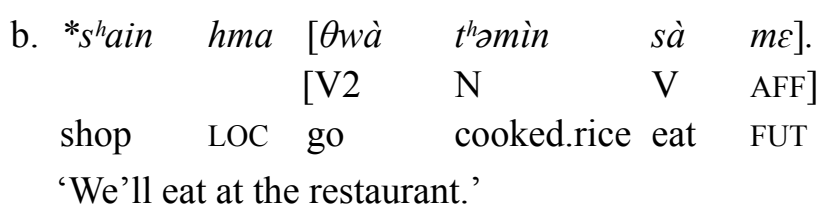

As noted above, preverbal V2s may be augmented with the verbal marker pidj. This does not affect the meaning of the overall construction:

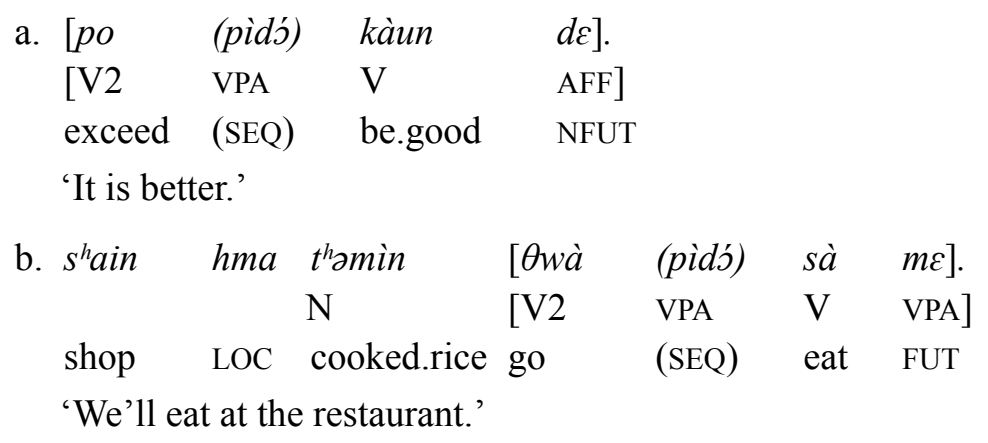

However, the addition of pids breaks up the displacement domain, and this makes it possible to move the V2 before the object, as in (25). The resulting construction is biclausal. This can be seen from the fact that the noun shain 'shop' can no longer serve as a locative-marked adjunct of the verb complex

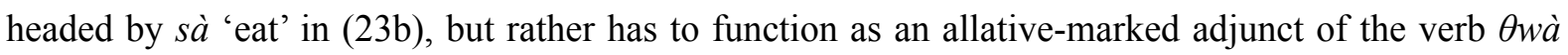
'go', forming a clausal constituent with it.

\begin{tabular}{|c|c|c|c|c|c|}
\hline 5) $s^{h}$ ain & go & $\begin{array}{l}{[\theta w a ̀} \\
{[\mathrm{V} 2}\end{array}$ & $\begin{array}{l}\text { pidó] } \\
\text { VPA] }\end{array}$ & $\begin{array}{l}t^{\text {hromin }} \\
\mathrm{N}\end{array}$ & $\begin{array}{l}{[s \grave{a}} \\
{[\mathrm{V}}\end{array}$ \\
\hline $\mathrm{s}$ & ALL & go & SEQ & cooked.rice & at \\
\hline
\end{tabular}

'We'll go to the restaurant and eat.'

The detachment of the preverbal V2 from the main verb is only possible if the relevant V2 is semantically transparent. Preverbal V2s that are strongly grammaticalized cannot be detached from the main verb, even if they are formally subordinate.

Ordering: [V2-VPA] vs. [AFF-V-AFF] vs. [AFF-V2-AFF-CL-VPA-AFF-SA]. The grammatical domains [V2-VPA], [AFF-V-AFF], and [AFF-V2-AFF-CL-VPA-AFF-SA] are defined by the order of elements in the verbal complex. The order of affixes, clitics, verbal phrasal affixes, and sentential affixes is generally fixed after main verbs and secondary verbs, following a rigid template. The order of main verbs and secondary verbs, on the other hand, is driven by the semantic content for the relevant verbs.

The exact placement of the affix Pòn 'further, more, in addition' as well as the clitics $t \dot{\prime}$ / dó 'CONTR' and $p a / b a$ 'IMPORT' is sensitive to the grammatical context (Jenny \& Hnin Tun 2016: 225-233). The relevant placement constraints are not critical, however, for how the ordering domain is defined.

Cross-slot dependency I: [AFF(-V)-V2-AFF-CL-VPA]. The grammatical domain [AFF(-V)-V2-AFF-CLVPA] is defined by a cross-slot dependency that holds between the preverbal negative affix ma and the postverbal verbal phrasal affixes $p^{h} \grave{u} /$ b̀̀ (negative) and né (prohibitive). The latter two morphemes can only occur in combination with the preverbal negative affix. Consider:

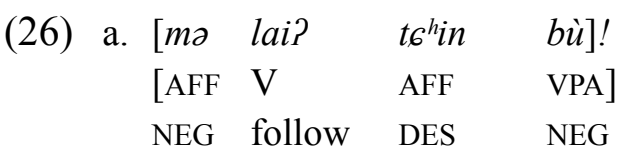

'I don't want to come along.' (Jenny \& Hnin Tun 2016: 216) 
b. *lai? țhin bù!

(27)

$\begin{array}{lll}\text { a. }\left[\begin{array}{lll}\text { mə } & \text { Pei? } & n \varepsilon ́\end{array}\right] \\ \text { [AFF } & \text { V } & \text { VPA] } \\ \text { NEG } & \text { sleep } & \text { PROH }\end{array}$

'Don't sleep.' (Jenny \& Hnin Tun 2016: 250)

b. *?ei? né!

Cross-slot dependency II: [AFF(-V)-V2-AFF]. The grammatical domain [AFF(-V)-V2-AFF] is defined by a cross-slot dependency that holds between the preverbal negative affix $m$ a and the postverbal aspectual affix $\theta \dot{e} / \partial \grave{e}$ 'yet', the latter of which depends on the former for its realization. Consider:

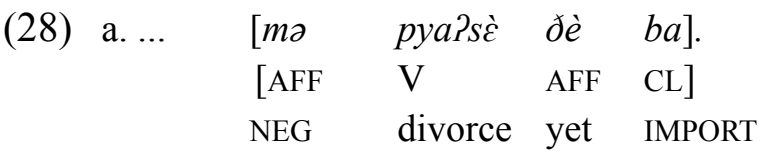

'[We] have not been officially divorced yet.' (Jenny und Hnin Tun 2016: 232)

b. *pya?sغ̀ ðè ba.

Cross-slot dependency III: [AFF-VPA]. The grammatical domain [AFF-VPA] is defined by a cross-slot dependency that holds between the postverbal verbal phrasal affix $t \varepsilon / d \varepsilon$ 'NFUT' and the postverbal aspectual affix $\theta \grave{e} / \partial \grave{e}$ 'yet', the latter of which depends on the former for its realization. Consider:

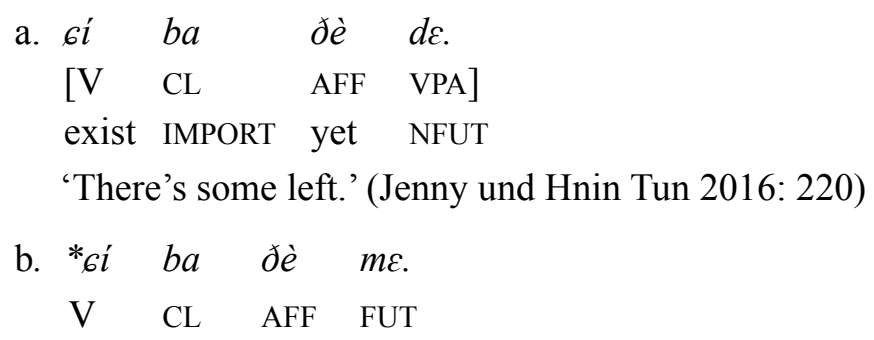

\subsubsection{Phonological cohesion domains in Burmese}

Stress anchoring: [V2-VPA] vs. [AFF-V-AFF-AFF-V2-AFF-CL-VPA-AFF] vs. [SA]. Stress ${ }^{11}$ anchoring evidences three different phonological domains within the Burmese verb complex. The first domain consists of the preverbal V2 and potentially the sequential marker pid'. The second domain consists of the main verb complex including all affixes, postverbal V2s, and verbal phrasal affixes, with stress falling on the main verb. The third domain, finally, comprises sentential suffixes, which generally do not belong to the same stress domain as the main verb, but rather instantiate a stress domain of their own. Consider:

\begin{tabular}{|c|c|c|}
\hline$[\theta w a \grave{a}]$ & {$[k a n$} & $d a]$ \\
\hline [V2] & {$[\mathrm{V}$} & VPA] \\
\hline & kick & NFUT.NMLZ \\
\hline
\end{tabular}

'[...], I would have gone to play [football].' (Jenny \& Hnin Tun 2016: 266)

Note that certain sentential suffixes cause additional phonological changes. The interrogative marker $l \grave{\varepsilon}$, for example, reduces the vowel of a preceding syllable to schwa, thus forming a sesquisyllabic

${ }^{11}$ Given the fact that Burmese is a tonal language, a brief comment on the nature of its stress system is in order. To date, detailed phonetic studies of Burmese stress are still missing. Our preliminary observations suggest that stress in Burmese is a combination of intensity and length in combination with the full realization of a syllable with regard to tones (no neutralization) or vowels (no reduction). 
stress domain with it (see the following section). However, as these changes are not general phonological processes, we do not consider them further.

Sesquisyllabicity: [AFF-V(2)]. An important phonological cohesion domain in Burmese may be characterized by a "sesquisyllabic" structure (Matisoff 1989). Sesquisyllabic phonological cohesion domains consists of a first weak syllable, which is open and toneless and contains the neutral vowel / $\partial /$ as a nucleus, and a second "strong" syllable, which is fully tonal and contains any vowel expect for the neutral vowel /ə/, e.g. hnəkàun 'nose' (see Jenny \& Hnin Tun 2016: 23). Sesquisyllabicity defines the phonological domain $[\mathrm{AFF}-\mathrm{V}(2)]$. Consider:

\begin{tabular}{|c|c|c|c|c|c|}
\hline$[m \partial$ & $s \grave{a}]$ & dzin & $d \dot{~}$ & bù. & [ma 'sàdzindóbù ] \\
\hline [AFF & V] & AFF & $\mathrm{CL}$ & VPA & \\
\hline NEG & eat & DES & CONTR & NEG & \\
\hline
\end{tabular}

'[He] doesn’t want to eat anymore.' (Jenny \& Hnin Tun 2016: 25)

Voicing: [V-V2-AFF-CL-VPA-AFF]. Another phonological domain is evidenced by a voicing constraint affecting voiceless stops, fricative, and nasals at morpheme boundaries within it (Jenny \& Hnin Tun 2016: 25). The domain includes strongly grammaticalized postverbal V2s, postverbal affixes, verbal phrasal affixes and clitics that have the appropriate phonological shape. ${ }^{12}$ Preverbal V2s, verb stems as well as preverbal affixes are excluded from this domain. Voicing is illustrated in the following example, in which the causative secondary verb se, the desiderative suffix $t_{6}{ }^{h} i n$, as well as the negation suffix $p^{h} \grave{u}$ all occur in with voiced onsets. By contrast, the main verb sà escapes voicing despite its intervocalic position.

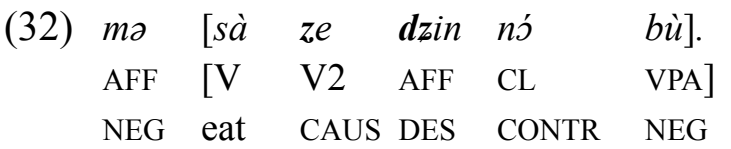

'(I) don't want to let (them) eat anymore.'

Assimilation: [V-V2-AFF-VPS]. A further phonological domain is evidenced by two constraints on assimilation at morpheme boundaries within it (although we note that their application varies to some extent across speakers, contexts and articulation rates). The first type of assimilation is an instance of regressive manner assimilation in the course of which a syllable-final glottal stop or nasal vowel assimilates to the place of articulation of a following consonants, e.g. /hou? k'́l [hóuk:'́] 'right' ('be EMPH'). The second type of assimilation is an instance of progressive manner assimilation through which a stop assimilates to the manner of articulation of a preceding nasal, e.g. /kàun $t \varepsilon /[\mathrm{kàund} \varepsilon \sim$ kàunn $\varepsilon$ ] 'it's good' ('good NFUT'). The nasal triggering the assimilation may in turn assimilate to the place of articulation of the following stop, e.g. /kàun phùl [kàunbù kàumbù] 'it's not good' ('good NEG'). The two types only affect postverbal affixes as well as a small number of postverbal V2s, but they do not operate on other morpheme types. Consider:

\begin{tabular}{|c|c|c|c|c|c|}
\hline (33) $[\ldots]$ & mə & pyj̀ & ta? & phù. & [məpyว̀dapp $\left.{ }^{h} \grave{u}\right]$ \\
\hline & $\mathrm{AFF}$ & $\mathrm{V}$ & V2 & VPA & \\
\hline & NEG & speak & ABIL & NEG & \\
\hline
\end{tabular}

\footnotetext{
12 Note that a seemingly simpler, domain-free analysis in terms of voicing between full vs schwa vowels fails because voicing does not occur in object-verb combinations.
} 


\subsubsection{Synopsis of Burmese cohesion domains}

Table 8 and Table 9 below give an overview of the grammatical and phonological cohesion domains that have been described in the preceding sections.

Table 8. Grammatical cohesion domains in Burmese.

\begin{tabular}{ll}
\hline Grammatical Domain & Process \\
\hline$[\mathrm{V} 2-\mathrm{VPA}-\mathrm{AFF}-\mathrm{V}-\mathrm{AFF}-\mathrm{AFF}-\mathrm{V} 2-\mathrm{AFF}-\mathrm{CL}-\mathrm{VPA}-\mathrm{AFF}-\mathrm{SA}]$ & insertion potential, displacement potential \\
{$[\mathrm{AFF}-\mathrm{V} 2-\mathrm{AFF}-\mathrm{CL}-\mathrm{VPA}-\mathrm{AFF}-\mathrm{SA}]$} & ordering \\
{$[\mathrm{AFF}(-\mathrm{V})-\mathrm{V} 2-\mathrm{AFF}-\mathrm{CL}-\mathrm{VPA}]$} & cross-slot dependency I \\
{$[\mathrm{AFF}(-\mathrm{V})-\mathrm{V} 2-\mathrm{AFF}]$} & cross-slot dependency II \\
{$[\mathrm{AFF}-\mathrm{V}-\mathrm{AFF}]$} & ordering \\
{$[\mathrm{V} 2-\mathrm{VPA}]$} & ordering \\
{$[\mathrm{AFF}-\mathrm{VPA}]$} & cross-slot dependency III \\
\hline
\end{tabular}

Table 9. Phonological cohesion domains in Burmese.

\begin{tabular}{ll}
\hline Phonological Domain & Process \\
\hline$[\mathrm{AFF}-\mathrm{V}-\mathrm{AFF}-\mathrm{AFF}-\mathrm{V} 2-\mathrm{AFF}-\mathrm{CL}-\mathrm{VPA}-\mathrm{AFF}]$ & stress anchoring \\
{$[\mathrm{V}-\mathrm{AFF}-\mathrm{AFF}-\mathrm{V} 2-\mathrm{AFF}-\mathrm{CL}-\mathrm{VPA}-\mathrm{AFF}]$} & voicing \\
{$[\mathrm{V}-\mathrm{V} 2-\mathrm{AFF}-\mathrm{VPA}-\mathrm{AFF}]$} & assimilation \\
{$[\mathrm{V} 2-\mathrm{VPA}]$} & stress anchoring \\
{$[\mathrm{AFF}-\mathrm{V}(2)]$} & sesquisyllabicity \\
{$[\mathrm{SA}]$} & stress anchoring \\
\hline
\end{tabular}

\subsection{Mandarin Chinese}

Mandarin Chinese is the national language of China and Taiwan, and is one of the official languages of Singapore. It is one of the largest languages of the world in terms of number of speakers. At the beginning of the 21 st century, more than 870 million people were estimated to speak Mandarin as their first language (Wiedenhof 2015: 1). Table 10 summarizes the morpheme types that we identify in Mandarin.

Table 10. Mandarin morpheme types.

\begin{tabular}{|c|c|c|c|}
\hline Morpheme type & SELECTION & INFLECTION & Example \\
\hline VERB (V) & - & ASPECT, T/M & $z a ̀ i$ 在 'to be at' \\
\hline SECONDARY VERB (V2) & $\mathrm{V}$ & ASPECT, T/M & $z a ̀ i$ 在 'PROG', wán 完 'COMPL' \\
\hline REDUPL. SECONDARY VERB (V2 $\left.2_{\text {RED }}\right)$ & $\mathrm{V}$ & ASPECT & see example in (33) \\
\hline AFFIX (AFF) & $\mathrm{V}(2)$ & - & $y i$ 一 'DELIM', guo 过 'EXPER' \\
\hline VERBAL PHRASAL AFFIX (VPA) & VP & - & bù 不 ‘NEG’ \\
\hline SENTENTIAL AFFIX (SA) & $\mathrm{XP}$ & - & $m a$ 吗 'Q' \\
\hline
\end{tabular}


Verbs inflect for aspect and tense/mood, while polarity is coded at the phrasal level. V2 morphemes fall into two classes: preverbal and postverbal secondary verbs. They all select verbs in the sense that they are not able to support their own arguments and thus depend on the argument structure of the main verb. Their status as verbs rather than inflectional markers rests on the fact that they can be inflected for aspect, independently of the main verb. We only recognize one preverbal secondary verb, which is the durative secondary verb zài 在. Evidence for a selection relationship between zài and its main verb comes from the fact that it only combines with verbs that display an active Aktionsart (Li \& Thompson 1981: 217). Other preverbal auxiliaries such as néng 能 'can', yào 要 'want', etc. are not analyzed as secondary verbs, as there is no evidence that they select verbs for their realization.

As for postverbal secondary verbs, we identify two types: reduplicated secondary verbs and nonreduplicated ones. Reduplicated postverbal secondary verbs are reduplicated instances of main verbs occurring in what are called delimitative contexts. As reduplicated postverbal secondary verbs can only co-occur with their phonologically homophonous main verb, they can be said to be "selfselecting". They can optionally take a prefix $y i$, which derives from the numeral $y \bar{\imath}$ 'one'. ${ }^{13}$

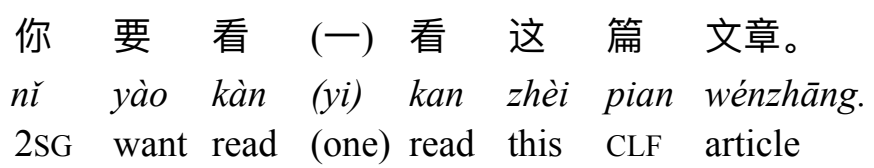

'You should read this article.' (Li \& Thompson 1981: 236)

The class of postverbal non-reduplicated secondary verbs is commonly known as "resultative verb compounds" (RVCs) in the literature. RVCs consist of two verbs, of which the first describes an action and the second - which is commonly referred to as the "complement" (bǔyǔ 补语) in traditional Chinese grammar - describes the result of the relevant action, e.g. kàn jiàn 看见 [look see] 'to see'. Li \& Thompson (1981: 54-58) give three defining characteristics of RVCs. First, RVCs can appear in a so-called "potential form", with the morphemes de or $b u$ standing between the two verbs, e.g. kàn de jiàn 看得见 [look ABIL see] 'able to see' and kàn bu jiàn 看不见 [look NEG see] 'not able to see'. Second, RVCs cannot be reduplicated. Third, the two verbs can usually not be separated by other morphological constituents (e.g. aspect markers, nouns, adverbials, etc.) with the exception of the morphemes $d e$ 得 or $b u$ 不 mentioned above. ${ }^{14}$ We analyze the resultative "complements" as secondary verbs because they do not license their own arguments but instead rely on the valence of the main verb, much like secondary verbs in Bunan, Chintang, and Burmese.

The morpheme type "affix" includes a number of aspectual markers such as the perfective marker le 了, attached to either V or V2 elements. The morpheme type "verbal phrasal prefix" comprises the

13 The optional presence of $y i$ is one reason why reduplicated postverbal secondary verbs are sometimes analyzed as cognate objects rather than verbs, e.g. xiăng [yi xiang] 想 [一想] 'think [a thought]' $\rightarrow$ 'give it a thought' (Wiedenhof 2015: 318). We do not follow this analysis as verbs in their delimitative form can take an additional object argument, as exemplified in (35) below. This suggests that the reduplicated secondary verb does not have the status of an object argument, but rather forms a part of the verb complex, with the main verb and the secondary verb together defining the overall valency of the verb complex.

14 This restriction does not hold for a specific type of "directional" RVC in which the second verb indicates the direction of a movement. However, if the two members of a directional RVC are separated, the construction can no longer occur in the potential form (Li \& Thompson 1981: 62-64). 
negation markers bù 不 15 and méi 没. The morpheme “sentential suffix", finally, comprises a number of sentential final markers such as the marker $l e\}^{16}$ (signaling a currently relevant state) or the question marker $m a$ 吗.

\subsubsection{Grammatical cohesion domains in Mandarin}

Displacement potential: [VPA-V2-VPA-V-AFF-VPA-AFF-V2 $2_{(\mathrm{RED})}-\mathrm{AFF}-\mathrm{SA}$ ]. The largest grammatical domain comprises the entire verbal complex, i.e. [VPA-V2-VPA-V-AFF-VPA-AFF-V2 (RED)-AFF-SA]. This domain is characterized by its lack of displacement potential. Accordingly, it is not possible to extract single morphemes from the verb complex irrespective of other morphemes. For example, it is not possible for individual morphemes or strings of morphemes to be left-dislocated to topic position in main clause contexts, although this topicalization is otherwise highly productive in Mandarin (see Li \& Thompson 1981: 15-16). Consider the failed left dislocation in the following data:

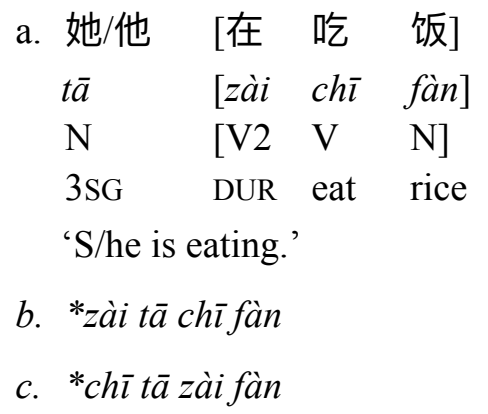

Ordering: [VPA-V2] vs. [VPA-V-AFF] vs. [VPA-AFF-V2(RED)-AFF-SA]. The domains [VPA-V2], [VPA-V-

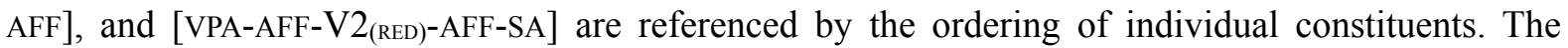
ordering of verbal phrasal affixes, affixes, postverbal secondary verbs, and sentential affixes is fixed. The ordering of verbs and secondary verbs, in turn, depends on the meaning of the relevant verbs, and the two morpheme types start their own ordering domains.

Insertion potential: [V-AFF-VPA-AFF-V2 (RED) $_{\text {-AFF]. The domain [V-AFF-VPA-AFF-V2 }}$ (RED)-AFF-SA] is characterized by its lack of insertion potential. That is to say, it is not possible to insert nouns, adverbials, etc. into the morpheme string. ${ }^{17}$ Preverbal secondary verbs and verbal phrasal affixes are not part of this domain, as they can be separated from the main verb by adverbs and adverbial phrases. This is illustrated in the two examples given below. In (36a), the progressive secondary verb zài is

15 Wiedenhof (2015: 201-204) distinguishes between a negative adverb bù 'not' and a negative copula bú 'be not', which are both written with the same character 不. Since an assessment of this proposal would necessitate an in-depth discussion of the syntax and dialectal restrictions of "copular" bú within Northern Mandarin, we do not adopt this analysis here, but rather follow Li \& Thompson (1981), who only postulate a negative adverb bì.

16 We follow Li \& Thompson (1981) in analyzing the sentence-final marker le and the verb-final marker le as two distinct morphemes, although they are written with the same character 了. Note, however, that other scholars (e.g. Wiedenhof 2015) analyze the two markers as exponents of one single morpheme. If one follows this analysis, one would have to postulate an additional morpheme type "enclitic" for Mandarin, as the resulting morpheme can then both select verbs (V) and sentences (S) as its syntactic host. This would make Mandarin look even more similar to other languages we discuss here.

17 We acknowledge that there are cases like niàn shū guo 念书过 [study book EXPER] 'have studied at one time' (Wiedenhof 2015: 230), in which the noun shü 'book' occurs between the verb stem niàn 'read, recite' and the aspectual ending guò. However, the morpheme shu has lost its lexical meaning in this construction and does not refer to a specific type of 'book' any longer. Also note that Mandarin does not exploit noun incorporation as a regular process. Accordingly, we consider the relevant example as an instance of lexicalization. 
separated from the main verb chī 'eat' by the adverbial phrase hěn kuài de 很快地 'very fast', while in (36b), the negator bu is separated from the main verb xǐzăo 洗澡 'wash' by the adverb tiāntiān 'daily'.

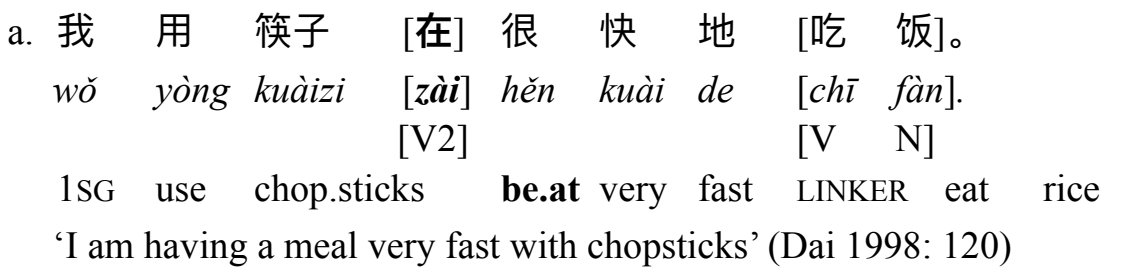

$\begin{array}{clll}\text { b. 她/他 } & {[\text { 不 }]} & \text { 天天 } & {[\text { 洗澡]。 }} \\ t \bar{a} & {[\boldsymbol{b u}]} & \text { tiāntiān } & {[\text { xǐzăo]. }} \\ & {[\mathrm{VPA}]} & & {[\mathrm{V}]} \\ 3 \mathrm{SG} & \text { NEG } & \text { daily } & \text { wash }\end{array}$

'S/he does not bathe every day.' (Li \& Thompson 1981: 420)

Sentential suffixes are not part of this domain either, as they can be separated from the verb complex by undergoer arguments.

$\begin{array}{lllll}\text { 她/他 } & \text { [买] } & \text { 房子 } & {[\text { [ }} & \text { 吗]? } \\ t \bar{a} & {[\text { ăi }]} & \text { fángzi } & {[l \boldsymbol{l}} & \mathbf{m a}] ? \\ \mathrm{~N} & {[\mathrm{~V}]} & \mathrm{N} & {[\mathrm{SA}} & \mathrm{SA}] \\ 3 \mathrm{SG} & \text { buy } & \text { house } & \text { CRS } & \mathbf{Q}\end{array}$

'Did s/he buy a house?' (Li \& Thompson 1981: 239)

\subsubsection{Phonological cohesion domains in Mandarin}

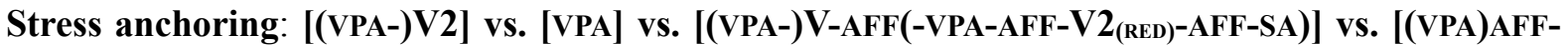

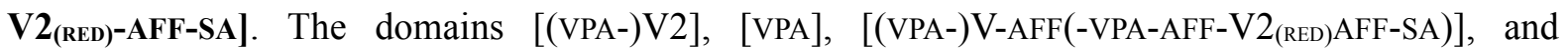
[(VPA-)AFF-V2 (RED)-AFF-SA] are defined by stress anchoring. We here use the term "stress" in the sense of Duanmu (2000: 72), who makes a distinction between full and weak syllables for Mandarin. ${ }^{18}$ Full syllables are stressed and carry lexical tone, while weak syllables are unstressed and do not carry lexical tone. The relevant domains are evidenced by the fact that they consist of at least one full syllable that may be followed by a number of weak syllables. Affixes are consistently weak (see Li \& Thompson 1981: 185), while postverbal secondary verbs are most often weak as well (see Li \& Thompson 1981: 29-30, 185; Wiedenhof 2015: 317-318), but can apparently also be realized as full syllables in certain contexts. ${ }^{19}$ When the postverbal verbs are realized as full syllables, they constitute a stress domain with subsequent morphemes, which are consistently weak. Verbal phrasal prefixes may also be unstressed, in which case they form one stress domain with a following secondary verb or main verb (see Wiedenhof 2015: 28). Preverbal secondary verbs, on the other hand, always retain

\footnotetext{
${ }^{18}$ For a historiographic discussion of whether Chinese indeed has stress, see Chen (2000). We consider this settled.

${ }^{19} \mathrm{Li} \&$ Thompson (1981) give examples such as tā shuì le yi shui 她/他睡了一睡 [3[SG] sleep PFV one sleep] 'S/he slept a little.' (233) or ň cāi yi cāi 你猜一猜 [2[SG] guess one guess] 'You try to guess.' (234), in which the postverbal secondary verbs retain their tone and hence constitute full syllables. In the literature we consulted, we could not find any information about the conditions under which postverbal secondary verbs retain their tone. We thus confine ourselves to conclude that postverbal secondary verbs show variable behavior with regard to stress.
} 
their stress. The following examples illustrate various morpheme types that form one stress domain with the main verb.

$\begin{array}{clllll}\text { a. 你 } & {[\text { 骂 }} & (\text { 一) } & \text { 吗 }] & \text { 她/他 } & \text { 们。 } \\ n \check{l} & {[m a ̀} & (y i) & m a] & t \bar{a} & m e n . \\ & {[\mathrm{V}} & \mathrm{AFF} & \mathrm{V} 2] & & \\ 2 \mathrm{SG} & \text { scold } & \text { (one) } & \text { scold } & 3 & \mathrm{PL}\end{array}$

'You scold them a little.' (Li \& Thompson 1981: 30)

b. [不 贵].

[bu gui $]$.

[VPA V]

NEG be.expensive

'not expensive' (Wiedenhof 2015: 28)

Tone sandhi I: [V2-VPA] vs. [V-AFF-VPA-AFF(-V2(RED-AFF-SA)] vs. [V2(RED)-AFF-SA]. The domains [V2-VPA], [V-AFF-VPA-AFF(-V2(RED)-AFF-SA)], and [V2(RED)-AFF-SA] are defined by a tonal sandhi phenomenon. The pitch of the "neutral" or "reduced" tone of weak syllables generally depends on the tone of the last preceding syllable with a full tone (Duanmu 2000: 241; Wiedenhof 2015: 19-20). The neutral tone is typically realized with a high-level pitch after tone 3 (wǒ ne 我呢 ' $1 \mathrm{SG}$ RLV'), with a mid-level pitch after tone 2 (lái le 来了 'come PFV'), with a mid-low-level pitch after tone 1 (tuĩ ba 推 吧 'push SUG'), and with a low-level pitch after tone 4 (mài de 卖的 'sell NMLZ'). Postverbal secondary verbs and sentential suffixes constitute their own sandhi domain if the secondary verbs carry tone. Otherwise, the two morpheme types merge into one sandhi domain with the preceding morphemes.

\subsubsection{Synopsis of Mandarin cohesion domains}

Table 11 and Table 12 below give an overview of the grammatical and phonological cohesion domains that have been described in the preceding sections.

Table 11. Grammatical cohesion domains in Mandarin.

\begin{tabular}{ll}
\hline Domain & Process \\
\hline$\left[\mathrm{VPA}-\mathrm{V} 2-\mathrm{VPA}-\mathrm{V}-\mathrm{AFF}-\mathrm{VPA}-\mathrm{AFF}-\mathrm{V} 2_{(\mathrm{RED})}-\mathrm{AFF}-\mathrm{SA}\right]$ & displacement potential \\
{$\left[\mathrm{V}-\mathrm{AFF}-\mathrm{VPA}-\mathrm{AFF}-\mathrm{V} 2_{(\mathrm{RED})}-\mathrm{AFF}\right]$} & insertion potential \\
{$\left[\mathrm{VPA}-\mathrm{AFF}-\mathrm{V} 2_{(\mathrm{RED})}-\mathrm{AFF}-\mathrm{SA}\right]$} & ordering \\
{$[\mathrm{VPA}-\mathrm{V}-\mathrm{AFF}]$} & ordering \\
{$[\mathrm{VPA}-\mathrm{V} 2]$} & ordering \\
\hline
\end{tabular}


Table 12. Phonological cohesion domains in Mandarin.

\begin{tabular}{ll}
\hline Domain & Process \\
\hline$\left[\mathrm{V}-\mathrm{AFF}-\mathrm{VPA}-\mathrm{AFF}\left(-\mathrm{V} 2_{(\mathrm{RED})}-\mathrm{AFF}-\mathrm{SA}\right)\right]$ & tone sandhi \\
{$\left[(\mathrm{VPA}-) \mathrm{AFF}-\mathrm{V} 2_{(\mathrm{RED})}-\mathrm{AFF}-\mathrm{SA}\right]$} & stress anchoring \\
{$[(\mathrm{VPA}-) \mathrm{V}-\mathrm{AFF}]$} & stress anchoring \\
{$[\mathrm{V} 2-\mathrm{AFF}-\mathrm{SA}]$} & tone sandhi \\
{$\left[(\mathrm{VPA}-) \mathrm{V} 2_{(\mathrm{RED})}\right]$} & stress anchoring \\
{$[\mathrm{V} 2-\mathrm{VPA}]$} & tone sandhi \\
{$[\mathrm{VPA}]$} & stress anchoring \\
\hline
\end{tabular}

\subsection{Synthesis}

Since the effects of L2 admixture are also often sought in the degree of inflectional SYNTHESIS, we also counted the number of inflectional categories that can be expressed by the maximally inflected verb form (Bickel \& Nichols 2005). Table 13 reveals that Bunan and Chintang have relatively high degrees (8-9), while Burmese and Mandarin have lower degrees (2-4). "Valency" refers to markers of argument structure (partly reflecting coronal root augments wide-spread in Sino-Tibetan) that are inflectional in as far as they react to the argument structure of other verb stems in compounding and/ or interact with the form of agreement morphology. "Voice" refers to antipassivization, passivization, and other mechanisms of syntactic detransitivization (Bickel et al. 2020).

Table 13. Degree of verbal inflectional synthesis. The coding procedure follows that of Bickel \& Nichols (2005), further expanded in Bickel et al. (2020). "agr" stands for "agreement", A for the most agent-like, $P$ for the most patient-like argument.

\begin{tabular}{lll}
\hline Language & Count & Categories \\
\hline Bunan & 8 & A-agr, P-agr, evidentiality, polarity, tense, valency, voice, mood \\
Chintang & 9 & A-agr, P-agr, aspect, mood, polarity, tense, valency, voice, connectives \\
Burmese & 4 & A-agr, aspect, mood, polarity \\
Mandarin & 2 & aspect, tense/mood \\
\hline
\end{tabular}

\section{Results}

There are various ways in which the distribution of morpheme types, cohesion domains, and synthesis degrees could be affected by differences in L2 admixture. In response to this, we cast the net wide and analyze the data with regard to five different variables: ${ }^{20}$

1. presence of specific morpheme types, e.g. does an L2-admixed language have preverbs?

2. presence of specific domains, e.g. does an L2-admixed language have a [V-AFF-AFF-V2AFF-CL-VPA-AFF] domain?

20 The data for morpheme types are in Tables 1, 4, 7, and 10, the data for domains in Tables 2-3, 5-6, 8-9, and 11-12, and the data for synthesis in Table 13. 
3. presence and count of specific cohesion constraints that define domains, e.g. is an L2admixed language sensitive to cross-slot dependencies and if so, how many distinct domains are defined by cross-slot dependencies?

4. $\quad$ size (in morpheme types) of these domains, e.g. how long are the domains defined by cross-slot dependencies in an L2-admixed language?

5. presence of specific inflectional categories (synthesis), e.g. does an L2-admixed language have P-Agreement?

We do not expect categorical answers to any of these questions, but we expect quantitative differences in the odds ${ }^{21}$ and counts, e.g. the odds for preverbs being present or the count of cohesion constraints might be lower in high-admixture languages than in low-admixture languages. To estimate such differences we turn to statistical modeling. ${ }^{22}$ The basic idea is to quantify the extent to which the difference in L2 admixture (i.e. Burmese and Mandarin vs. Bunan and Chintang) increase or decrease the odds of a certain type and/or its count or size. We model the odds with what is technically known as a Bernoulli (or "logistic") regression and the counts with what is known as Poisson (or "count") regression model, following standard procedures (see Levshina 2015 or Winter 2020 for languageoriented introductions and tutorials). In these models, the difference in L2 admixture is expressed on a logarithmic scale so that an L2 coefficient near 0 means that log odds and log counts do not differ between high-admixture and low-admixture languages. In this case there is what is known as a null effect. A negative coefficient means that the log odds and log counts are lower in the high-admixture languages, as would be expected under the hypothesis that mass admixture simplifies morphology.

We focus on overall L2 effects, i.e. mean L2 effects that hold for the (log) odds and counts in a variable. We do not model the variation in how strongly an L2 effect might vary for specific levels of a variable, i.e. the specific types, domains, constraints, or categories that occur. For example, we estimate the mean L2 effect on the (log) odds of morpheme types to be present, but not how this effect might differ between, say, preverbs and affixes; or the mean effect on the (log) count of phonological constraints, but not how this count might differ between, say, voicing and glottalization constraints. The distribution of these levels is far too heterogenous across languages - some indeed occur only in one or two languages. This makes it impossible to estimate how their variation might interact with the L2 effects. However, we do allow for variation between languages (corresponding to what is technically known as "varying" or "random intercepts"). As a result, our estimates of L2 effects represent the overall effects after any such variation is factored out.

We are interested as much in the absence as in the presence of L2 effects. Therefore we fit the models in a Bayesian framework. ${ }^{23}$ This means that we estimate the probability distribution of the L2 effects, i.e. how probable it is that an effect is 0 , or 2 or any log odds value in-between. We report these estimates as density curves that indicated how probable each value is for a given variable. We furthermore compare the predictive performance of models that include the L2 factor and those that exclude the factor with regard to held out or as yet unobserved data. This allows insight into the relevance of the L2 factor for capturing the data independently of how strong the effect is (cf. the Supporting Material for details).

21 The odds are the probability of presence against the probability of absence, e.g. if something is present with .75 probability, it has odds of $.75 / .25=3 / 1=3$, i.e. it is three times as likely to be present. Odds allow easier modeling than probabilities, especially on their natural logarithms ("log odds", also known as "logits").

22 See the Supporting Materials for detailed technical description and https://osf .io/mt98r/ for executable code and machine-readable data.

23 The more familiar $p$-value tests only allow rejection of a null effect but cannot quantify the evidence for a null effect. 
Figure 2 presents the results. There is an overall difference between the estimates for morpheme types (reflecting SELECTION and INFLECTION) and the COHESION variables (domains and constraints) on the one hand, and the estimate for SYNTHESIS on the other hand. We describe these results in turn.

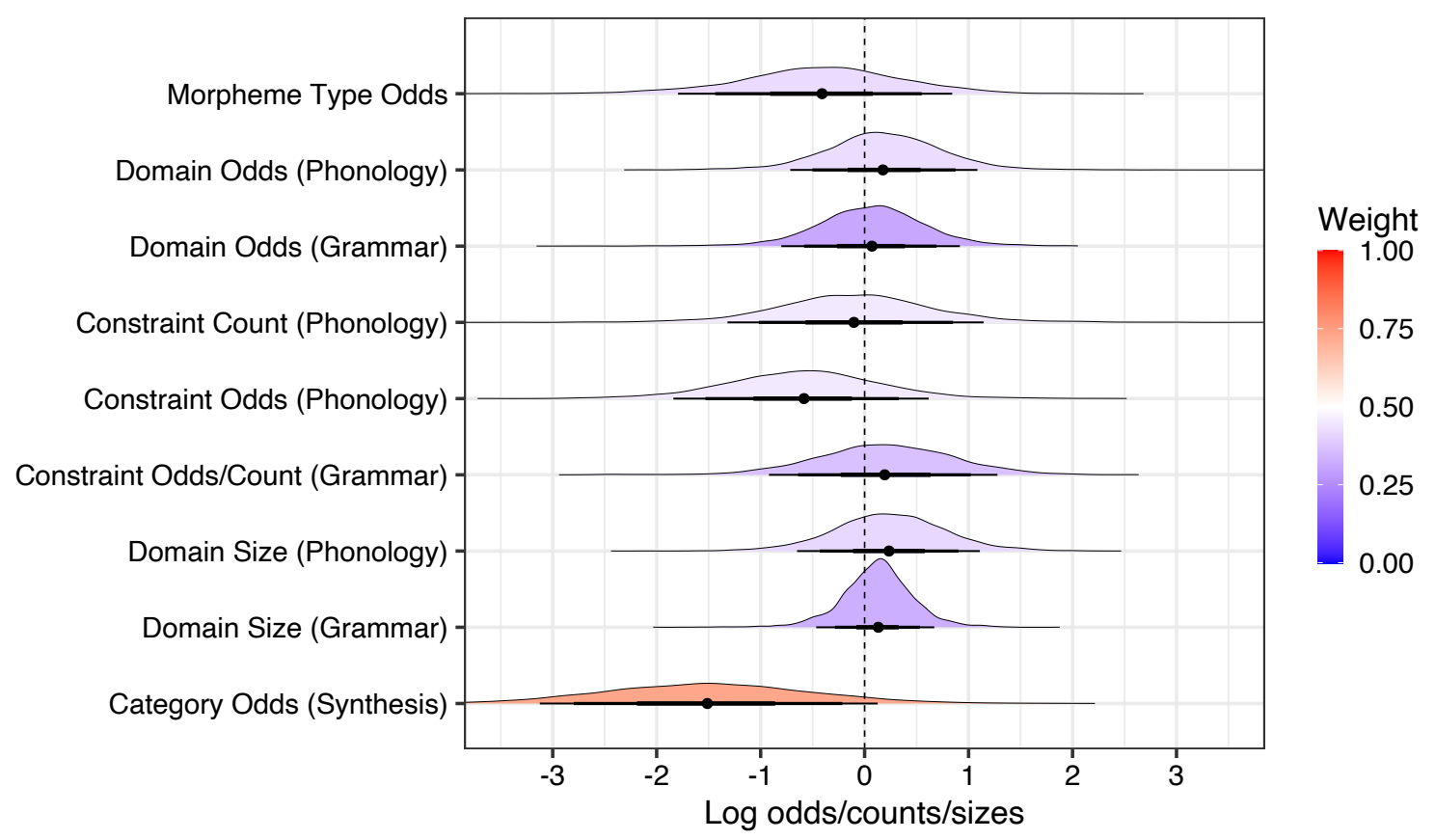

Figure 2. Posterior probabilities of the L2 effect on morphology (in log odds/counts/sizes). Black dots indicate the medians and black horizontal lines the 50\%, 80\% and 90\% intervals around them (with decreasing thickness); the dashed vertical line is at 0 (null effect). The coloring is proportional to predictive performance (model "weight"). Values closer to 0 (blue) indicate better performance without the L2 factor, values closer to 1 (red) indicate better performance with the L2 factor, values around 5 (white) suggest ambiguous evidence. See Table S1 in the Supporting Materials for the numbers.

\subsection{Morpheme types and cohesion}

The variables of morpheme types and COHESION (domains and constraints) mostly show L2 admixture effects close to 0 (Figure 2). Models without the L2 factor have indeed better predictive performance (blue colors), lending support to a null effect. One seeming exception is the phonological constraint odds, which are estimated to be slightly lower in high-admixture languages than in low-admixture languages (i.e. a negative L2 coefficient). However, 0 is included in the $80 \%$ interval of the estimates (medium-thickness line), and the model with the L2 factor has slightly weaker predictive performance $(.45$, blue) than the model without this factor (.55). These findings suggest a null effect, although the model needs to be interpreted with some caution since some constraints only occur in single languages, e.g. sequisyllabicity only in Burmese (see the Supporting Materials for further statistical discussion).

Another potential exception concerns morpheme types, where the median estimate is again below 0 , tentatively suggesting lower odds for high-admixture languages (Figure 2). However, 0 is included in even the 50\% interval of the estimates (thick black line), and the model with the L2 factor has somewhat weaker performance than the model without the factor (.42 vs .58; Table S1). Together, this evidence favors a null effect, and this is confirmed by our qualitative results: the distribution of morpheme types aligns with the L2 divide in only 2 out 7 cases (cf. Table 14). For the two types that do align, the evidence of an L2 effect is relatively weak, as we show in what follows. 
Table 14. Morpheme types in Bunan (Bun), Chintang (Chi), Burmese (Bur), and Mandarin (Man), as evidenced by their selection and inflection behavior. Grey shading indicates presence, white cells indicate absence of the type.

\begin{tabular}{|c|c|c|c|c|c|c|}
\hline Morpheme type & Selects & Inflects for & Bun & Chi & Bur & Man \\
\hline $\mathrm{V} 2$ & $\mathrm{~V}$ & at least aspect or tense & & & & \\
\hline preverbs $(\mathrm{PV})$ & $\mathrm{V}$ & - & & & & \\
\hline affix (AFF) & $\mathrm{V}(2)$ & - & & & & \\
\hline clitic $(\mathrm{CL})$ & $\mathrm{X}(\mathrm{P})$ & - & & & & \\
\hline verbal phrasal affix (VPA) & VP & - & & & & \\
\hline free phrasal affix (FPA) & $\mathrm{XP}$ & - & & & & \\
\hline sentential affix (SA) & $\mathrm{S}$ & - & & & & \\
\hline
\end{tabular}

The first case concerns preverbs, which are attested in the low-admixture languages Bunan and Chintang, but absent in the high-admixture languages Burmese and Mandarin. Preverbs reflect a bipartite stem structure that is sometimes claimed to be an archaic feature of Eurasia, surviving only in the Himalayas and the Caucasus (Bickel \& Nichols 2007). Within Sino-Tibetan, bipartite stems are found in several subgroups in the greater Himalayan region, some with more and some with less L2 admixture: rGyalrongic, Qiang, Tibetan, Tamangic, Newar, as well as West Himalayish and Kiranti (Hildebrandt 2005; Jacques 2018). This distribution suggests that preverbs might reconstruct to the proto-language and that their absence in Burmese and Mandarin indeed results from massive L2 admixture. At the same time, bipartite stems have been posited elsewhere as areal spread phenomena (DeLancey 1996), and so we cannot exclude the possibility that their distribution in Sino-Tibetan is innovative and derived. More extensive research is needed to evaluate these contrasting scenarios.

The second alignment with L2 admixture concerns XP-selecting morphemes ("free phrasal affixes") which are again limited to Bunan and Chintang. However, it is unlikely that the distribution of such XP-selecting elements is directly driven by L2 effects because such elements are widely attested in other languages with many L2 speakers, such as Turkish (cf. for example the interrogative clitic $m I$ ) or Nepali (e.g. the contrastive focus clitic ta). In view of this, the absence of XP clitics in Burmese and Mandarin is more likely to be an accidental gap. Indeed, under some analyses, the range of XP clitics would extend to Mandarin: it is sometimes suggested that verb-final le and sentence-final le (both written 了) are exponents of a single morpheme (e.g. Wiedenhof 2015). If this is right, Mandarin would have a clitic that behaves very similar to clitics in Chintang and Burmese. Thus, on balance, the distribution of morpheme types sides with the cohesion variables and shows evidence against an overall L2 difference, although perhaps not equally strong evidence.

Further inspection of the models without the L2 factor reveals relatively modest variation between languages, suggesting remarkable homogeneity in the sample. This is visualized in Figure 3 which shows the overall $\log$ odds/counts/sizes across all languages together with the deviations from this overall estimate by each language (i.e. what is technically known as "varying intercept effects"). With the exception of the phonological constraints, the estimates per language (colored in Figure 3) are relatively close to the overall estimate (black). For example, the domain sizes in grammar are estimated at 1.7 (corresponding to 1.67 in the data, 24 both on the log scale) and language-specific estimates only vary between -.02 and .05 around this (corresponding to .12 and .14 in the data). The

\footnotetext{
${ }^{24}$ For a proper comparison of estimates and data see Figure S2 in the Supporting Materials. Raw odds/counts/ sizes are deceptive because they ignore any differences between the levels of the variable (in the example, the actual constraint types that define each domain). The model estimates take this variation into account.
} 


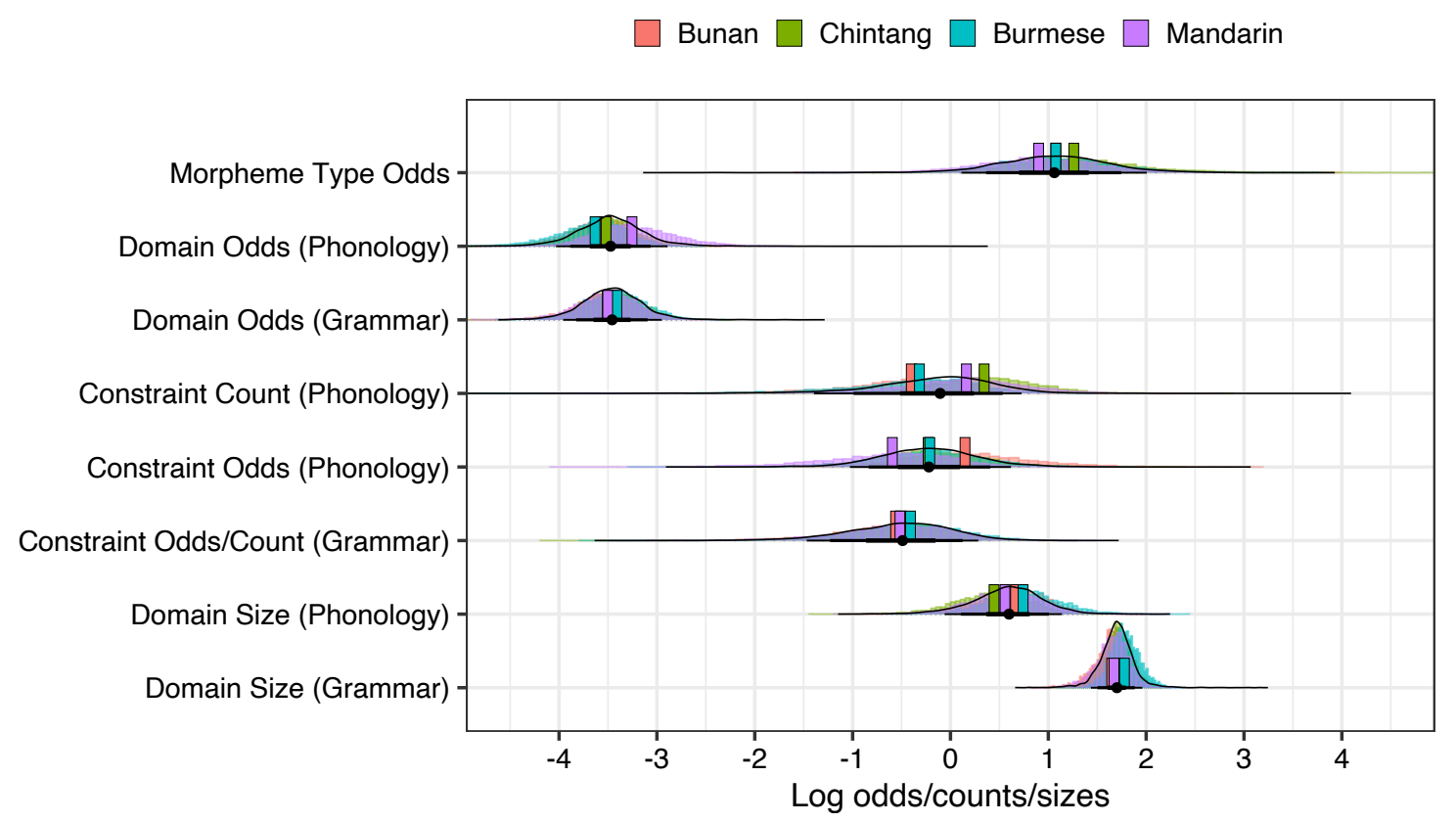

Figure 3. Posterior probabilities of the overall estimates (in log odds/counts/sizes) in models without the L2 factor (black outlines, with dots indicating the medians and horizontal lines the intervals around them like in Figure 2). The colored probabilities indicate the languagespecific deviations from the overall estimate. Vertical colored bars represent the medians (see Table $S 2$ in the Supporting Materials for details).

other variables are not as extreme as this example, but the language-specific estimates are all close to the overall estimates (see also Table S2 in the Supporting Materials). Consistent with this, we find that models without any information about language (i.e. without varying intercepts) have similar or higher predictive performance as models with this information, and there is positive evidence that the variation by language indeed contributes no information to the model fit. Table S3 in the Supporting Materials shows that models without language have consistently better predictive performance (with weights between .59 and .71), and that even the $50 \%$ intervals for the estimated contribution of the variation by language include 0 throughout. Figures S2 and S3 furthermore show that models without language information fit the data equally well as models that take the variation between languages into account. This suggests remarkably strong homogeneity in the sampled languages.

The exception to this is the phonological constraints model, where some constraints are limited to specific languages. The extent of variation by language is larger than in the other models, although the total statistical evidence is in fact ambiguous (cf. Section S4.2 in the Supporting Material for discussion).

\subsection{Synthesis}

The distribution of inflectional categories shows a strikingly different pattern. Figure 2 shows clear evidence for a difference between the two low-admixture languages and the two high-admixture languages. Here, $94 \%$ of the posterior probability mass is below 0 , and a model with the L 2 factor leverages nearly three times more weight than a model without the factor $(.73 \mathrm{vs} .27)$. The median effect of L2 admixture on synthesis is $-1.51 \mathrm{log}$ odds, which means that the odds for any given category in the high-admixture languages is only less than a quarter the odds of what we find in the low-admixture languages. 
The variation in SYNTHESIS between languages is modest compared to the L2 effect, although Mandarin has even fewer categories than the estimates for high-admixture languages and Chintang has more than the estimates for low-admixture languages (see Figure S1 in the Supporting Materials). Consistent with this, models that do not take variation by language into account have better predictive performance (leveraging .70 of the weights) and the contribution of this variation is likely to be 0 $(50 \% \mathrm{CI}=[-.03, .07]$; see Supporting Materials, Section S4.1).

\section{Discussion}

The evidence on morpheme types (as defined by SELECTION and INFLECTION) and phonological constraints remains somewhat ambiguous, but for all other COHESION variables and for SYNTHESIS the evidence is relatively strong: COHESION shows evidence against an effect from L2 admixture, while SYNTHESIS shows evidence for such an effect. This contrast shows that our coding system, method, and sample are in principle capable of detecting L2 effects in any of the variables. Together with the good fit of the models (see Figures S2 and S3 in the Supporting Materials) and the modest variation across languages (Figure 3), this suggests that the results are robust and indicative of meaningful patterns.

For SYNTHESIS, the effect we found is fully in line with current theory (Trudgill 2001, 2011; McWhorter 2007; Wray \& Grace 2007; Lupyan \& Dale 2010). Glossing over variations in the details (Bentz \& Winter 2013), the gist of the theory is that the transparency and regularity of analytical coding facilitates adult L2 learning compared to synthetic coding, and that languages adapt to this need when they undergo mass L2 admixture. As noted in the introduction, the same theory would also predict lower COHESION under L2 admixture since COHESION decreases transparency: boundaries become increasingly blurred the more constraints apply, elements are inter-dependent and it is no longer clear where a meaning is exactly signaled, domains becomes long and intricate to disentangle into their constituent morphemes, etc.

Yet, this prediction is not borne out in our sample. Here, COHESION escapes the effects of L2 admixture and with the exception of how phonological constraints are distributed, the languages in our sample turn out to be remarkably homogenous. But then, why would COHESION escape L2 admixture effects and why are the languages so similar? There are two scenarios that might explain this, but both need considerably more research to be evaluated and our sample is too small to clearly differentiate between them.

One scenario is that COHESION is shaped by universal principles that are resilient against contact (or any other) confound. For example, it is likely that certain domain-defining constraints are universally preferred and in fact facilitate adult L2 learning. A case in point is ordering constraints which are strongly preferred in the languages of the world and even show up probabilistically in language use when grammars do not impose categorical constraints (Mansfield et al. 2020). This is likely to extend to those morpheme types that are shared by all languages in the sample: affixes, i.e. V- and V2selecting elements, are very wide-spread in the languages of the world, suggesting frequent evolution. Given this, it is possible that their ubiquity in our sample reflects universal pressure that trumps possible effects from morphology-simplifying L2 admixture effects.

The other scenario is that certain COHESION patterns are diachronically very stable and this might trump the demands of second language learners. For example, the size of phonological domains has been found to be remarkably consistent in language families but not in linguistic areas (Bickel et al. 2009), and Sino-Tibetan in particular shows remarkably consistent prosodic structures in the mapping between syllables and morphemes (Bickel 2003). If there is such diachronic resilience it is likely to be old since the last common ancestor of our sample languages is at least 5,900 and 7,400 year old. It is 
possible that this extends to the V2 morpheme type, which is a likely pan-Sino-Tibetan trait, although a world-wide survey is needed to test how typologically distinctive it really is.

\section{Conclusion}

Our case study is limited to four languages, and we cannot generalize our findings beyond this. What our study does suggest, however, is that mass L2 admixture can indeed affect morphology in very unequal ways: it can leave a strong effect on SYNTHESIS, while COHESION and possibly some aspects of SELECTION and INFLECTION can escape it. A full assessment and explanation of this requires a worldwide survey that allows a systematic comparison of models of universal preference, diachronic stability, and chance developments.

What is clear for now is that theories of L2 effects on morphology need to carefully differentiate between different dimensions of morphology, with more precise mechanistic models of which aspects of learning affect which dimensions of morphology. In order to capture the relevant patterns, we need go beyond the traditional procedures of aggregating these dimensions in general complexity measures or of exclusively focusing on a single dimension and instead work with many separate dimensions in a comparative framework.

\section{Supporting Materials}

The Supporting Materials document contains technical details of the statistical analysis and is available at https://osf.io/mt98r/

\section{Acknowledgments}

This work was supported by Swiss National Science Foundation Grant No. CRSII1_160739. We are grateful to Jeroen Wiedenhof for helpful comments on our analysis of Chinese. This paper was originally under consideration at another journal but we withdrew it after one reviewer insisted that we change our entire research question and approach. This notwithstanding, we gratefully acknowledge the constructive and helpful comments by two other reviewers from that submission, as much as the two Studies in Language reviewers.

\section{Abbreviations}

$\begin{array}{ll}\text { 1,2,3 } & \text { first, second, third person } \\ \text { A } & \text { most agent-like argument } \\ \text { ABIL } & \text { abilitative } \\ \text { ADD } & \text { additive } \\ \text { ALL } & \text { allative } \\ \text { ALLO } & \text { allophoric } \\ \text { APPR } & \text { apprehensive } \\ \text { BEN } & \text { benefactive } \\ \text { CAUS } & \text { causative } \\ \text { CLF } & \text { classifier } \\ \text { CONTR } & \text { contrastive } \\ \text { CRS } & \text { currently relevant state } \\ \text { DAT } & \text { dative } \\ \text { DELIM } & \text { delimitative } \\ \text { DES } & \text { desiderative } \\ \text { DETR } & \text { detransitive } \\ \text { DIR } & \text { direct evidentiality } \\ \text { DUR } & \text { durative }\end{array}$

$\begin{array}{ll}\text { EGO } & \text { egophoric } \\ \text { EMPH } & \text { emphatic } \\ \text { EX } & \text { existential } \\ \text { EXCL } & \text { exclusive } \\ \text { EXPER } & \text { experiential } \\ \text { FOC } & \text { focus } \\ \text { FUT } & \text { future } \\ \text { ICVB } & \text { imperfective converb } \\ \text { IMP } & \text { imperative } \\ \text { IMPORT } & \text { importance } \\ \text { IND } & \text { indicative } \\ \text { INFER } & \text { inferential evidentiality } \\ \text { INSIST } & \text { insisting } \\ \text { INTR } & \text { intransitive } \\ \text { IPFV } & \text { imperfective } \\ \text { LOC } & \text { locative } \\ \text { MID } & \text { middle } \\ \text { NEG } & \text { negation }\end{array}$




$\begin{array}{llll}\text { NFUT } & \text { non-future } & \text { REP } & \text { reportative } \\ \text { NMLZ } & \text { nominalizer } & \text { RESUL } & \text { resultative } \\ \text { NSG } & \text { non-singular } & \text { RLV } & \text { relevance indicator } \\ \text { OPT } & \text { optative } & \text { S } & \text { sole argument of intransitive } \\ \text { P } & \text { most patient-like argument } & \text { SEQ } & \text { sequential } \\ \text { PCVB } & \text { perfective converb } & \text { SG } & \text { singular } \\ \text { PERF } & \text { perfect } & \text { SIM } & \text { simultaneous } \\ \text { PL } & \text { plural } & \text { SUG } & \text { suggestive } \\ \text { PROG } & \text { progressive } & \text { SUP } & \text { supine } \\ \text { PROH } & \text { prohibitive } & \text { TEL } & \text { telic } \\ \text { PST } & \text { past } & \text { TR } & \text { transitive } \\ \text { PTCP } & \text { participle } & \text { UND } & \text { undergoer } \\ \text { Q } & \text { question } & & \end{array}$

\section{References}

Aldenderfer, Mark \& Zhang Yinong. 2004. The prehistory of the Tibetan Plateau to the seventh century A.D.: perspectives and research from China and the West since 1950. Journal of World Prehistory 18(1). 1-55.

Anderson, Stephen R. 2005. Aspects of the theory of clitics. Oxford: Oxford University Press.

Behr, Wolfgang. 2004. 'To translate' is 'to exchange' 譯者易也 - linguistic diversity and the terms for translation in Ancient China. In N. Vittinghoff \& M. Lackner (eds.), Mapping meanings: the field of new learning in late Qing China (Sinica Leidensia 64), 173-209. Leiden: Brill.

Behr, Wolfgang. 2010. Role of language in early Chinese constructions of ethnic identity, Journal of Chinese Philosophy 37(4). 567-587.

Bentz, Christian \& Bodo Winter. 2013. Languages with more second language learners tend to lose nominal case. Language Dynamics and Change 3. 1-27.

Bickel, Balthasar \& Fernando Zúñiga 2017. The 'word' in polysynthetic languages: phonological and syntactic challenges. In Michael Fortescue, Marianne Mithun \& Nicholas Evans (eds.), The Oxford handbook of polysynthesis, 158-185. Oxford: Oxford University Press.

Bickel, Balthasar \& Johanna Nichols. 2005. Inflectional synthesis of the verb. In Martin Haspelmath, Matthew S. Dryer, David Gil, \& Bernard Comrie (eds.), The world atlas of language structures, 94-97. Oxford: Oxford University Press.

Bickel, Balthasar \& Johanna Nichols. 2007. Inflectional morphology. In: Timothy Shopen (ed.), Language typology and syntactic description, 2nd edn., 169-240. Cambridge: Cambridge University Press.

Bickel, Balthasar, Goma Banjade, Martin Gaenszle, Elena Lieven, Netra Prasad Paudyal, Ichchha Purna Rai, Manoj Rai, Novel Kishore Rai, Sabine Stoll. 2007. Free prefix ordering in Chintang. Language 83. 43-73.

Bickel, Balthasar, Johanna Nichols, Taras Zakharko, Alena Witzlack-Makarevich, Kristine Hildebrandt, Michael Rießler, Lennart Bierkandt, Fernando Zúñiga \& John B. Lowe. 2020. The AUTOTYP typological databases, Version 0.1.1. https://github.com/autotyp/autotyp-data.

Bickel, Balthasar, Kristine A. Hildebrandt \& René Schiering. 2009. The distribution of phonological word domains: A probabilistic typology. In Janet Grijzenhout \& Baris Kabak (eds.), Phonological domains: universals and deviations, 47-75. Berlin: de Gruyter Mouton.

Bickel, Balthasar. 2003. Prosodic tautomorphemicity in Sino-Tibetan. In David Bradley, Randy J. LaPolla, Boyd Michailovsky \& Graham Thurgood (eds.), Variation in Sino-Tibetan and South East Asian languages, 89-99. Canberra: Pacific Linguistics.

Booij, Geert. 2010. Construction morphology. Oxford: Oxford University Press.

Bradley, David. 1997. Tibeto-Burman languages and classification. In David Bradley (ed.), Tibeto-Burman languages of the Himalayas, 1-71. Canberra: Pacific Linguistics.

Bruening, Benjamin. 2018. The Lexicalist Hypothesis: both wrong and superfluous. Language 94, 1-42.

Chen, Matthew Y. 2000. Tone sandhi: patterns across Chinese dialects. Cambridge: Cambridge University Press. 
Dai, John Xiang-Ling. 1998. Syntactic, phonological, and morphological words in Chinese. In Jerome L. Packard (ed.), New approaches to Chinese word formation: morphology, phonology and the lexicon in Modern and Ancient Chinese, 104-134. Berlin: de Gruyter Mouton.

DeLancey, Scott. 1996. The Bipartite Stem Belt: disentangling areal and genetic correspondences. In David Librik \& Roxane Beeler (eds.), Proceedings of the 22nd Annual Meeting of the Berkeley Linguistics Society February 16-19, 1996, 37-54. Berkeley: Berkeley Linguistics Society.

DeLancey, Scott. 2013. Creolization in the divergence of the Tibeto-Burman languages. In Thomas Owen-Smith \& Nathan Hill (eds.), Trans-Himalayan linguistics: Historical and descriptive linguistics of the Himalayan area, 41-70. Berlin: de Gruyter Mouton.

DeLancey, Scott. 2015. The historical dynamics of morphological complexity in Trans-Himalayan. Linguistic Discovery 13. 60-79.

Dixon, Robert M. W. \& Alexandra A. Aikhenvald. 2002. Word: A typological framework. In Robert M. W. Dixon \& Alexandra A. Aikhenvald (eds.), Word: A cross-linguistic typology, 1-41. Cambridge: Cambridge University Press.

Dixon, Robert M. W. 1977. A grammar of Yidiny. Cambridge: Cambridge University Press.

Duanmu, San. 2000. The phonology of Standard Chinese, $2^{\text {nd }}$ edn. Oxford: Oxford University Press.

Hall, T. Alan \& Ursula Kleinhenz (eds.). 1999. Studies on the phonological word. Amsterdam: John Benjamins.

Hall, T. Alan, Kristine A. Hildebrandt \& Balthasar Bickel. 2008. Introduction: theory and typology of the word. Linguistics 46. 183-192.

Haspelmath, Martin. 2011. The indeterminacy of word segmentation and the nature of morphology and syntax. Folia Linguistica 45. 31-80.

Hildebrandt, Kristine A. 2007. Prosodic and grammatical domains in Limbu. Himalayan Linguistics 8. 1-34.

Hildebrandt, Kristine A. 2014. The prosodic word. In John R. Taylor (ed.), The Oxford handbook of "the word", 221-245. Oxford: Oxford University Press.

Hyman, Larry M. 2008. Directional asymmetries in the morphology and phonology of words, with special reference to Bantu. Linguistics 46. 309-350.

Jacobsen, William H. Jr. 1980. Washo bipartite verb stems. In Kathryn Klar, Margaret Langdon \& Shirley Silver (eds.), American Indian and Indoeuropean Studies: Papers in Honor of Madison S. Beeler, 85-99. Berlin: Mouton.

Jacques, Guillaume 2018. Bipartite verbs in Japhug and other Trans-Himalayan languages. Linguistics of the Tibeto-Burman Area 41. 75-191.

Jenny, Mathias \& San San Hnin Tun. 2016. Burmese: A comprehensive grammar. New York: Routledge.

Levshina, Natalia. 2015. How to do Linguistics with R. Amsterdam: John Benjamins

Lewis, M. Paul (ed.). 2009. Ethnologue: Languages of the world, $16^{\text {th }}$ edn. Dallas: SIL International

Li, Charles N. \& Sandra A. Thompson. 1981. Mandarin Chinese: A functional reference grammar. Berkeley: University of California Press.

Lupyan, Gary \& Rick Dale. 2010. Language structure is partly determined by social structure. PLoS ONE 5(1), e8559

Mansfield, John, Sabine Stoll \& Balthasar Bickel. 2020. Category clustering: a probabilistic bias in the morphology of argument marking. Language 96. 255-293.

Matisoff, James A. 1989. The bulging monosyllable or the mora the merrier: echo-vowel adverbialization in Lahu. In Jeremy H.C.S. Davidson (ed.), Southeast Asian linguistics: Essays in honour of Eugénie J.A. Henderson, 163-197. London: SOAS.

McWhorter, John. 2007. Language interrupted: Signs of non-native acquisition in standard language grammars. New York: Oxford University Press.

Nespor, Marina \& Irene Vogel. 2007. Prosodic Phonology. Berlin: de Gruyter Mouton.

Post, Mark W. 2007. A grammar of Galo. Bundoora: La Trobe University PhD dissertation.

Post, Mark W. 2009. The phonology and grammar of Galo "words": A case study in benign disunity. Studies in Language 33. 934-974.

Sagart, Laurent, Guillaume Jacques, Yunfan Lai, Robin J. Ryder, Valentin Thouzeau, Simon J. Greenhill \& Johann-Mattis List. 2019. Dated language phylogenies shed light on the ancestry of Sino-Tibetan. Proceedings of the National Academy of Sciences 116. 1031710322. doi:10.1073/pnas.1817972116. 
Schiering, René, Balthasar Bickel \& Kristine A. Hildebrandt. 2010. The prosodic word is not universal, but emergent. Journal of Linguistics 46. 657-709.

Sharma, Devidatta. 1989. Tribal languages of Himachal Pradesh, part I. Delhi: Mittal.

Thurgood, Graham. 2017. Sino-Tibetan: genetic and areal subgroups. In Graham Thurgood \& Randy J. LaPolla (eds.), The Sino-Tibetan languages, 3-39. London: Routledge.

Trudgill, Peter. 2001. Contact and simplification: Historical baggage and directionality in linguistic change. Linguistic Typology 5. 371-374.

Trudgill, Peter. 2011. Sociolinguistic typology: Social determinants of linguistic complexity. Oxford: Oxford University Press.

van Driem, George. 2001a. Languages of the Himalayas: An ethnolinguistic handbook of the greater Himalayan region. Leiden: Brill.

van Driem, George. 2001b. Zhangzhung and its next of kin in the Himalayas. In Yasuhiko Nagano \& Randy LaPolla (eds.), New research on Zhangzhung and related Himalayan languages, 31-44. Osaka: National Museum of Ethnology.

Widmer, Manuel. 2017. A grammar of Bunan. Berlin: de Gruyter Mouton.

Wiedenhof, Jeroen. 2015. A grammar of Mandarin. Amsterdam: John Benjamins.

Winter, Bodo. 2020. Statistics for Linguists. London: Routledge

Wray, Alison \& George W. Grace. 2007. The consequences of talking to strangers: Evolutionary corollaries of socio-cultural influences on linguistic form. Lingua 117. 543-578.

Zhang, Menghan, Shi Yan, Wuyun Pan \& Li Jin. 2019. Phylogenetic evidence for Sino-Tibetan origin in northern China in the Late Neolithic. Nature 569. 112-115. doi:10.1038/s41586-019-1153-z. 


\title{
Morphological structure can escape reduction effects from mass admixture of second language speakers: evidence from Sino-Tibetan Supplementary Materials: Statistical Models*
}

\author{
Balthasar Bickel
}

\section{S1 Data}

The data provide for five ways of quantifying morphology:

- odds of presence vs absence of specific morpheme types

- odds of presence vs absence of specific domains, split in phonology vs grammar

- odds and number of domains in which specific cohesion rules/constraints hold, split in phonology vs grammar

- size (in morpheme types) of these domains, split in phonology vs grammar

- odds of presence vs absence of specific inflectional categories (synthesis)

The data on morpheme types are contained in Tables 1, 4, 7, 8, and, as a synopsis, in Table 13 in the main paper. A machine-readable version is available as morpheme_types.csv. The data on cohesion domains appear in Tables 2-3, 5-6, 8-9, and 11-12 and are collected in machine-readable form in the file domains.csv. The survey of inflectional categories is presented in Table 14 and in synthesis.csv.

In each of these data sets the languages are grouped as either L2 = "few" vs L2 = "much". "Few" means that the community includes only a handful of second language speakers (Chintang and Bunan); "much" means that there are several million of second language speakers (Mandarin and Burmese).

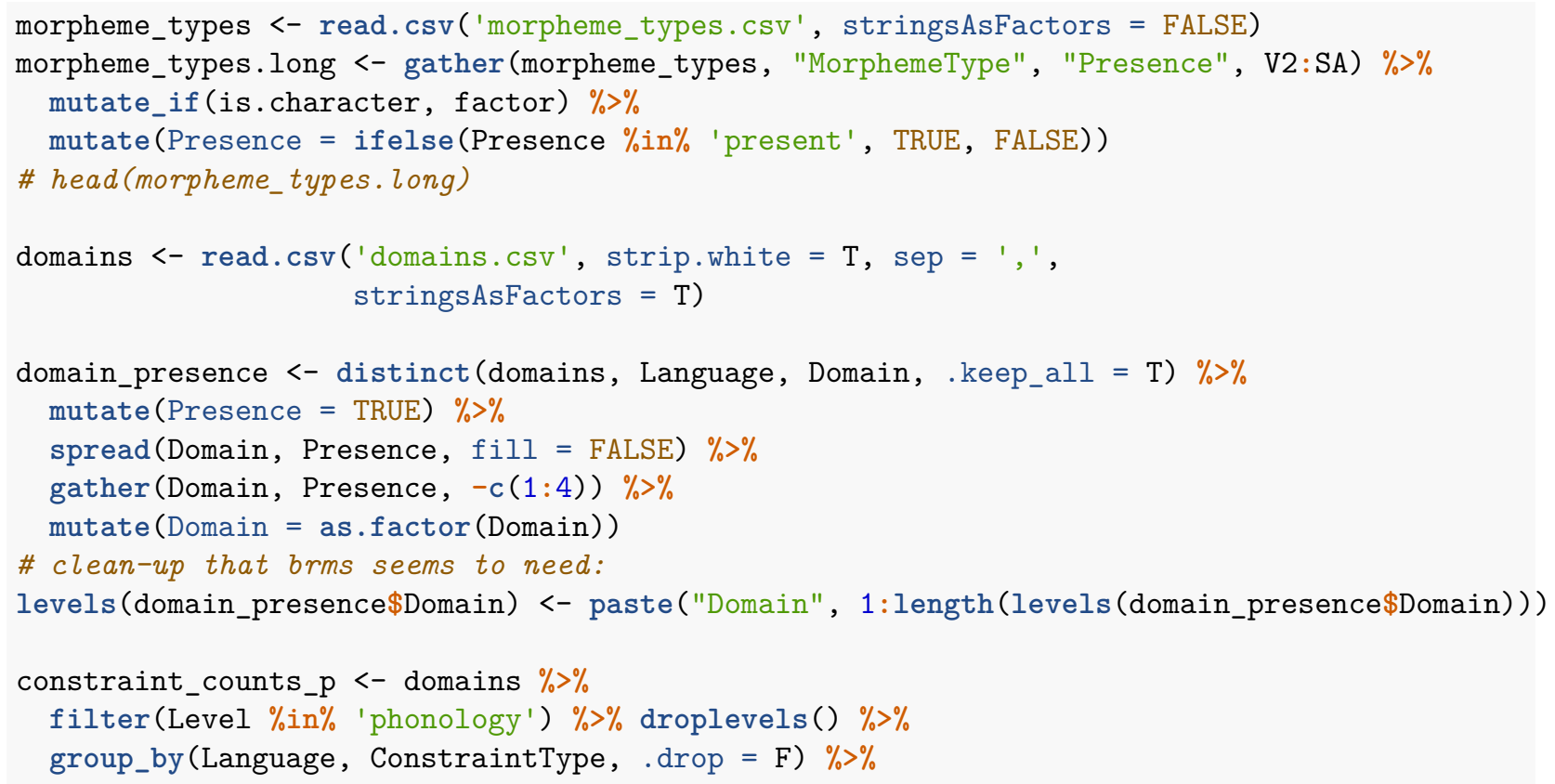

${ }^{*}$ This document was rmarkdown: :render'ed from an $\mathrm{R}$ script available at https://osf.io/mt98r 


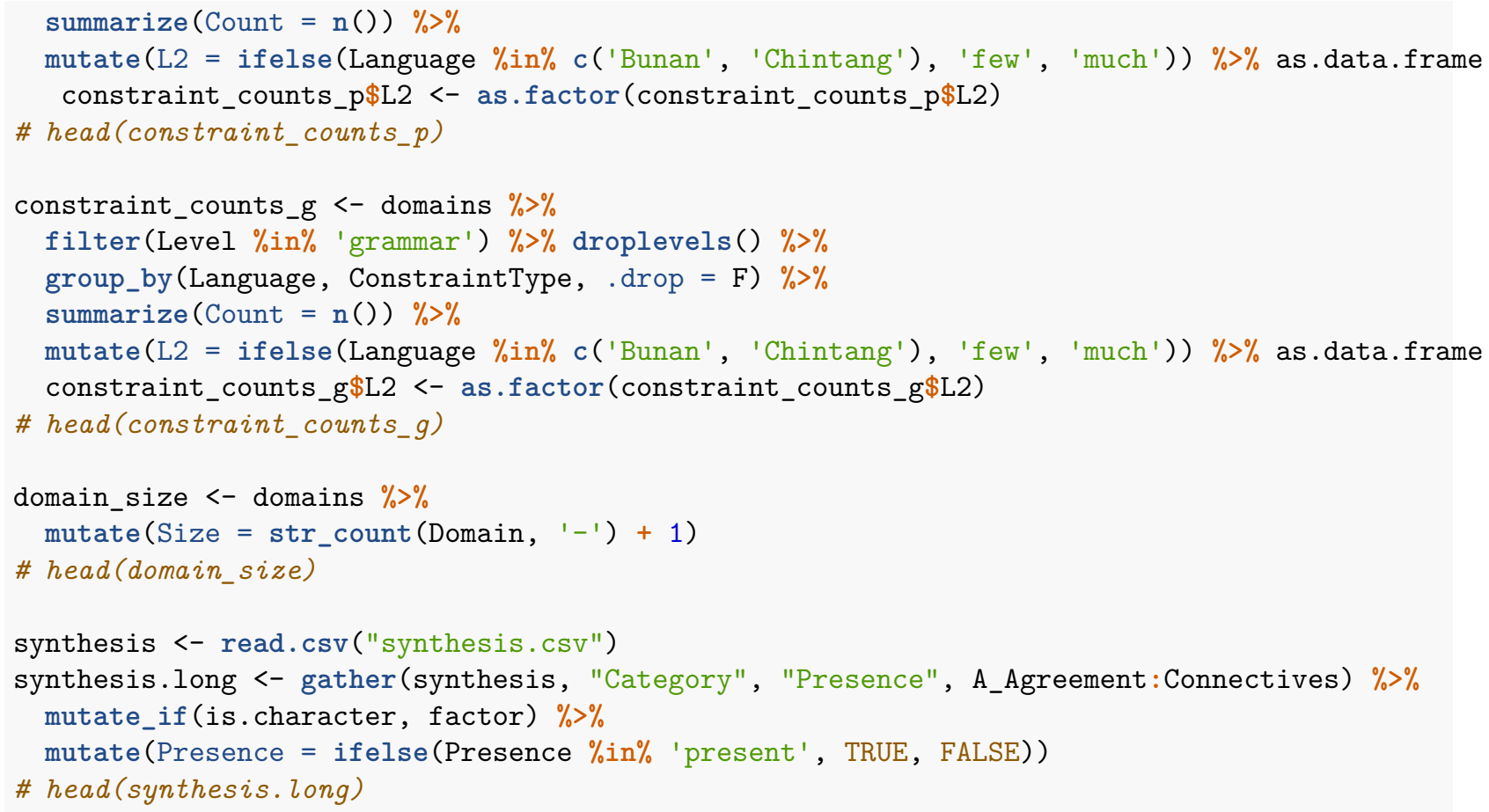

\section{S2 Models and model evaluation methods}

We assess the effect of L2 on the odds, counts or sizes of the various patterns in generalized linear multilevel ("mixed effects") model. We assume Bernoulli likelihoods for the odds and Poisson likelihoods for the counts and sizes (counts of morpheme types), each with their canonical links (log odds and log, respectively). For the predictors we use deviation coding so that the intercept represents that grand mean and the L2 coefficient indicates the difference in the log odds/counts/size between high-admixture and low-admixture languages. Here is a helper function to set up the contrast matrix:

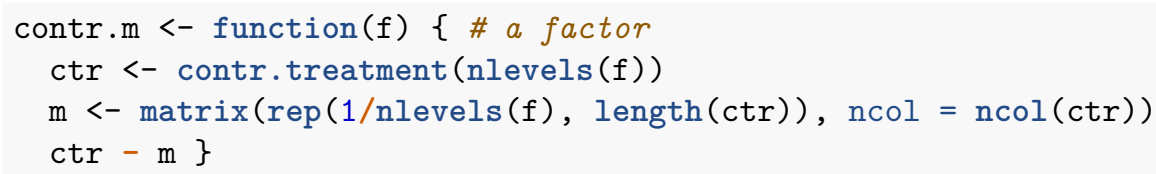

As explained in the main text, we focus on mean L2 effects and do not include varying ("random") slopes or interaction terms because the distribution of the relevant levels (individual types, domains, constraints and categories) is far too sparse across languages to allow consistent estimates - indeed, many levels occur only in one single language. However, we do include varying intercepts by language in order to achieve better overall estimates (through shrinkage) and to allow factoring out the variation between languages. In the Poisson models, we furthermore include what is sometimes called "observation-level random effects (OLRE)" in order to absorb various sources of overdispersion (Harrison 2014). ${ }^{1}$

Given the fact that we are as interested in the absence as in the presence of L2 effects, we fit the models in a Bayesian framework. We rely on Stan (Carpenter et al. 2017) and the R package brms (Bürkner 2018) for this. We choose a weakly regularizing Student- $t$ prior centered on 0 because (i) our null hypothesis is theoretically specific and privileges L2 estimates near 0, and (ii) flatter priors expect too much probability mass at the extremes of a Bernoulli model and unrealistically large counts in Poisson models (McElreath 2020). For the group-level ("random") effects we use a weakly regularizing half- $\operatorname{Cauchy}(0,1)$ prior.

\footnotetext{
${ }^{1}$ We also tried negative-binomial likelihoods in the Poisson models, but they didn't improve the fit much and instead yielded many transition divergences in the NUTS sampler.
} 


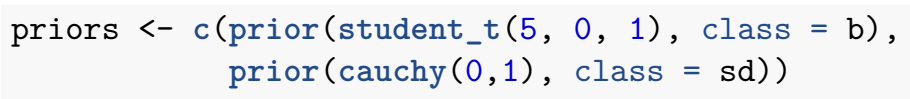

We assess the performance of models by how well they predict held out or as yet undocumented observations, i.e. through the expected log pointwise predictive density (elpd). We estimate elpds through Pareto-smoothed importance sampling with moment matching (PSIS+) from the posterior log probabilities (Vehtari et al. 2016; Paananen et al. 2019; McElreath 2020). In some models (mentioned below), however, one or more predictor levels occur so sparsely that they cannot be predicted when holding out even just single observations, either through importance sampling or explicit cross-validation (i.e. refitting the model by leaving out one observation at a time). In these cases, we resort to the Watanabe-Akaike Information Criterion (WAIC) as an estimator of the elpd (Vehtari et al. 2016; McElreath 2020).

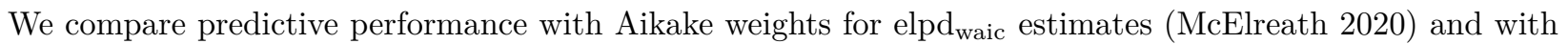
Akaike weights corrected by Bayesian bootstrapping (Yao et al. 2018) for elpd $d_{p s i s}+$ estimates (also known as "pseudo-BMA+"). We choose this method because it takes into account the full posterior uncertainty and, unlike stacking, regularizes weights away from 0 and 1 . For nested binary models, the methods perform equally well (Yao et al. 2018).

In order to assess the variation between languages, we furthermore examine a version of the intra-class (intra-group) correlation coefficient that is generalized to Bayesian non-Gaussian models. The performance package (Lüdecke et al. 2020) implements this as the Variance Partition Coefficient (VPC) defined as 1 minus the ratio between the variance of posterior predictive distributions not conditioned by the varying intercept and the variance of these distributions conditioned by the varying intercepts. Values close to 0 mean that the two predictive variances are similar to each other, i.e. that the varying intercepts have no impact and that the estimates for each language are virtually the same as the estimate for the overall intercept, i.e. the grand mean ('complete pooling').

\section{S2.1 Odds of specific morpheme types}

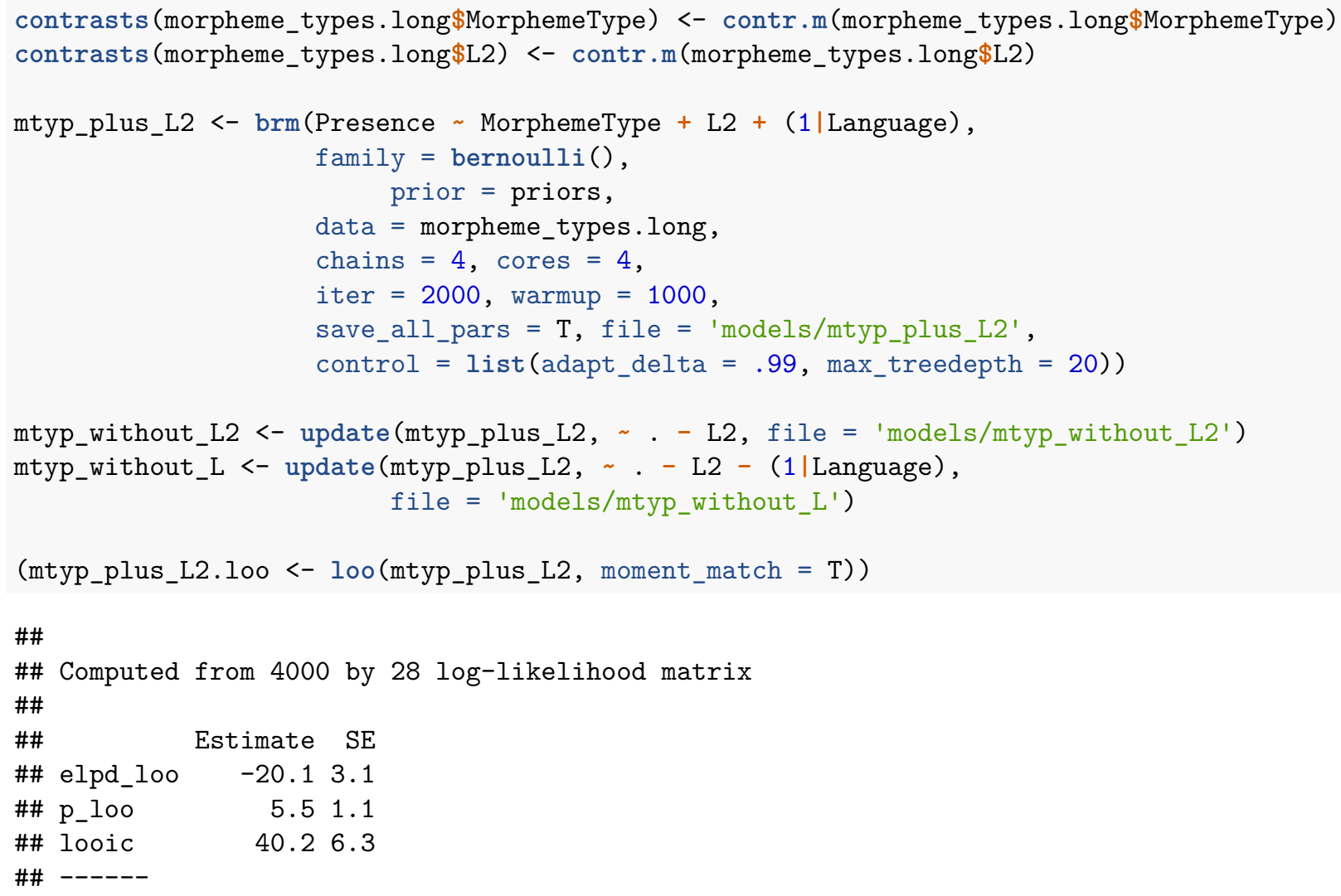




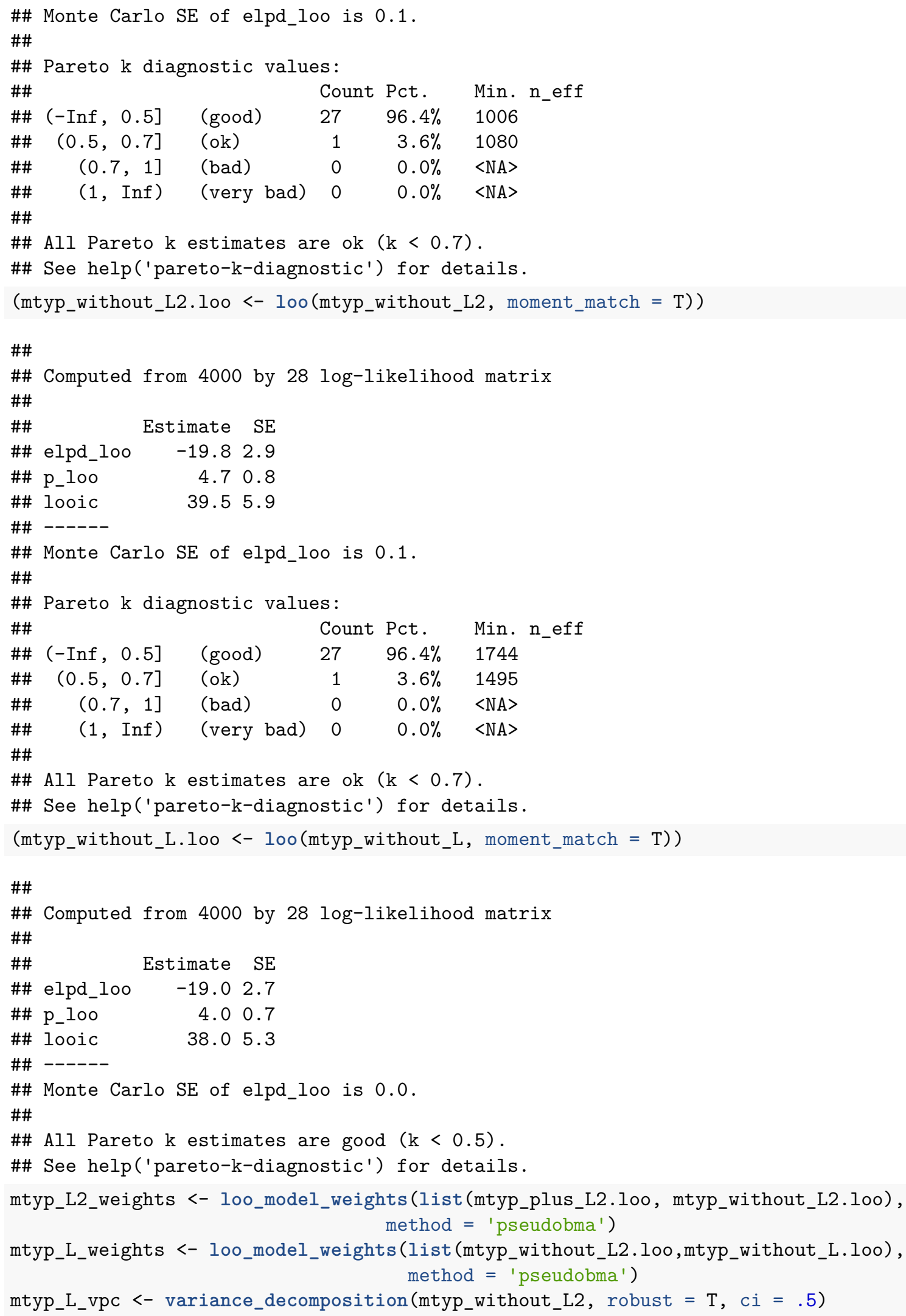




\section{S2.2 Odds of specific domains: phonology}

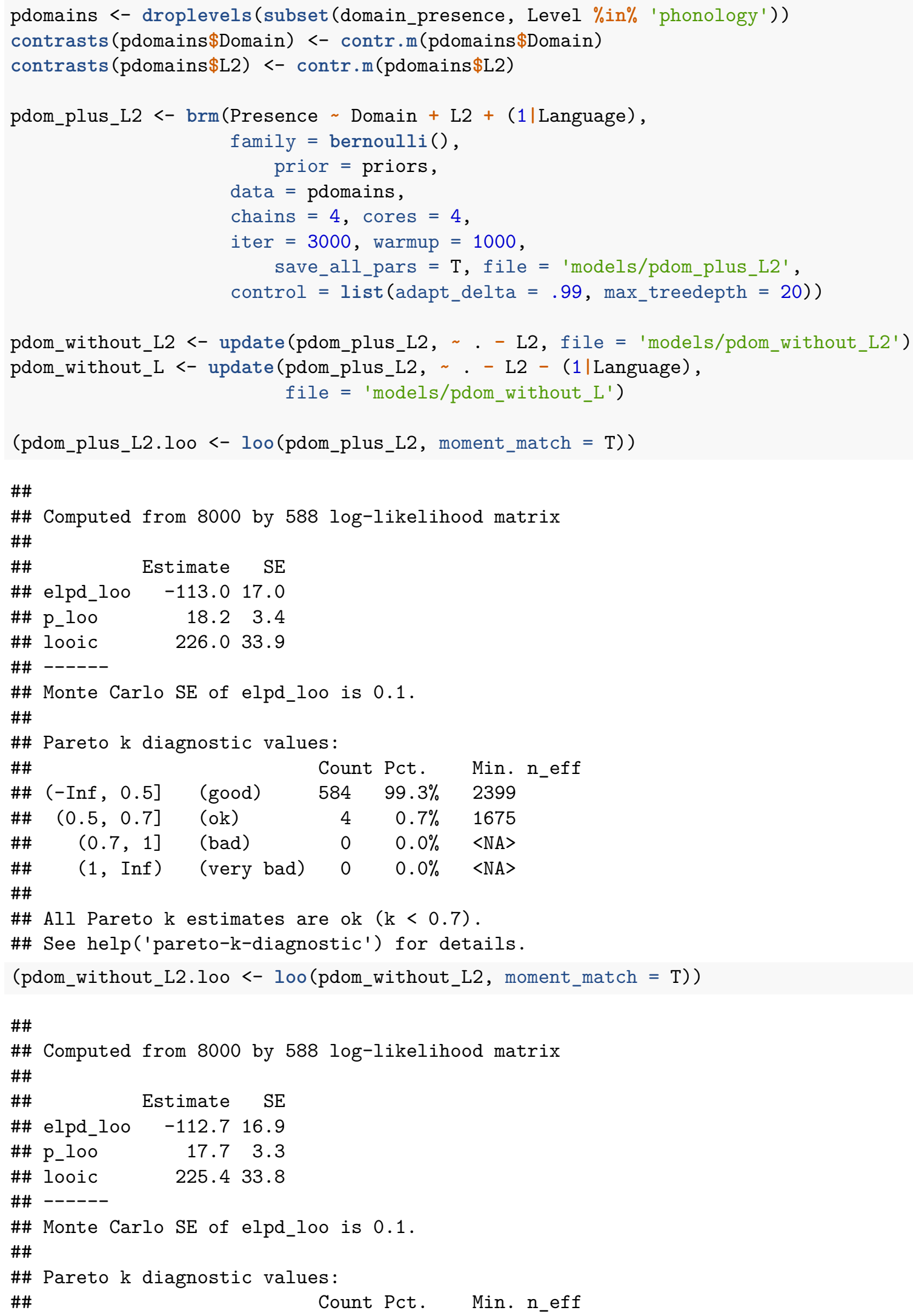




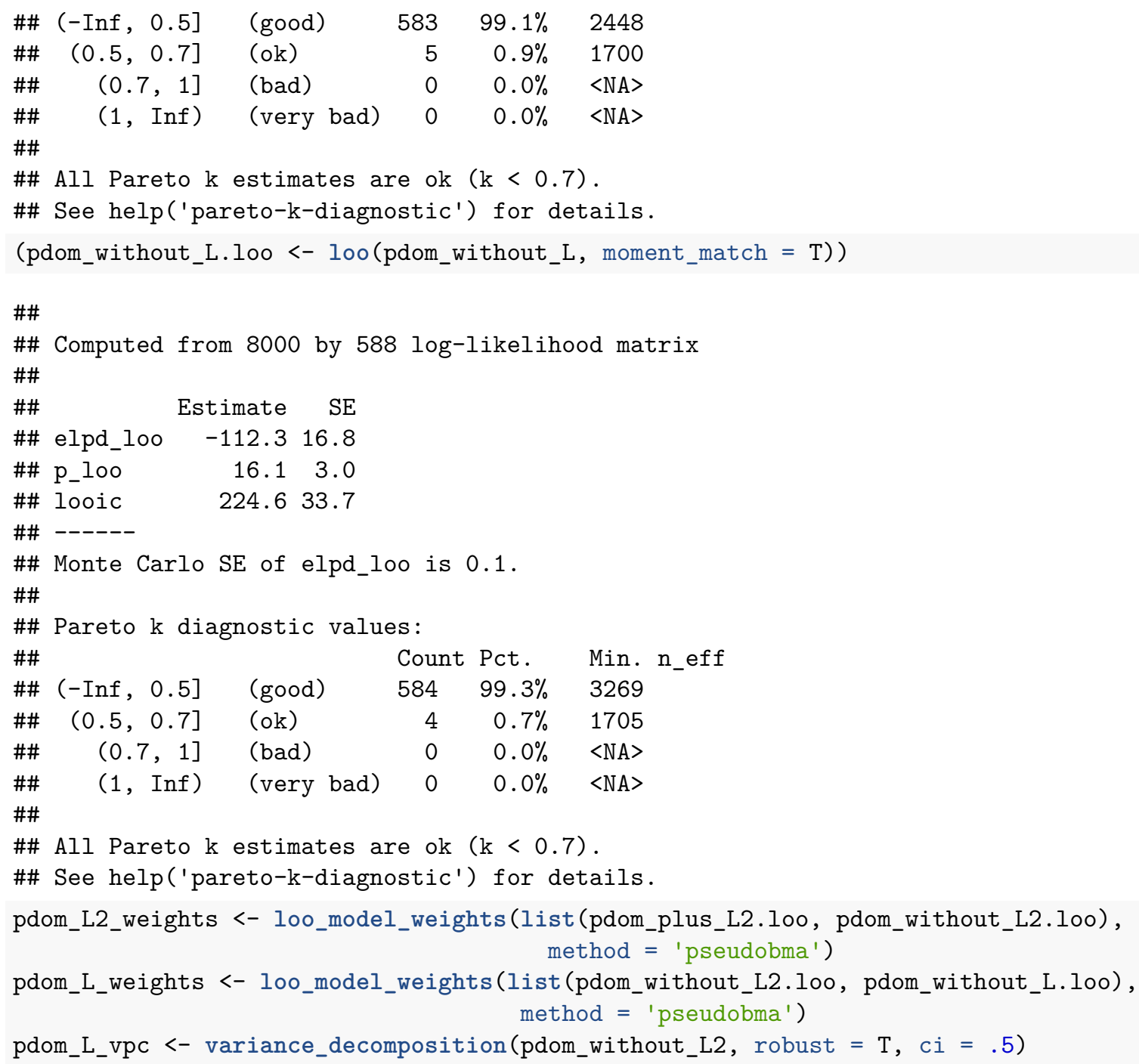

\section{S2.3 Odds of specific domains: grammar}

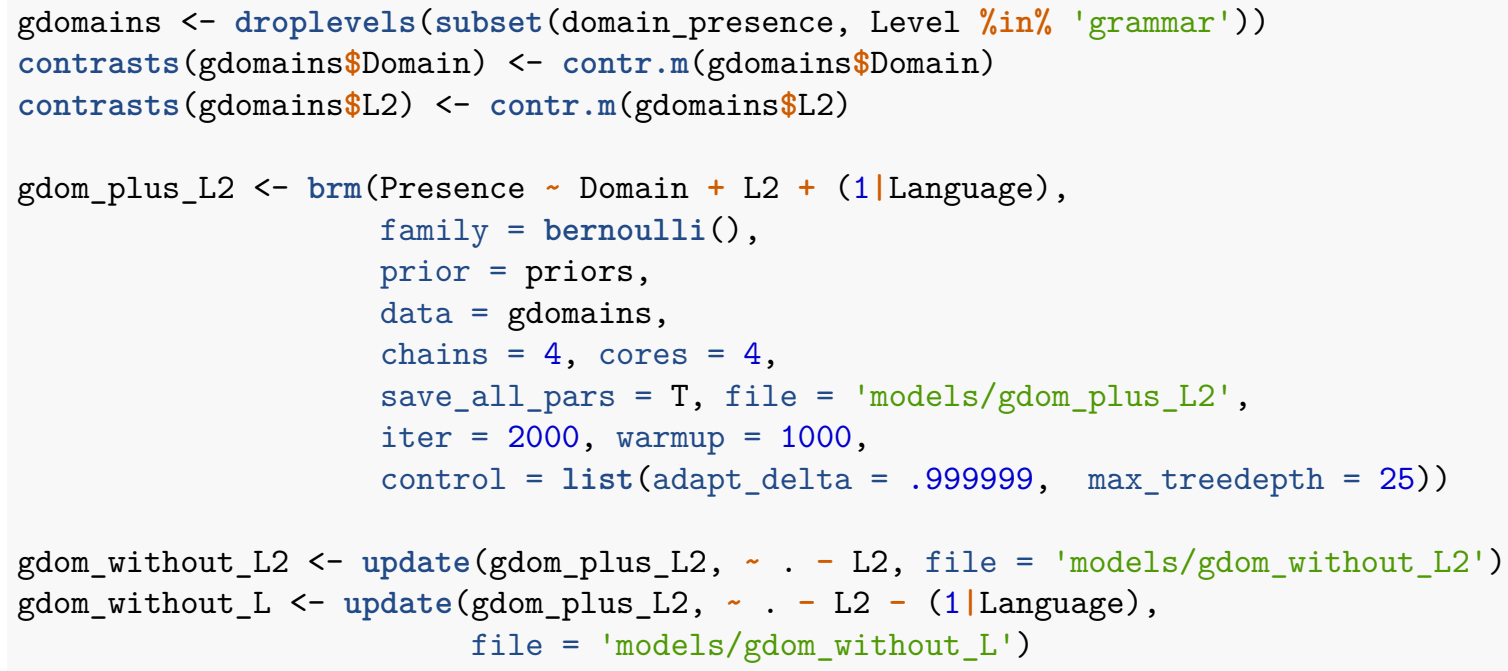




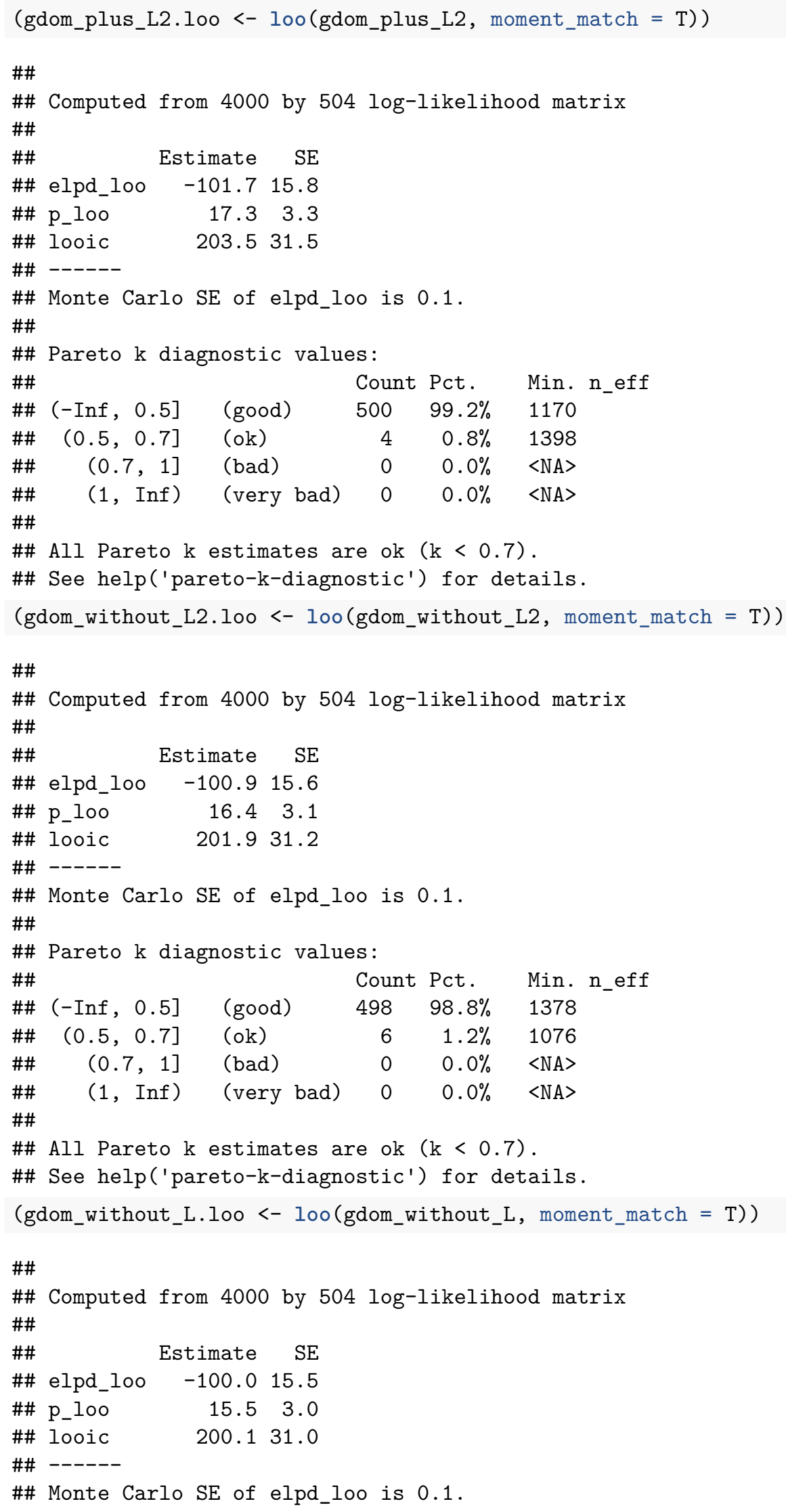




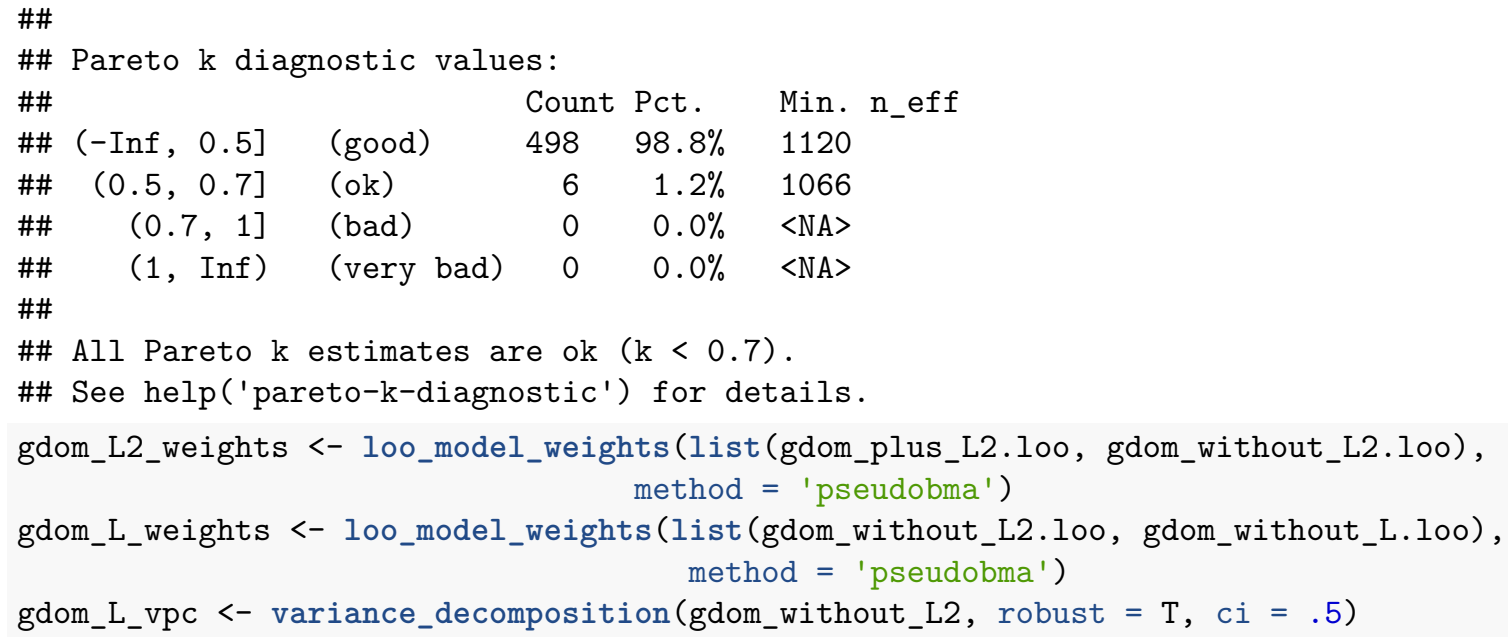

\section{S2.4 Odds and count of cohesion constraints: phonology}

In order to model both the odds and the counts, we fit a mixture model that combines a Bernoulli likelihood for the odds of a constraint and a Poisson likelihood for counts above $0 .{ }^{2}$ This corresponds to what is known as a hurdle model, where the Bernoulli estimator $\theta_{0}$ ( hu in brms) captures the log odds of 0s (i.e. the "hurdle" that needs to be crossed for the Poisson estimates to kick in). Since some of the constraints have a sparse distribution, leave-one-out cross-validation is problematic, and its approximation through importance sampling violates the Pareto smoothing assumptions (with a large proportion of $\hat{k}>.7$ ). In response to this, we resort to the WAIC.

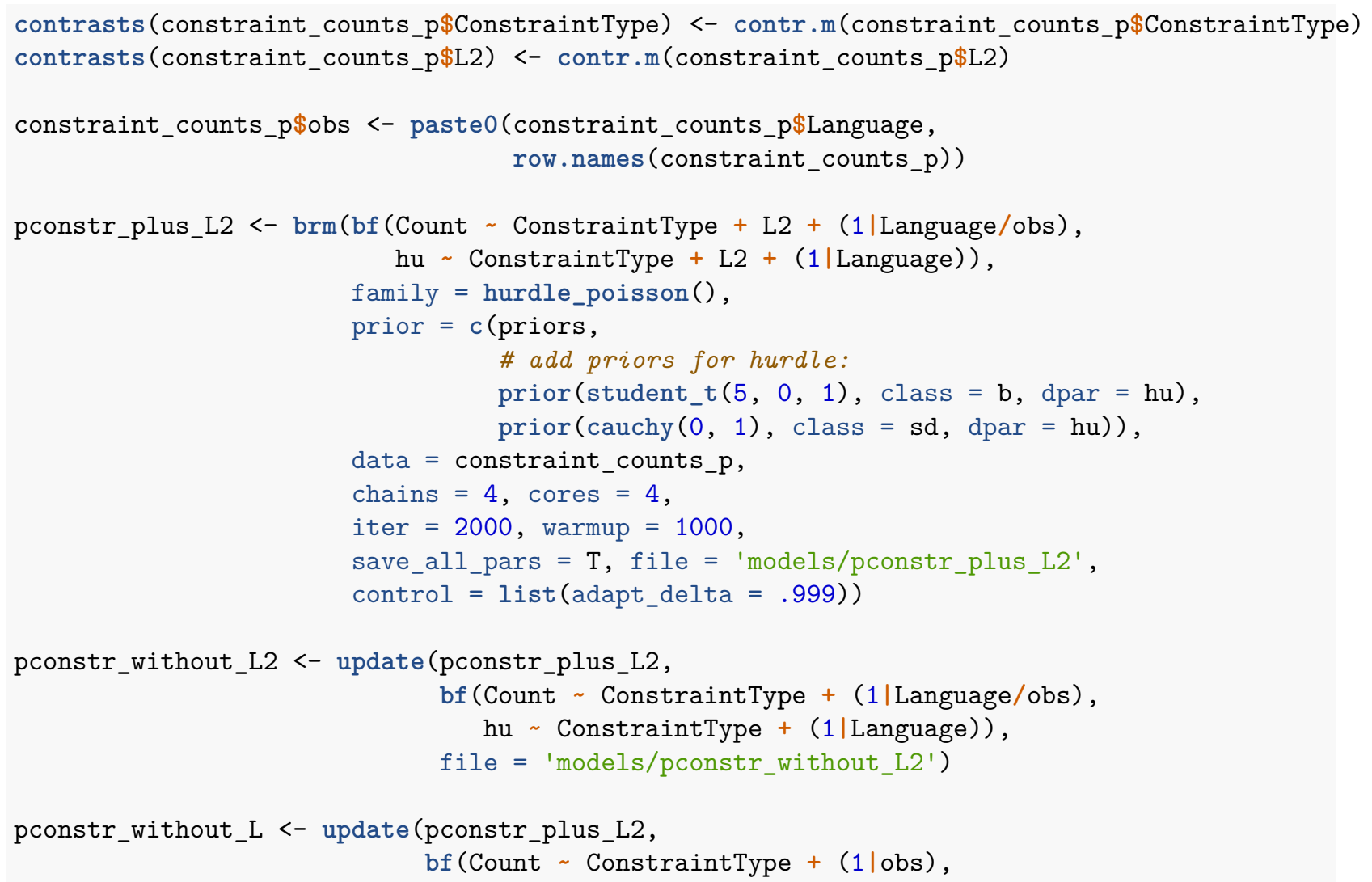

\footnotetext{
${ }^{2}$ See McElreath (2020) for a gentle introduction into mixture models.
} 


$$
\begin{gathered}
\text { hu } \sim \text { ConstraintType) } \\
\text { file }=\text { 'models/pconstr_without_L' })
\end{gathered}
$$

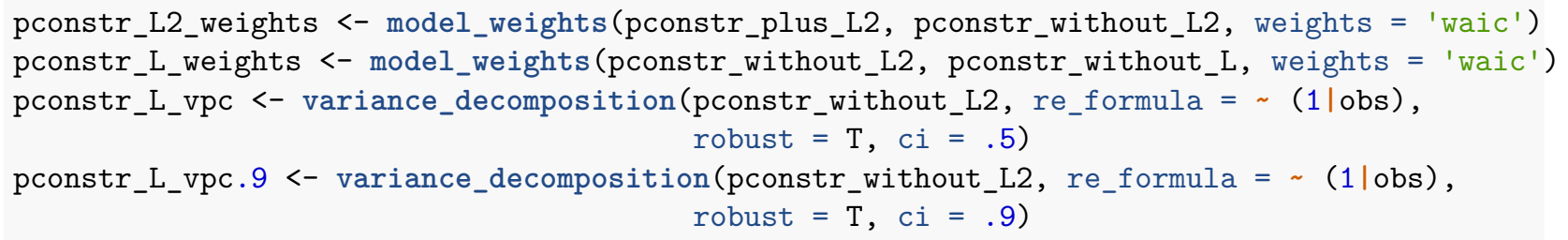

However, closer inspection of the data suggests that the sparse distribution yields separation in some cases (i.e. some (combinations of) predictor levels predict 0 vs non- 0 counts perfectly). Although the models fitted above nevertheless describe the data fairly well (see Figures S2 - S3), the separation effect leads to problems in floating point accuracy in the predicted pointwise probability estimates. ${ }^{3}$ A solution is better regularizing priors (Gelman et al. 2008). Trying several distinct priors suggests that they need to be very strong to overcome the separation effects - in fact so strong that they risk influencing the posterior too much. But we fit these models in the spirit of a sensitivity analysis:

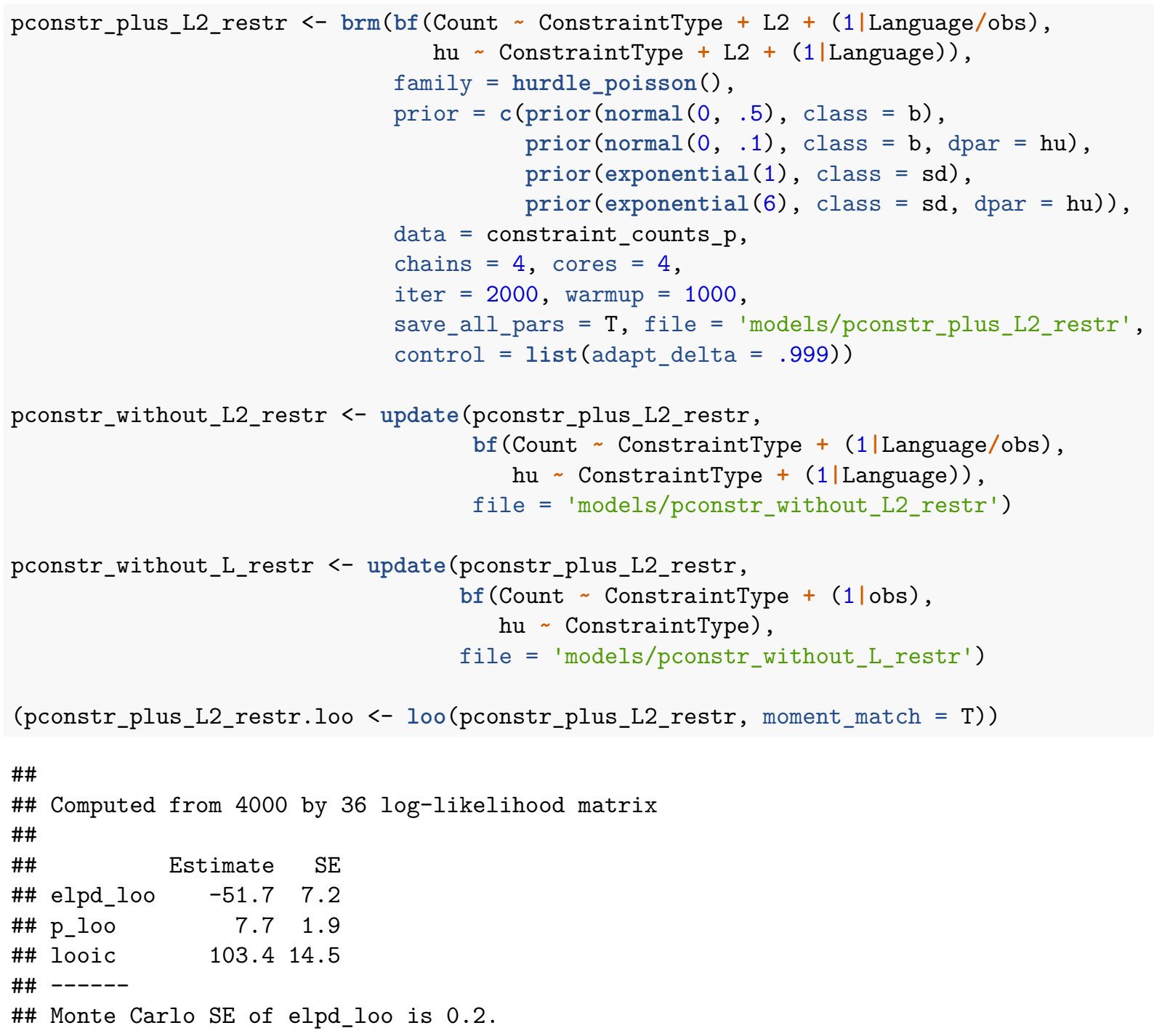

${ }^{3}$ I am grateful to Aki Vehtari for this suggestion (https://discourse.mc-stan.org/t/loo-moment-match-and-reloo-errors/ 17498, August 18, 2020). 


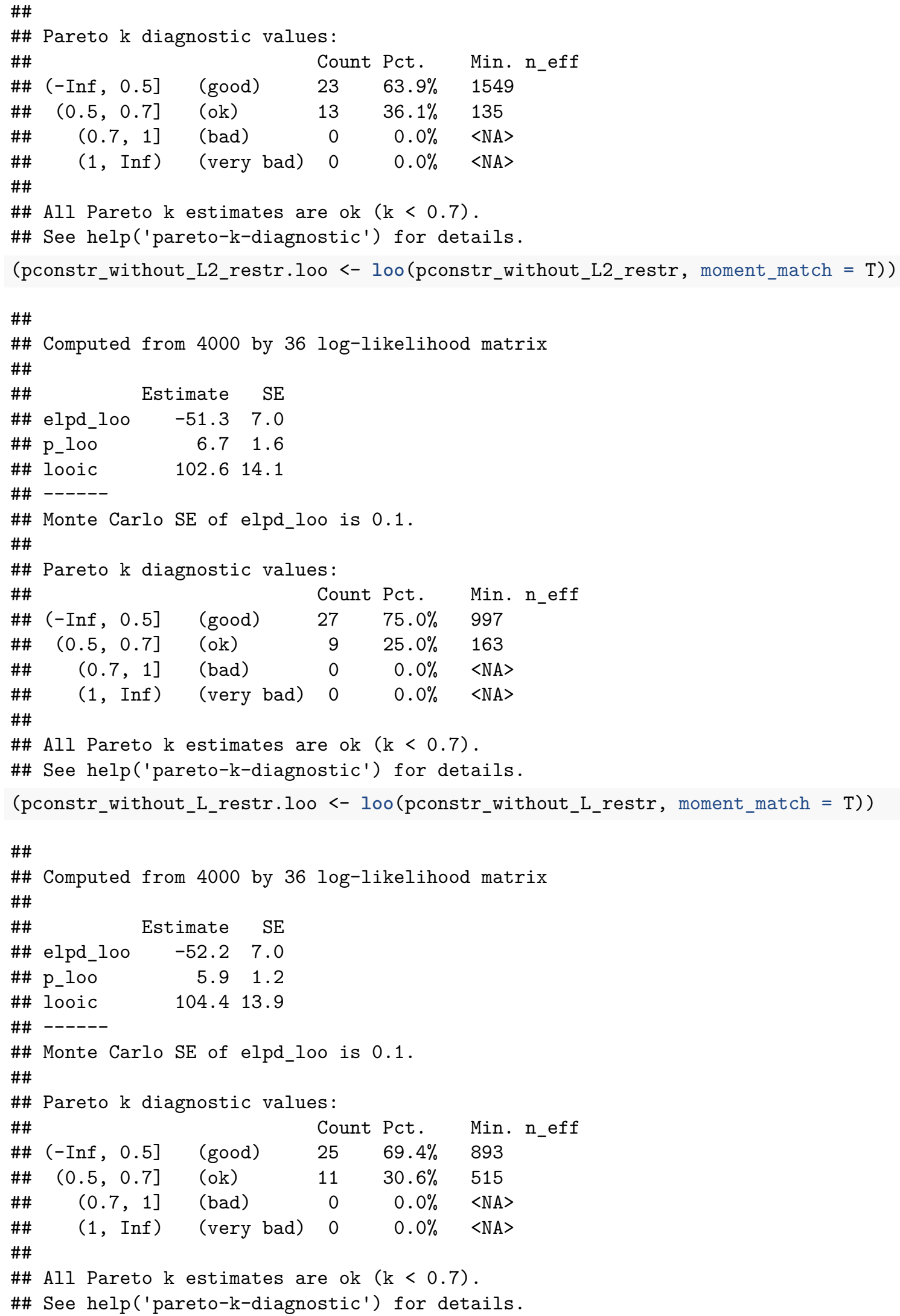




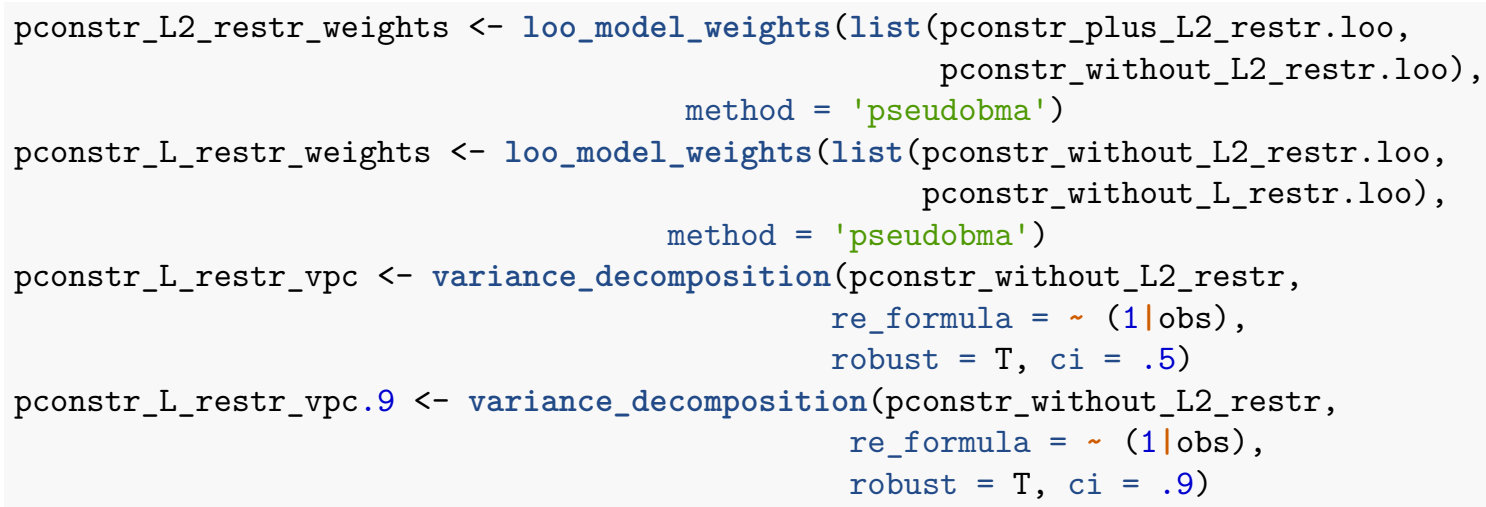

\section{S2.5 Odds and count of cohesion constraints: grammar}

In this data set, 'absence' (0) values are limited to one language (Mandarin) and so (unlike in the preceding model) we cannot reasonably fit the Bernoulli component as dependent on L2 admixture. Instead, we take the hurdle parameter $\theta_{0}$ to be identical across predictors. Note that in this case, brms uses an identity link for $\theta_{0}$, i.e. the estimate is reported on the probability scale $\left(p_{0}\right)$, not on the log odds scale.

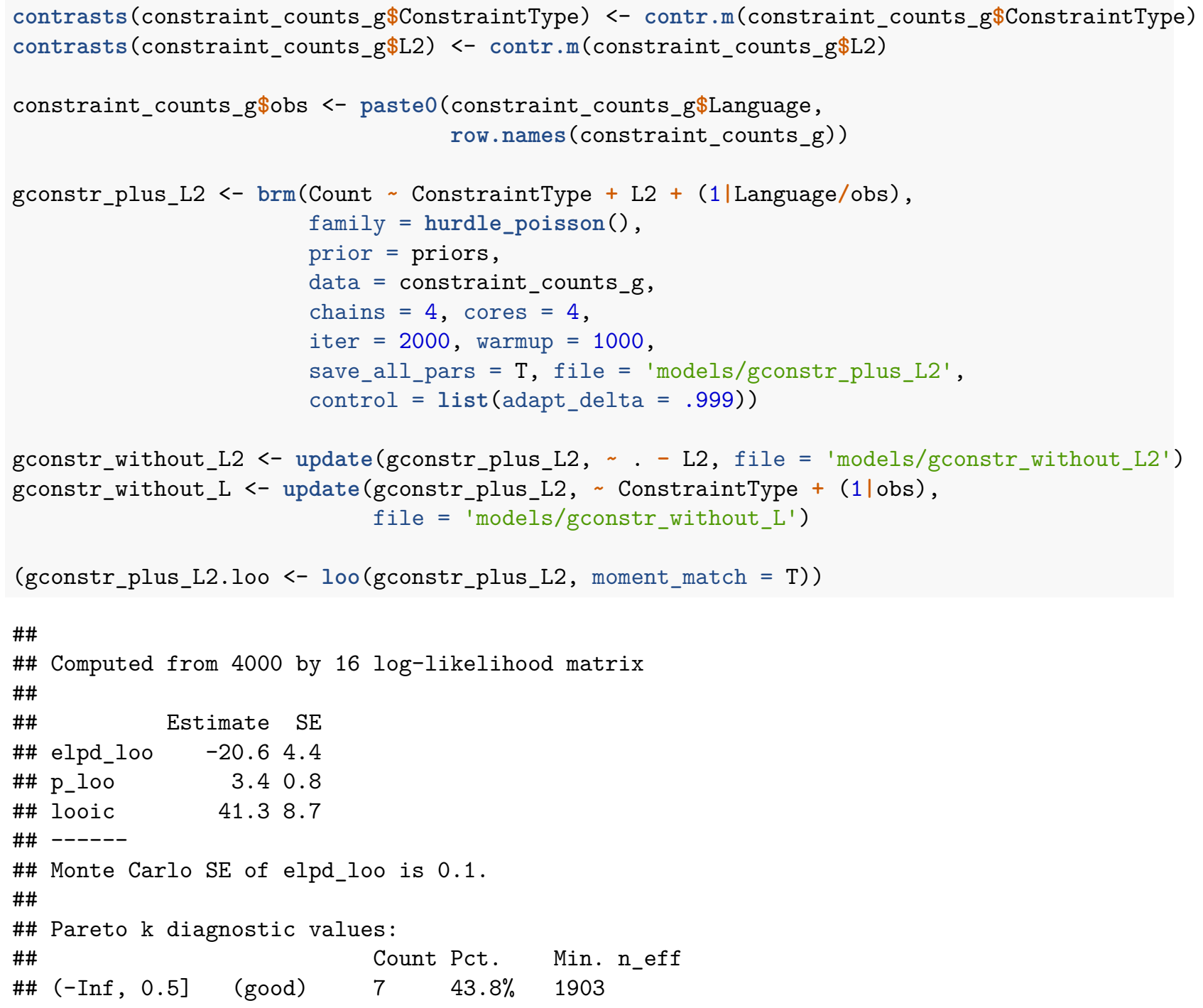




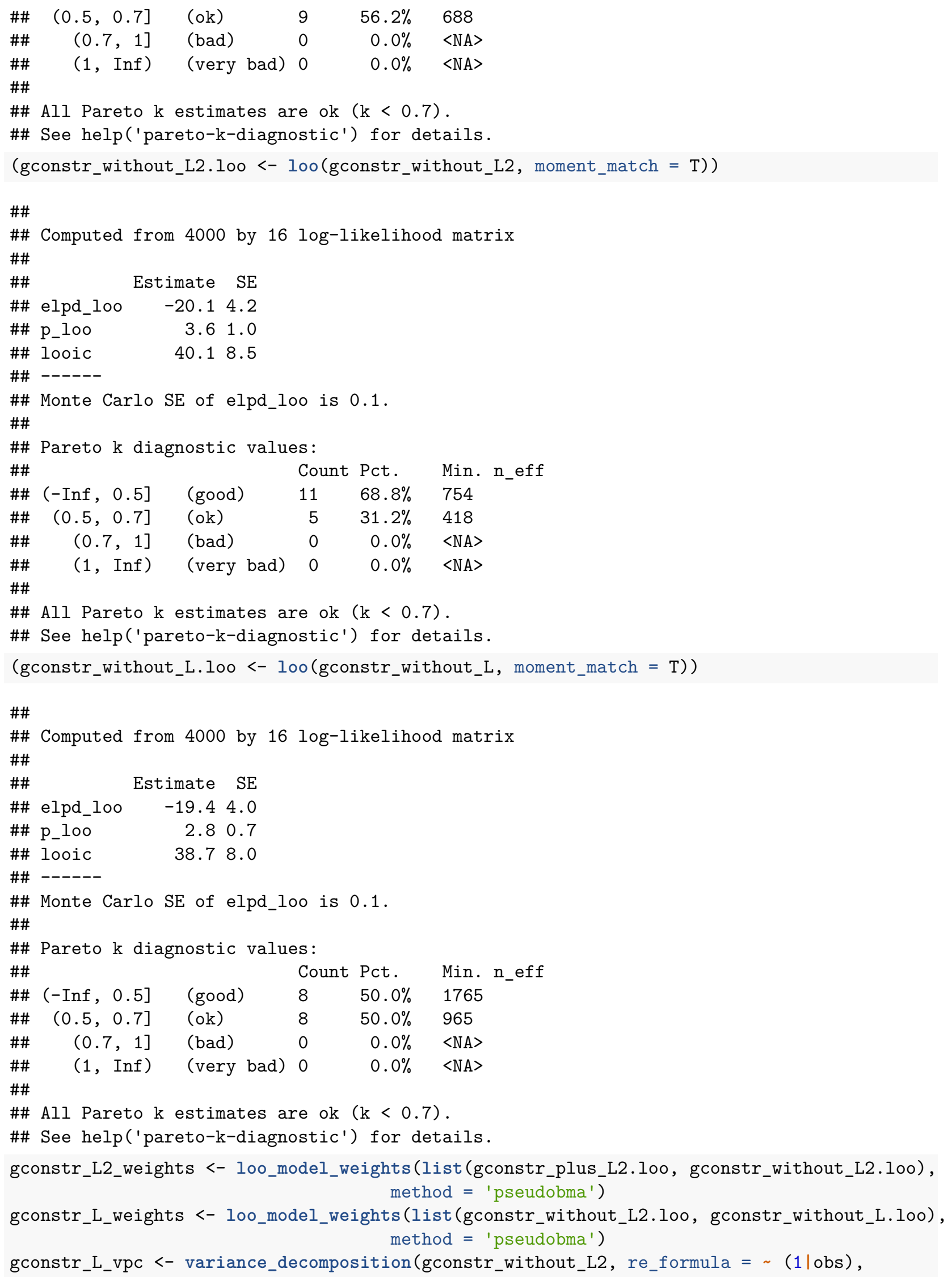




$$
\text { robust }=\mathrm{T}, \mathrm{ci}=.5 \text { ) }
$$

\section{S2.6 Domain Size: phonology}

Here, 0 values are impossible since a domain must minimally include the verb stem. Therefore, we truncate the Poisson distribution with a lower bound of 1 . The data show again the same sparsity problem as for the phonological constraints hurdle models. We resort to the WAIC again.

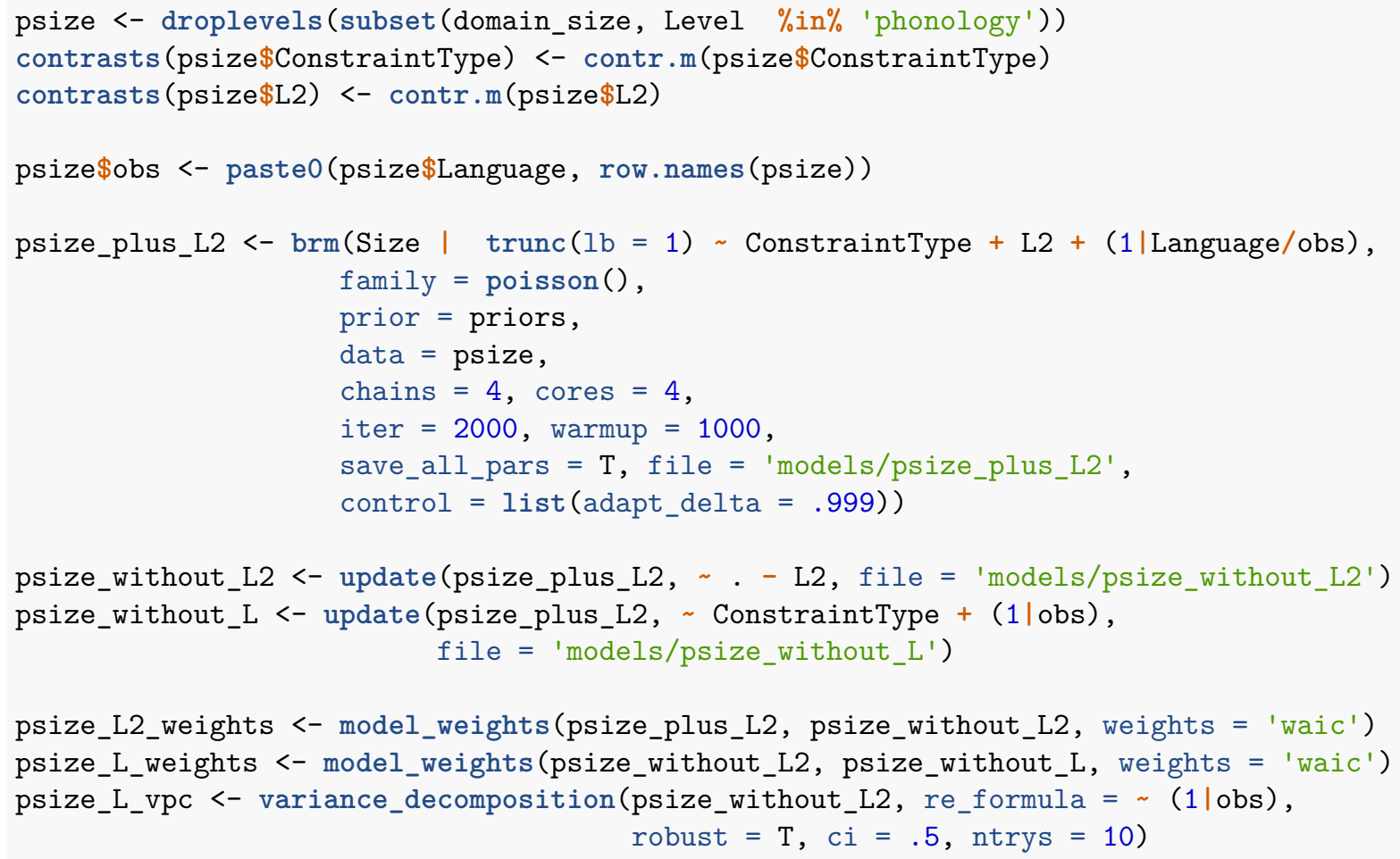

\section{S2.7 Domain Size: grammar}

We again truncate the Poisson distribution since sizes cannot be smaller than 1 .

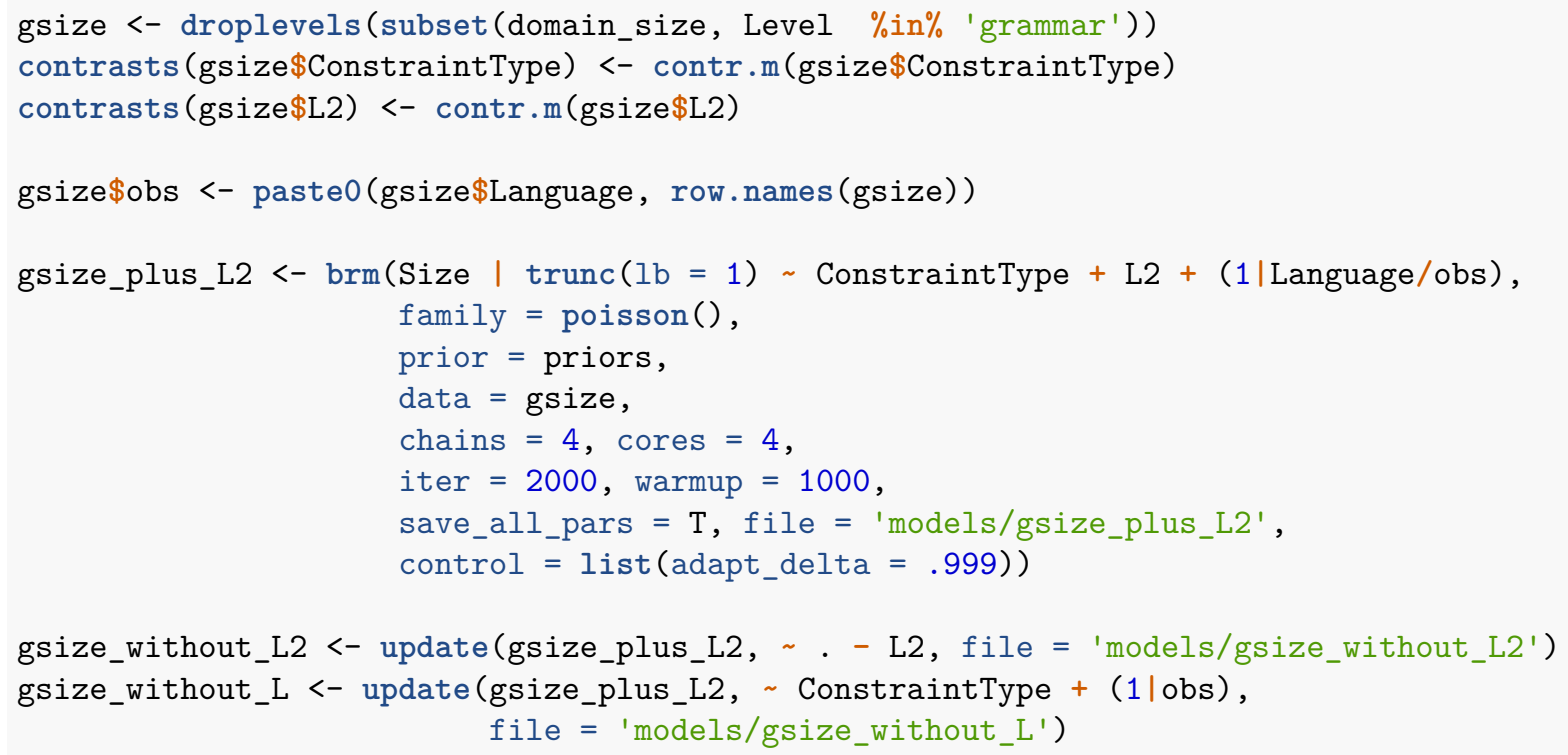




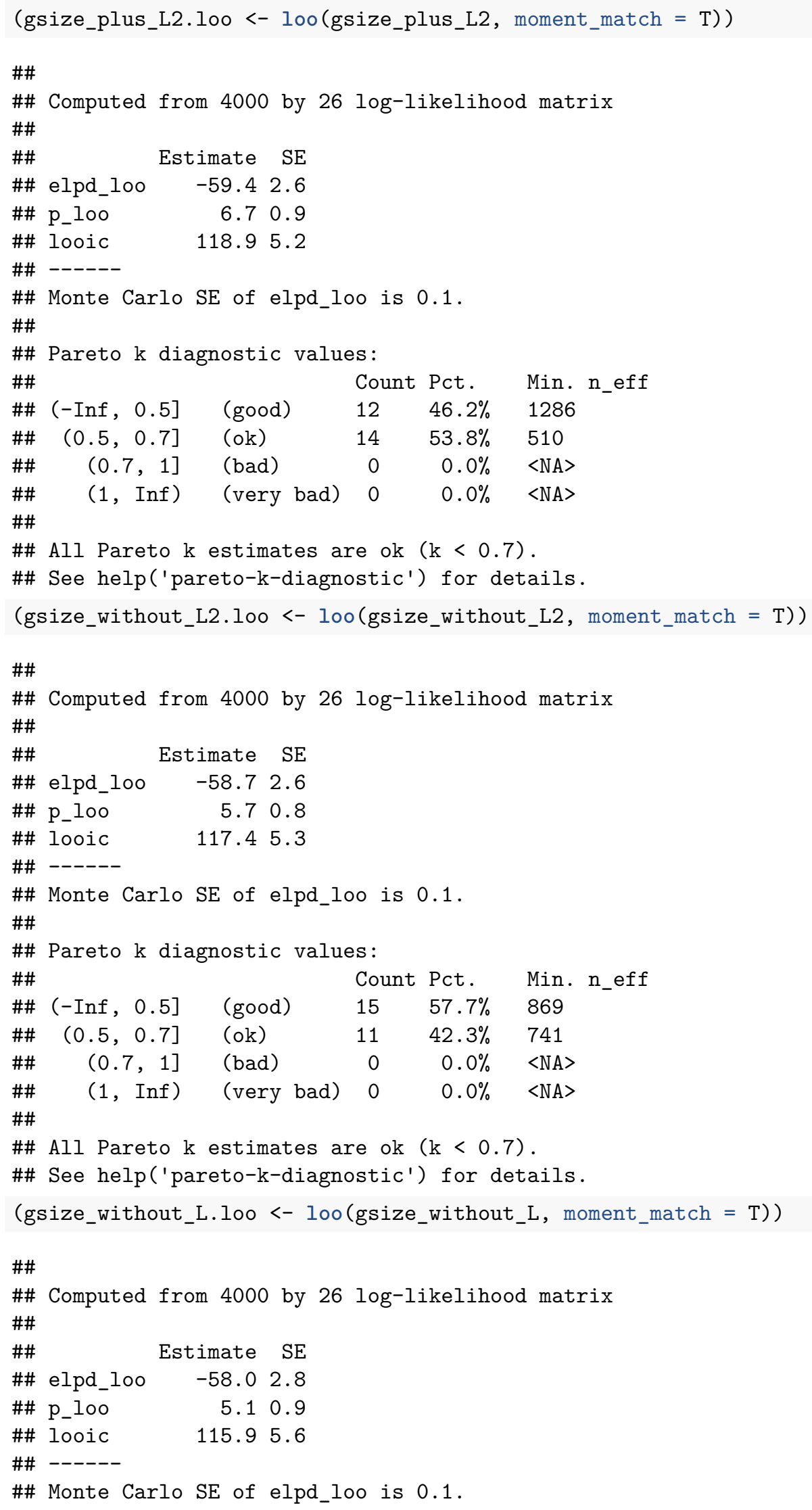


\#\# Pareto k diagnostic values:

\#\#

$\begin{array}{lllll}- \text { Inf, 0.5] (good) } & 15 & 57.7 \% & 1362\end{array}$

\#\# $\quad(0.5,0.7] \quad$ (ok) $\quad 11 \quad 42.3 \% \quad 712$

$\# \quad(0.7,1] \quad(\mathrm{bad}) \quad 0 \quad 0.0 \% \quad\langle\mathrm{NA}\rangle$

$\# \quad(1$, Inf $) \quad($ very bad) $0 \quad 0.0 \% \quad\langle\mathrm{NA}\rangle$

\#\#

\#\# All Pareto $\mathrm{k}$ estimates are ok $(\mathrm{k}<0.7)$.

\#\# See help('pareto-k-diagnostic') for details.

gsize_L2_weights <- 10o_model_weights(1ist(gsize_plus_L2.1oo, gsize_without_L2.1oo), method = 'pseudobma')

gsize_L_weights <- loo_model_weights(list(gsize_without_L2.loo, gsize_without_L.loo), method $=$ 'pseudobma')

gsize_L_vpc <- variance_decomposition(gsize_without_L2, re_formula = (1/obs), robust $=\mathrm{T}, \mathrm{ci}=.5$ )

\section{S2.8 Synthesis: odds of inflectional categories}

In this data set, there is a substantial L2 effect and so we keep this factor when fitting models without varying intercepts.

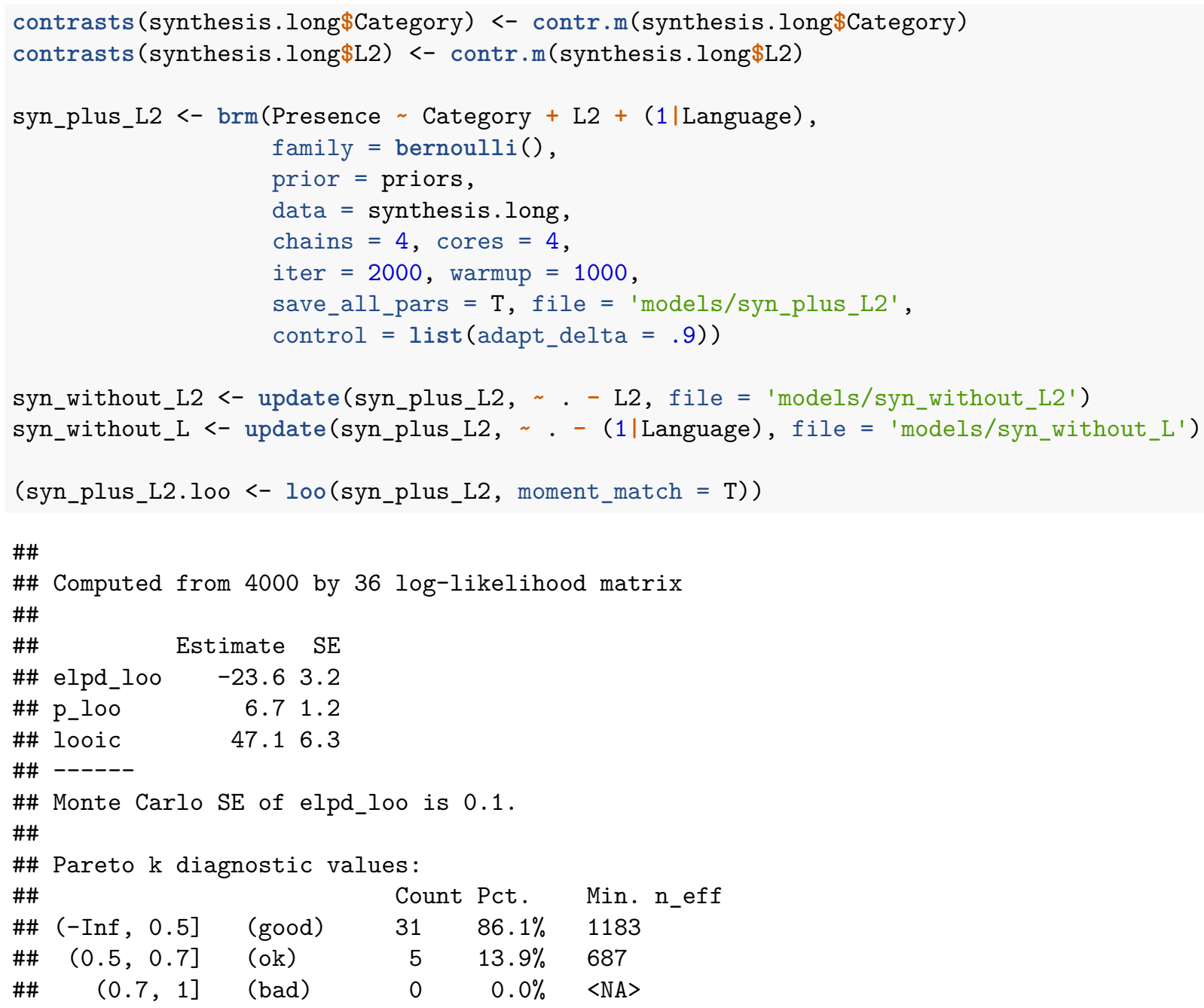




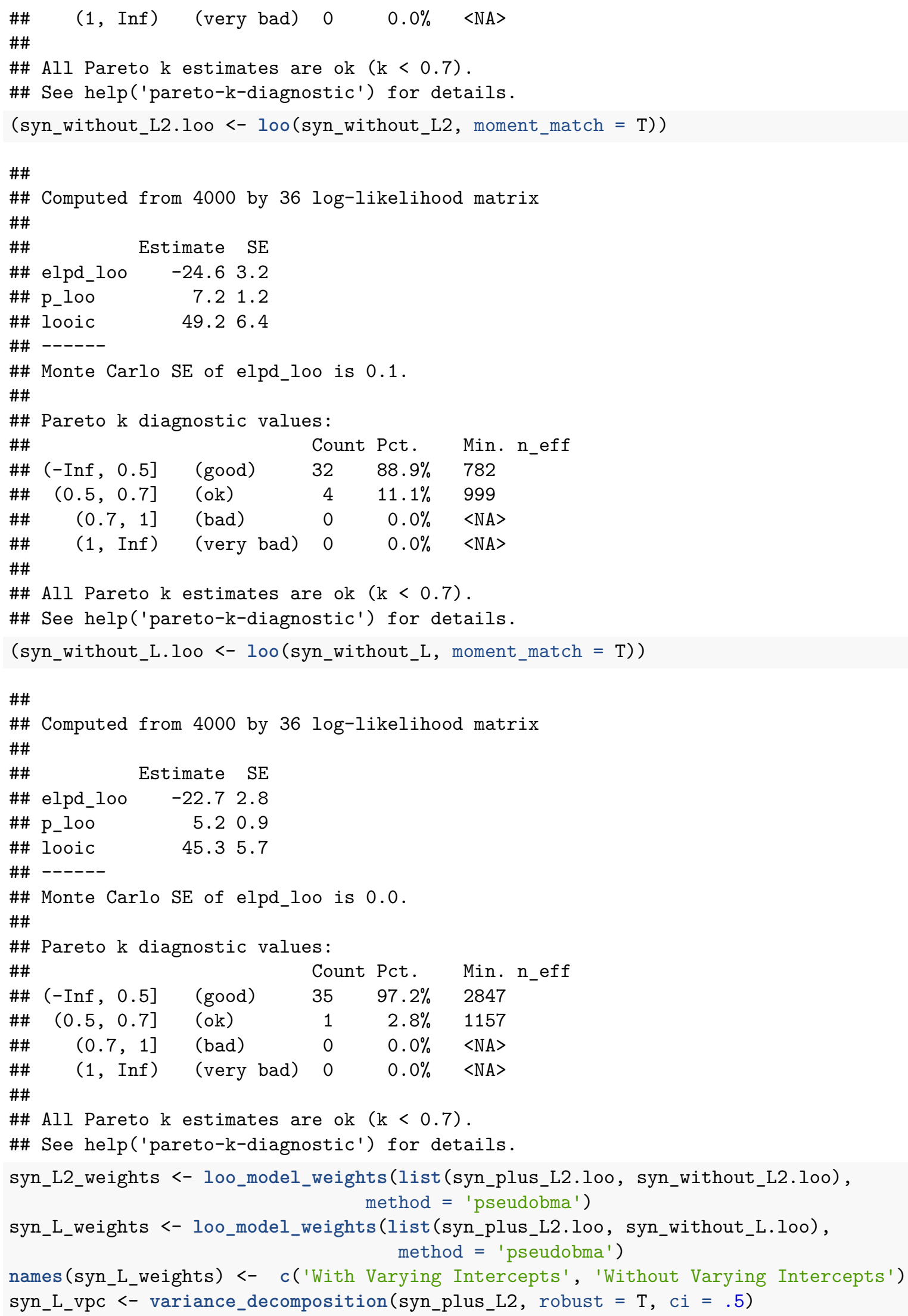




\section{S3 Model evaluation}

All models converged well, with no divergent transitions, $\hat{R}=1$, and large effective sample sizes. See the models directory at the repository of the present file https://osf.io/mt98r for details and model summaries. ${ }^{4}$ The elpd $\mathrm{p}_{\mathrm{psis}+}$ estimates all had Pareto $\hat{k}<.7$, suggesting that assumptions are met and there are no overly influential observations. For models involving phonological constraints (pconstr.* and psize.*), we used WAIC approximations because of data sparsity. The elpd waic estimates come with high variance, and so these results need to be interpreted with caution.

\section{S4 Comparisons}

\section{S4.1 L2 effects}

The phonological constraints model (pconstr_plus_L2) estimates effects both on the log counts ( $\mu$ or mu) and on the log odds $\left(\theta_{0}\right.$ or hu). We collect the results separately. Note that the log odds in this model are the $\log$ odds of 0 s, i.e. absence, not the odds of presence. In order to make the estimates comparable to the log odds estimates in the other variables, we inverse their sign. For the grammatical constraints model (gconstr_plus_L2), we estimated $\theta_{0}$ independent of the predictors. brms reports this on the response scale (identity link). The result is very low, with a posterior median probability of $0 \mathrm{~s}, \hat{p}_{0}=0.096$, that captures the data well.

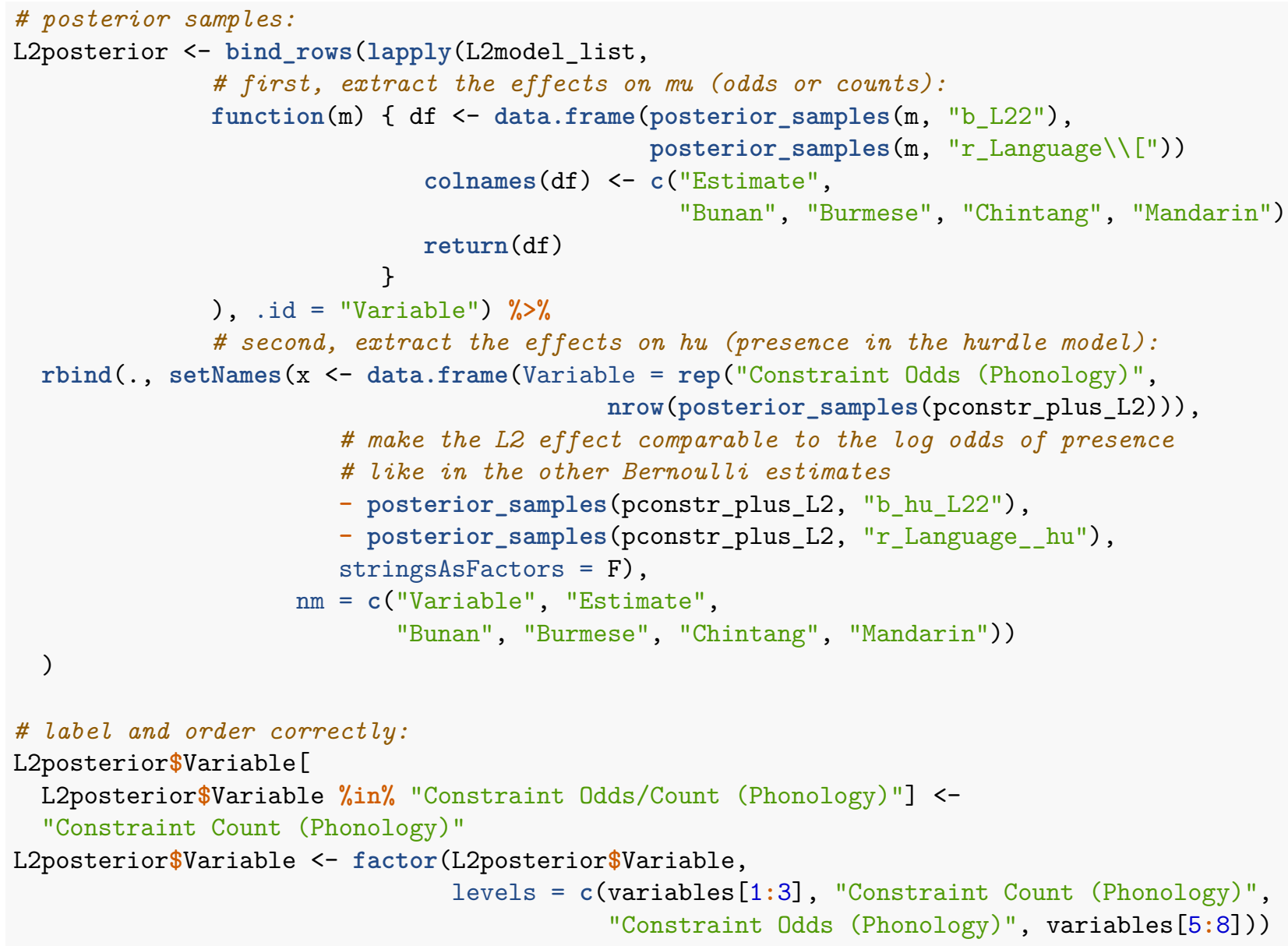

Next, we bind together the model weights; see Table S1 and the color shading in Figure 2 of the main paper.

\footnotetext{
${ }^{4}$ DOI $10.17605 /$ OSF. IO/MT98R
} 


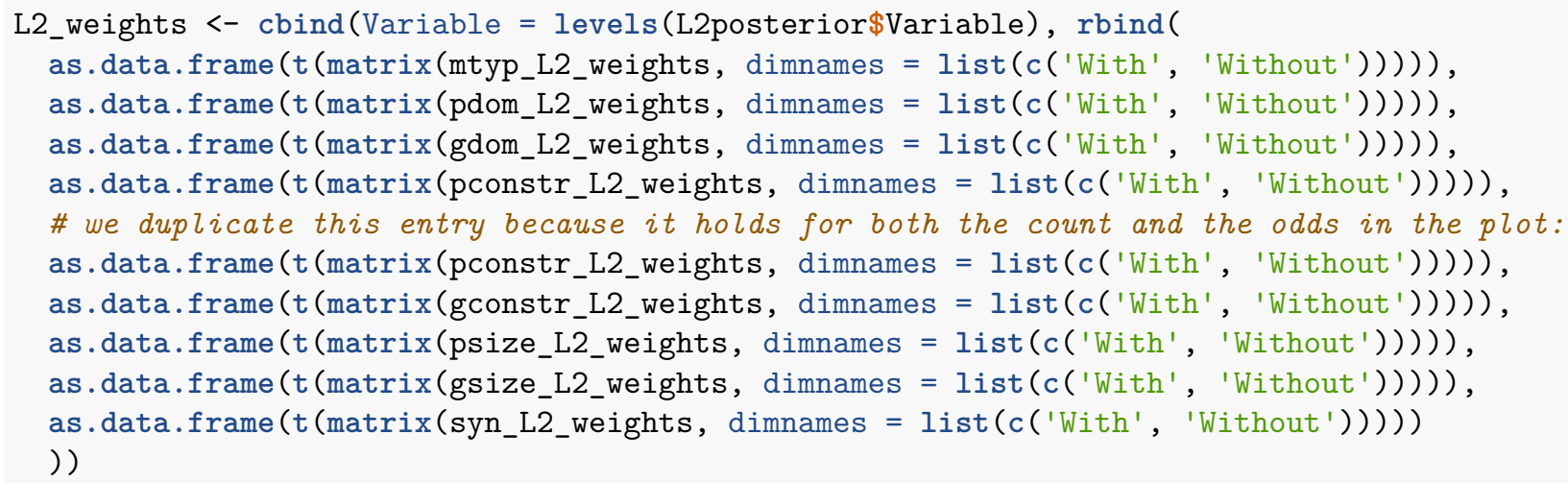

The sensitivity analysis of the phonological constraints model is fully in line with these results although the strong priors of course privilege null models and need to be interpreted cautiously. The estimated effect of the L2 factor is $\hat{\theta_{1}}=-0.02,50 \% \mathrm{CI}=[-0.09,0.05]$ on the odds and $\hat{\mu}=-0.04,50 \% \mathrm{CI}=[-0.34,0.26]$ on the counts. The model with the L2 factor leverages less weight than the model without the L2 factor (bootstrapped Aikake weight $=0.4$ ).

Table S1: Comparison of predictive performance through Akaike weights

\begin{tabular}{lrr}
\hline Variable & With L2 factor & Without L2 factor \\
\hline Morpheme Type Odds & 0.425 & 0.575 \\
Domain Odds (Phonology) & 0.428 & 0.572 \\
Domain Odds (Grammar) & 0.311 & 0.689 \\
Constraint Odds/Count (Phonology) & 0.454 & 0.546 \\
Constraint Odds/Count (Grammar) & 0.365 & 0.635 \\
Domain Size (Phonology) & 0.417 & 0.583 \\
Domain Size (Grammar) & 0.328 & 0.672 \\
Category Odds (Synthesis) & 0.731 & 0.269 \\
\hline
\end{tabular}

For synthesis, we furthermore assess the L2 effect more closely. The probability mass of L2 log odds below 0 is:

round (mean (posterior_samples (syn_plus_L2) \$b_L22 < 0),2)

\#\# [1] 0.94

Median $\log$ odds and CI:

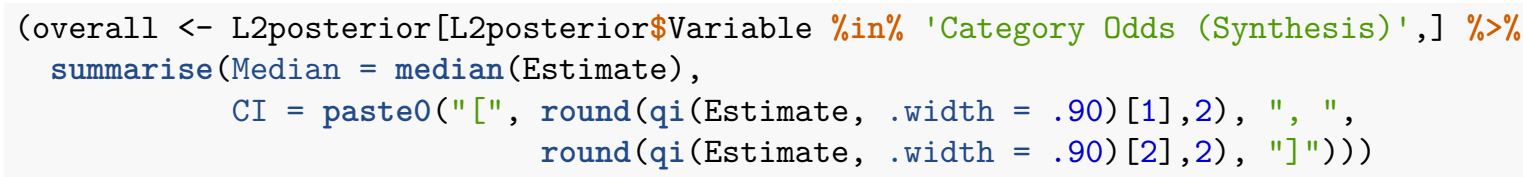

\begin{tabular}{r|l}
\hline Median & CI \\
\hline-1.512556 & {$[-3.12,0.13]$} \\
\hline
\end{tabular}

Median odds ratio:

round (median (exp (posterior_samples (syn_plus_L2)\$b_L22)), 2)

\#\# [1] 0.22

Figure S1 gives an overview of the estimated variation by language. 


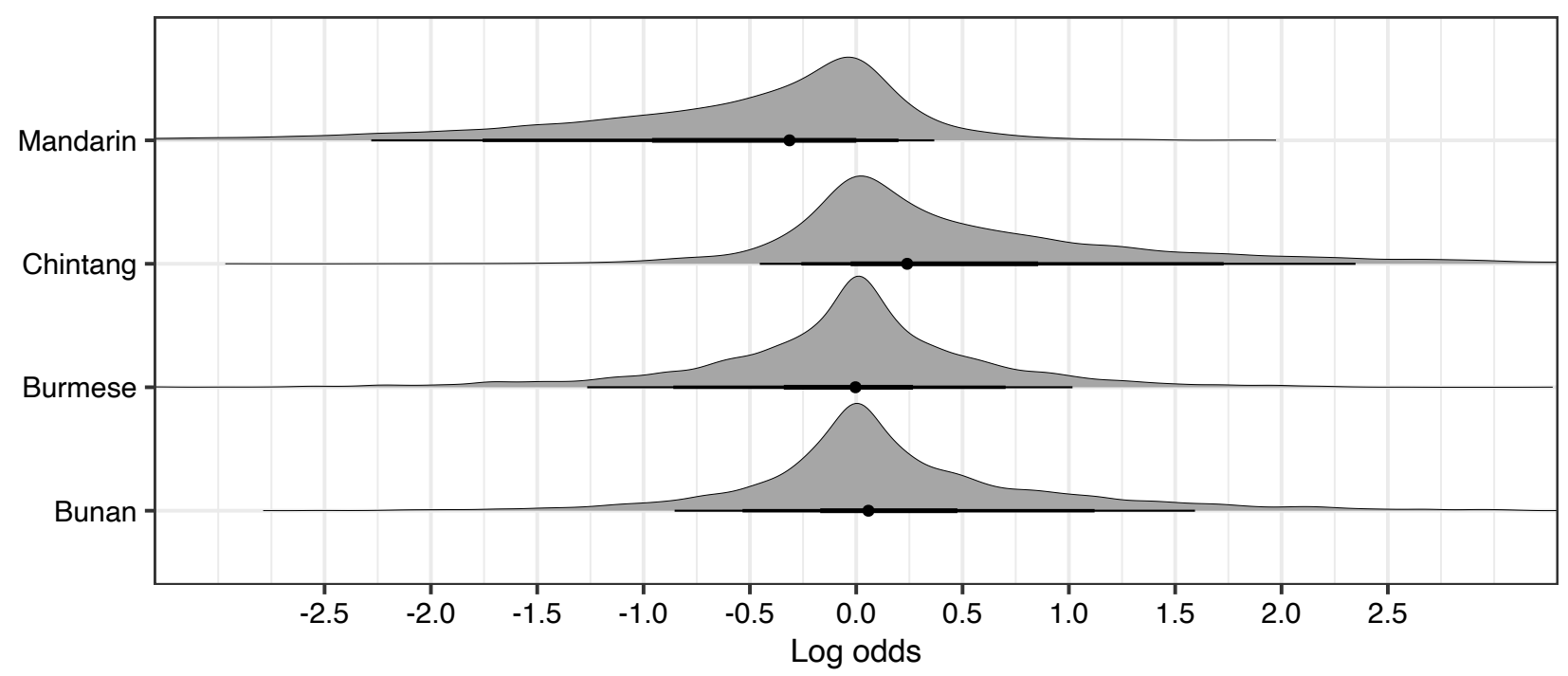

Figure S1: Estimated variation of the grand mean in a model of synthesis with an L2 factor. Black horizontal bars indicate the $90 \%, 80 \%$ and $50 \%$ CIs around the median (decreasing bar widths). The variation by language is modest compared to the overall L2 effect $($ cf. Median $=-1.51,90 \% \mathrm{CI}=[-3.12,0.13])$ 
Consistent with the estimates in Figure S1, we find that models without varying intercepts have better predictive performance than models with varying intercepts:

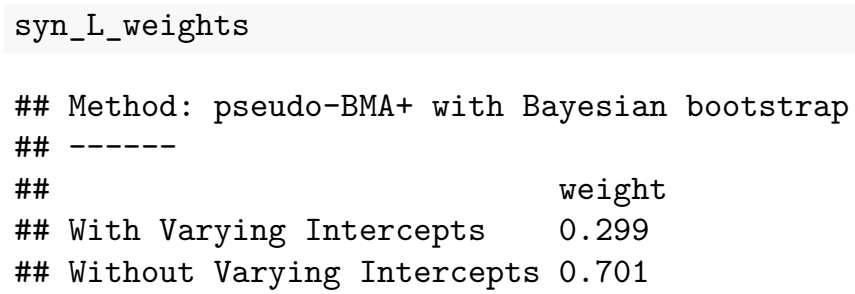

Also, even the $50 \%$ CI of the VPS includes 0:

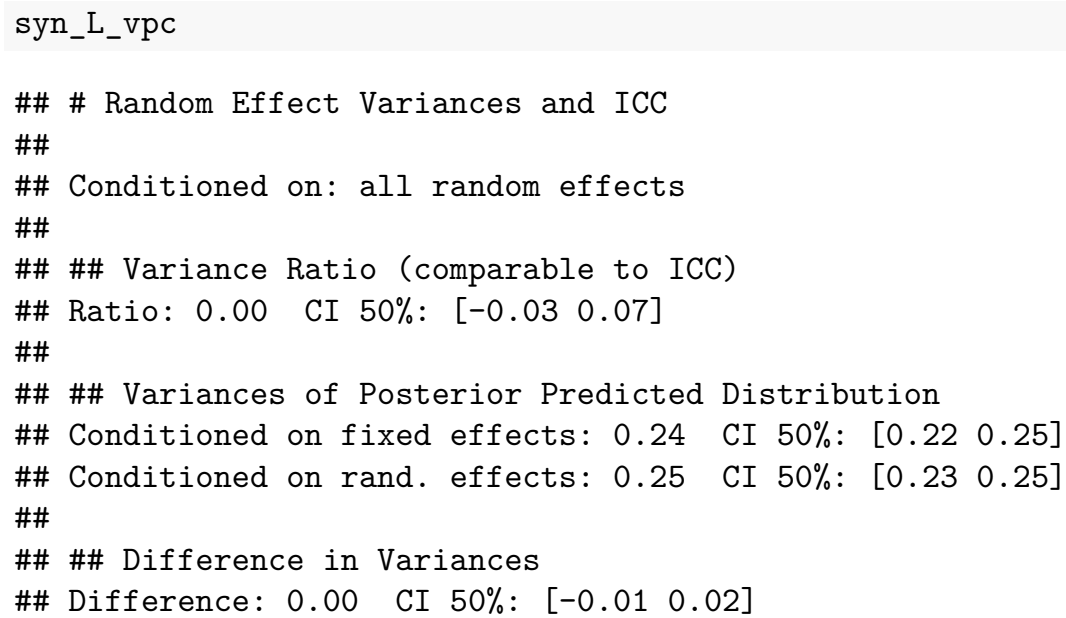

\section{S4.2 Null-effect models}

For the variables with evidence against an L2 effect (i.e. all except the synthesis model), we also collect the posterior estimates of the grand mean (the intercept), so we can inspect the spread of the estimates and the variation by language (varying intercepts). The results are show in Figure 3 of the main paper and tabulated in Table S2 below.

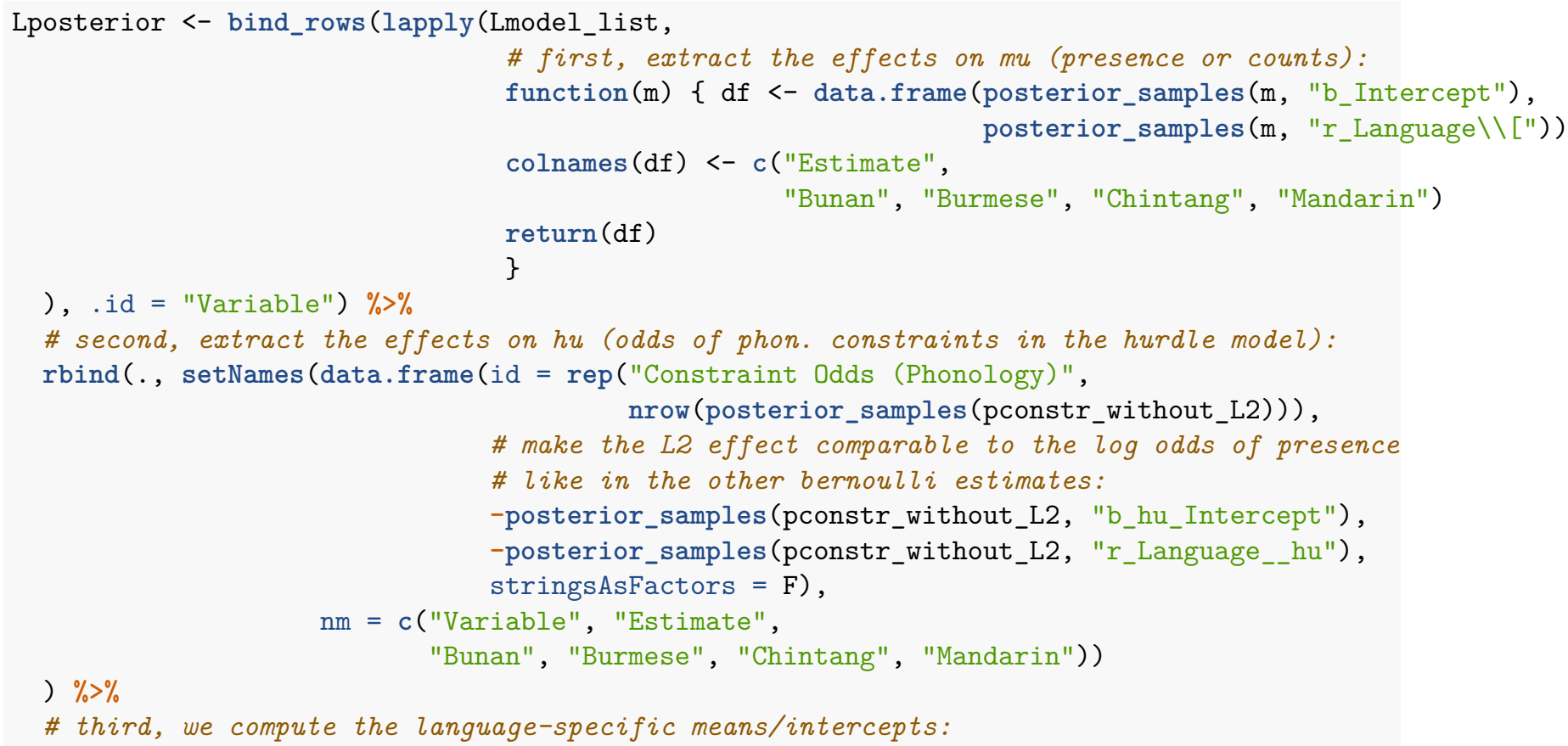




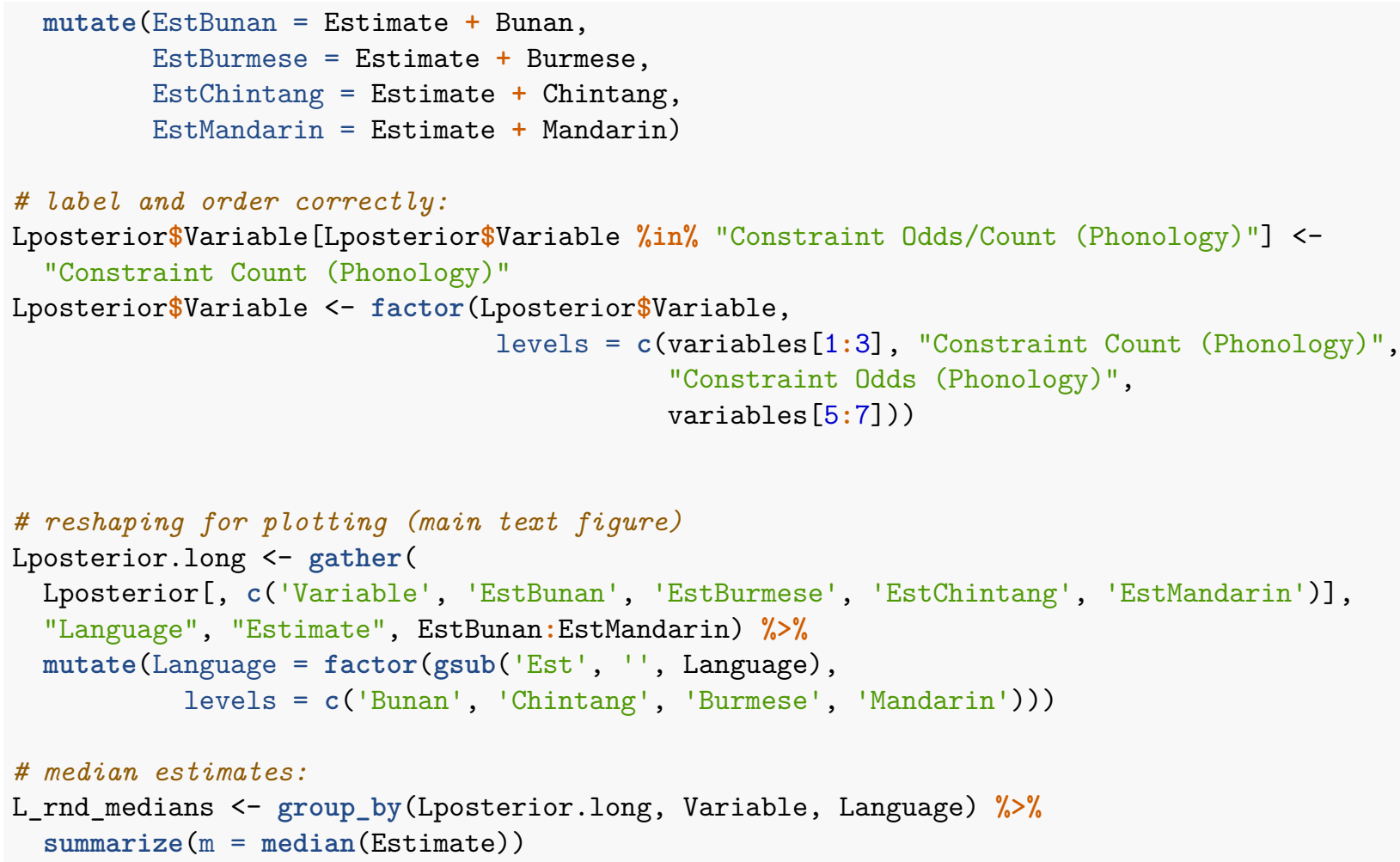


Table S2: Intercept and language-specific deviations from it. CI $=90 \%$ (quantile-based) credible interval. Note that in the case of grammatical constraints, we estimate a global hurdle estimate $(\theta)$. The median posterior estimate for the presence of some constraint is $\theta_{1}=0.906$, with $90 \% \mathrm{CI}=[0.75,0.98]$

\begin{tabular}{|c|c|c|c|c|c|}
\hline Variable & Intercept Median & Intercept CI & Language & Median & CI \\
\hline \multirow{4}{*}{ Morpheme Type Odds } & \multirow{4}{*}{1.06} & \multirow{4}{*}[0.11,2.01]{} & Bunan & 0.00 & {$[-0.75,0.95]$} \\
\hline & & & Burmese & 0.00 & {$[-0.77,0.96]$} \\
\hline & & & Chintang & 0.11 & {$[-0.48,1.37]$} \\
\hline & & & Mandarin & -0.07 & {$[-1.18,0.58]$} \\
\hline \multirow{4}{*}{ Domain Odds (Phonology) } & \multirow{4}{*}{-3.47} & \multirow{4}{*}[-4.03,-2.89]{} & Bunan & -0.06 & {$[-0.81,0.37]$} \\
\hline & & & Burmese & -0.11 & {$[-0.97,0.29]$} \\
\hline & & & Chintang & -0.02 & {$[-0.69,0.48]$} \\
\hline & & & Mandarin & 0.16 & {$[-0.24,1.01]$} \\
\hline \multirow{4}{*}{ Domain Odds (Grammar) } & \multirow{4}{*}{-3.46} & \multirow{4}{*}[-3.96,-2.95]{} & Bunan & -0.01 & {$[-0.6,0.35]$} \\
\hline & & & Burmese & 0.02 & {$[-0.39,0.52]$} \\
\hline & & & Chintang & 0.00 & {$[-0.47,0.45]$} \\
\hline & & & Mandarin & -0.02 & {$[-0.59,0.36]$} \\
\hline \multirow{4}{*}{ Constraint Count (Phonology) } & \multirow{4}{*}{-0.11} & \multirow{4}{*}[-1.39,0.73]{} & Bunan & -0.20 & {$[-1.39,0.52]$} \\
\hline & & & Burmese & -0.16 & {$[-1.38,0.65]$} \\
\hline & & & Chintang & 0.36 & {$[-0.29,1.84]$} \\
\hline & & & Mandarin & 0.18 & {$[-0.54,1.6]$} \\
\hline \multirow{4}{*}{ Constraint Odds (Phonology) } & \multirow{4}{*}{-0.22} & \multirow{4}{*}[-1.03,0.62]{} & Bunan & 0.27 & {$[-0.31,1.64]$} \\
\hline & & & Burmese & 0.00 & {$[-0.95,0.91]$} \\
\hline & & & Chintang & 0.00 & {$[-0.95,0.88]$} \\
\hline & & & Mandarin & -0.28 & {$[-1.72,0.32]$} \\
\hline \multirow{4}{*}{ Constraint Odds/Count (Grammar) } & \multirow{4}{*}{-0.49} & \multirow{4}{*}[-1.47,0.28]{} & Bunan & -0.03 & {$[-0.8,0.47]$} \\
\hline & & & Burmese & 0.02 & {$[-0.51,0.76]$} \\
\hline & & & Chintang & 0.00 & {$[-0.71,0.59]$} \\
\hline & & & Mandarin & 0.00 & {$[-0.75,0.56]$} \\
\hline \multirow{4}{*}{ Domain Size (Phonology) } & \multirow{4}{*}{0.60} & \multirow{4}{*}[-0.06,1.14]{} & Bunan & 0.03 & {$[-0.4,0.68]$} \\
\hline & & & Burmese & 0.08 & {$[-0.28,0.9]$} \\
\hline & & & Chintang & -0.09 & {$[-0.83,0.29]$} \\
\hline & & & Mandarin & -0.01 & {$[-0.62,0.56]$} \\
\hline \multirow{4}{*}{ Domain Size (Grammar) } & \multirow{4}{*}{1.70} & \multirow{4}{*}[1.43,1.96]{} & Bunan & -0.03 & {$[-0.4,0.18]$} \\
\hline & & & Burmese & 0.05 & {$[-0.15,0.42]$} \\
\hline & & & Chintang & 0.00 & {$[-0.27,0.29]$} \\
\hline & & & Mandarin & -0.02 & {$[-0.36,0.22]$} \\
\hline
\end{tabular}


These results suggest that the variation by language is minimal, except for the phonological constraints data. This is confirmed by the results from model performance comparison and from variance partitioning:

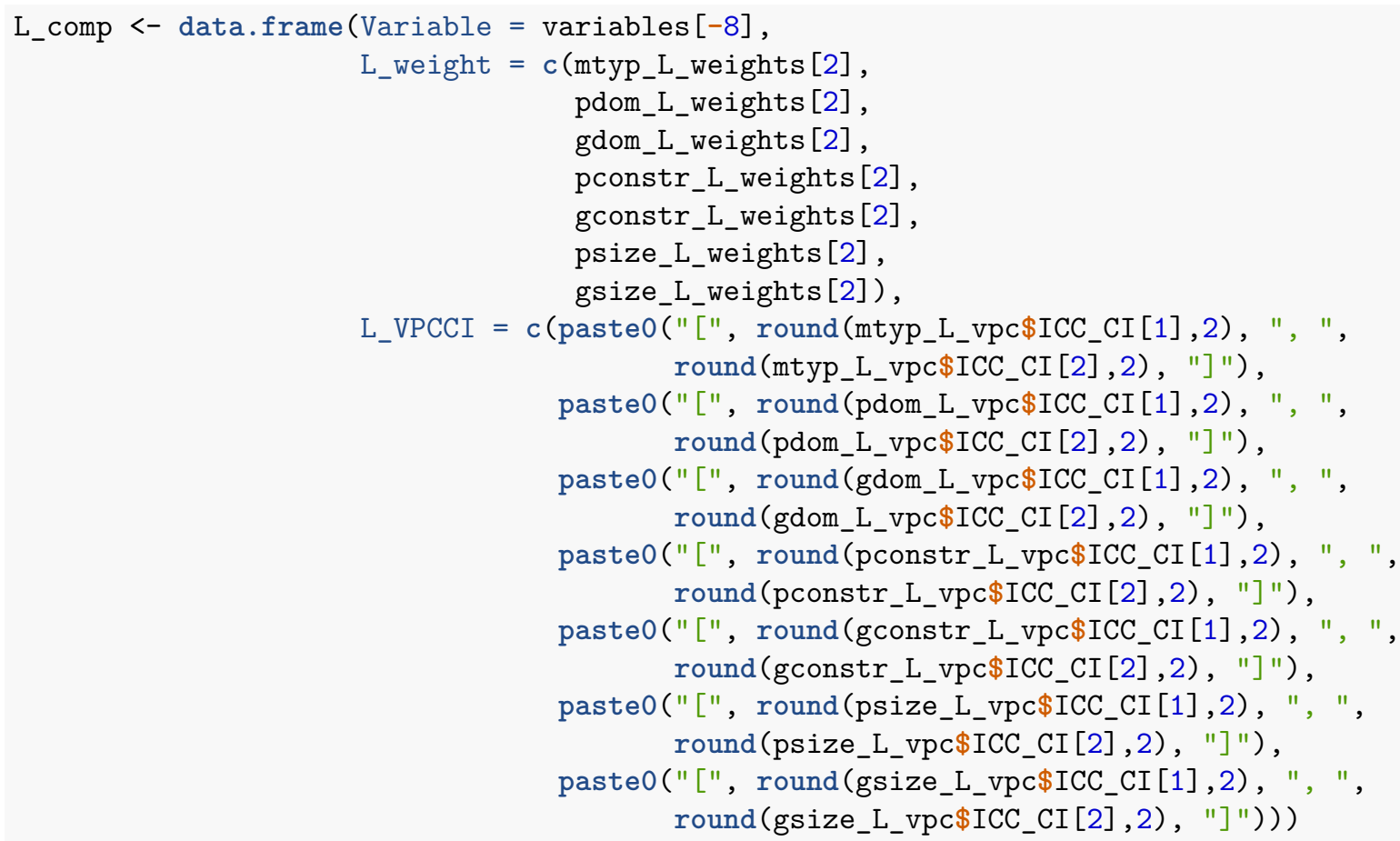

With the exception of phonological constraints again, models without varying intercepts by language consistently leverage more weights $(0.59$ - 0.71) than models with varying intercepts (Table S3). In line with this, the VPC estimates always include 0 even in their $50 \%$ credibility interval by a fair margin.

Table S3: Akaike weight of models without varying intercepts and the $50 \% \mathrm{CI}$ of the variance partition coefficient (VPC)

\begin{tabular}{lrl}
\hline Variable & Weight & VPC \\
\hline Morpheme Type Odds & 0.673 & {$[-0.15,0.17]$} \\
Domain Odds (Phonology) & 0.588 & {$[-0.29,0.17]$} \\
Domain Odds (Grammar) & 0.710 & {$[-0.23,0.19]$} \\
Constraint Odds/Count (Phonology) & 0.354 & {$[-0.46,0.32]$} \\
Constraint Odds/Count (Grammar) & 0.666 & {$[-0.68,0.42]$} \\
Domain Size (Phonology) & 0.666 & {$[-0.35,0.26]$} \\
Domain Size (Grammar) & 0.669 & {$[-0.33,0.24]$} \\
\hline
\end{tabular}

The exceptional status of the phonological constraints model is confirmed by the sensitivity analysis. Despite the strong priors against large intercept variation in the Bernoulli component $(\operatorname{Exp}(6))$, we find that the hurdle model as a whole leverages less weight without than with the varying intercept, with bootstrapped Akaike weight $=0.346$. This is the same estimate as the WAIC estimate for model with weaker priors in Table S3. The source of this is both the Bernoulli and the Poisson component (Table S2), although the model with stronger priors (unsurprisingly) reduces the variation in the Bernoulli component and shifts the signal to the Poisson component (Table S4).

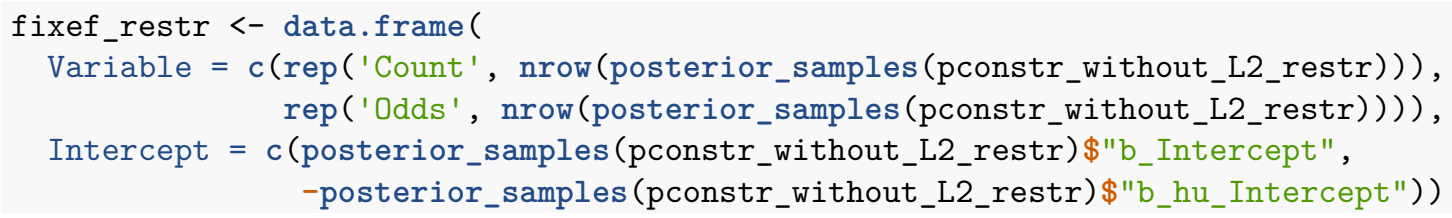




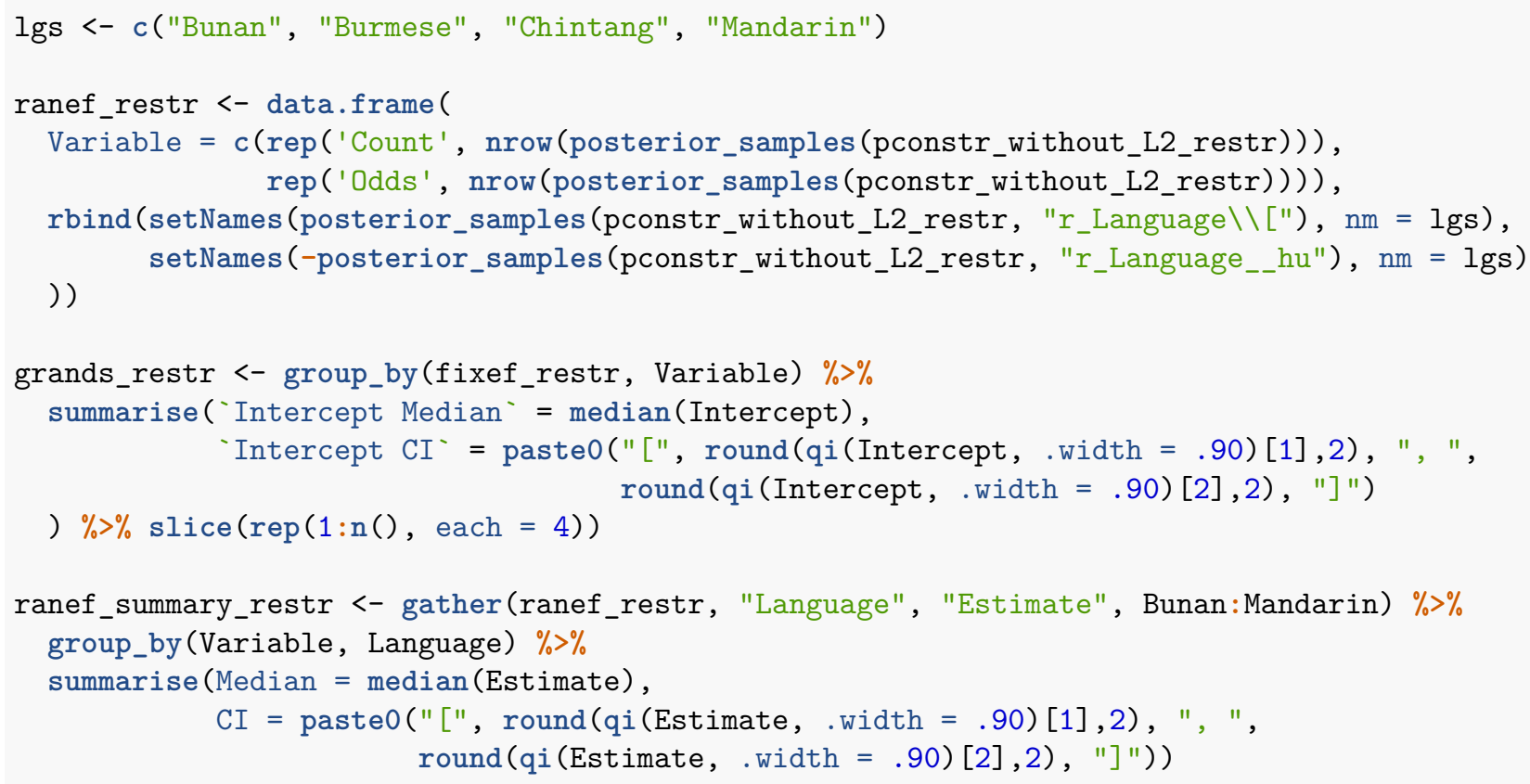

Table S4: Sensitivity analysis: Intercept and language-specific deviations from it in the phonological constraints model with stronger priors. CI $=90 \%$ (quantile-based) credible interval.

\begin{tabular}{|c|c|c|c|c|c|}
\hline Variable & Intercept Median & Intercept CI & Language & Median & $\overline{\mathrm{CI}}$ \\
\hline \multirow{4}{*}{ Count } & \multirow{4}{*}{0.22} & \multirow{4}{*}[-0.89,0.93]{} & Bunan & -0.25 & {$[-1.36,0.51]$} \\
\hline & & & Burmese & -0.18 & {$[-1.41,0.6]$} \\
\hline & & & Chintang & 0.43 & {$[-0.21,1.77]$} \\
\hline & & & Mandarin & 0.25 & {$[-0.49,1.57]$} \\
\hline \multirow{4}{*}{ Odds } & \multirow{4}{*}{-0.22} & \multirow{4}{*}[-0.81,0.35]{} & Bunan & 0.02 & {$[-0.17,0.48]$} \\
\hline & & & Burmese & 0.00 & {$[-0.3,0.31]$} \\
\hline & & & Chintang & 0.00 & {$[-0.29,0.29]$} \\
\hline & & & Mandarin & -0.02 & {$[-0.51,0.2]$} \\
\hline
\end{tabular}

However, these results do not support strong conclusions. The actual elpd estimates do not in fact differ much between models with and models without varying intercepts, with overlapping standard errors (Table S5), similar in fact to what we observe in the other models (see Sections S2.1 - S2.7). This is true under both weaker and stronger priors. Additional doubts come from the variance partition (VPC) estimates. Both the model with weaker and the model with stronger priors include 0 in their $50 \%$ CI VPC: $[-0.46,0.32]$ and [-0.39, 0.29], respectively, so the predicted variance between languages seems to be in a similar ballpark as the total variance.

These observations are further confirmed by posterior predictive checks (Gabry et al. 2019). There is no appreciable difference in model fit between models with (Figure S2) and models without (Figure S3) varying intercepts, and this also true for the phonological constraints model. There are only few $90 \%$ CIs that fail to include the observed data. ${ }^{5}$

\footnotetext{
${ }^{5}$ The example in the main text is computed via log(mean(gsize $\$$ Size)) and group_by (gsize, Language) $\%>\%$ summarize $(\log (\operatorname{mean}(\operatorname{Size})))$
} 
Table S5: Expected log pointwise predictive density (elpd) estimates for the phonological constraints models. Note that for the models with weaker priors, these estimates are based on the WAIC, but for those with stronger priors, they are based on Pareto-smootheed importance sampling with moment matching (PSIS+; cf. Section S2.4)

\begin{tabular}{llrr}
\hline Priors & Models & elpd & SE \\
\hline \multirow{2}{*}{ Weak } & With varying intercepts by language & -50.1 & 7.08 \\
\cline { 2 - 4 } & Without varying intercepts by language & -50.7 & 7.03 \\
\hline \multirow{2}{*}{ Strong } & With varying intercepts by language & -51.3 & 7.05 \\
\cline { 2 - 4 } & Without varying intercepts by language & -52.2 & 6.95 \\
\hline
\end{tabular}



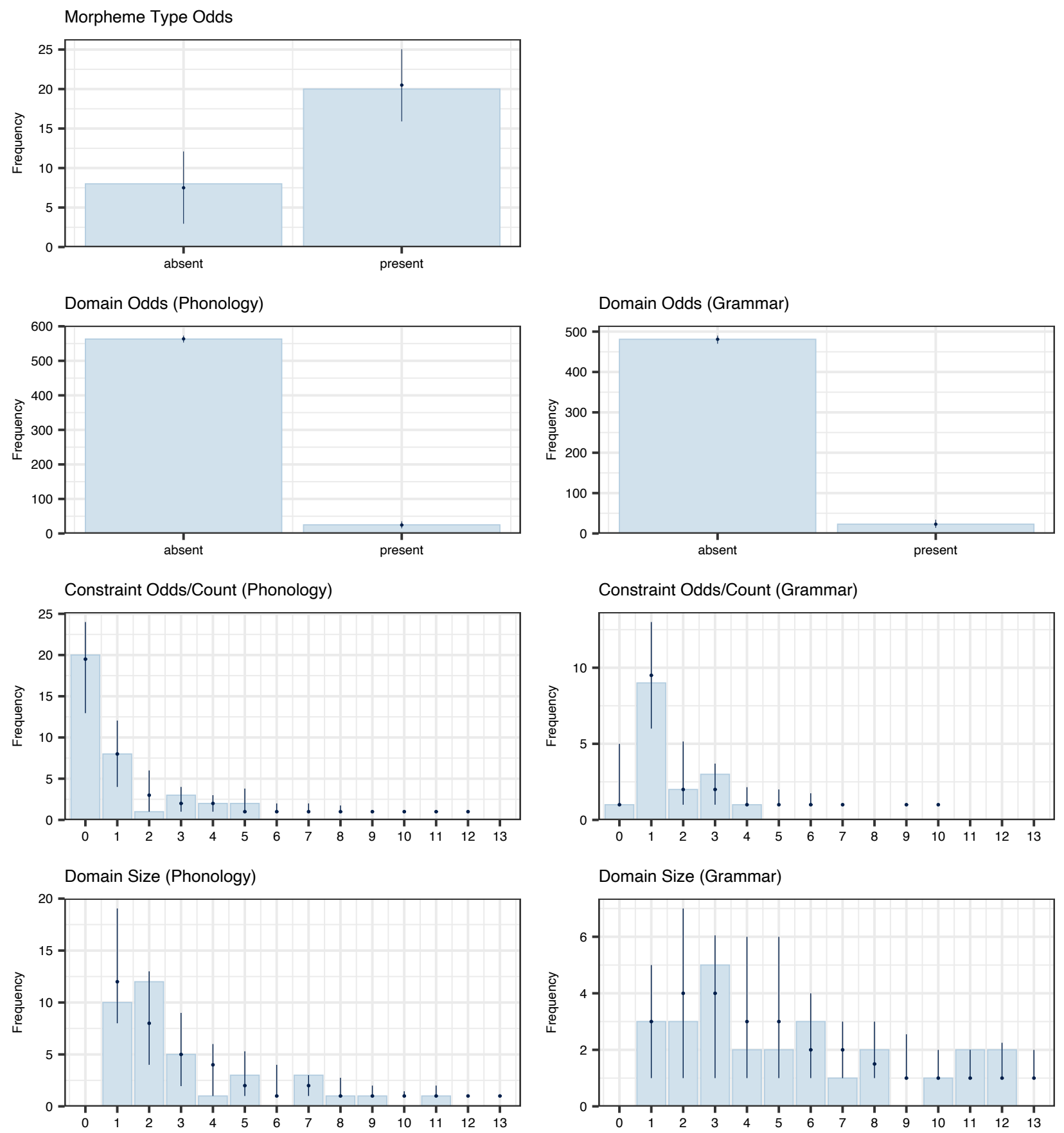

Figure S2: Posterior predictive checks of models without the L2 factor. The blue bars represent the frequencies of presence/absence and the counts/sizes in the observed data. The black dots are the median posterior predictions and the lines capture their $90 \%$ CI. 


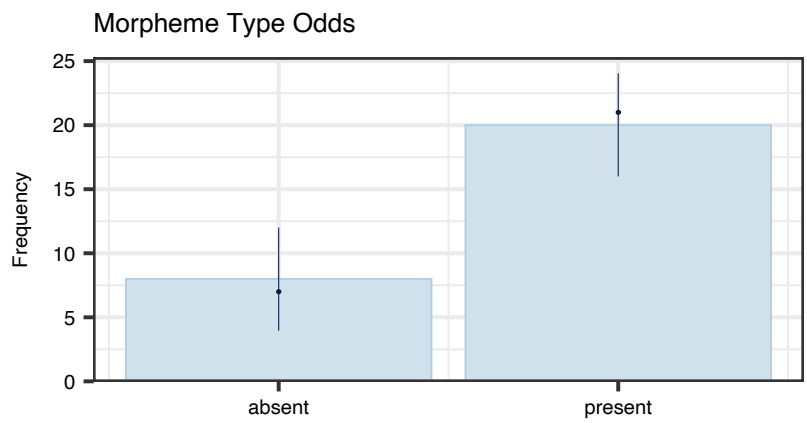

Domain Odds (Phonology)

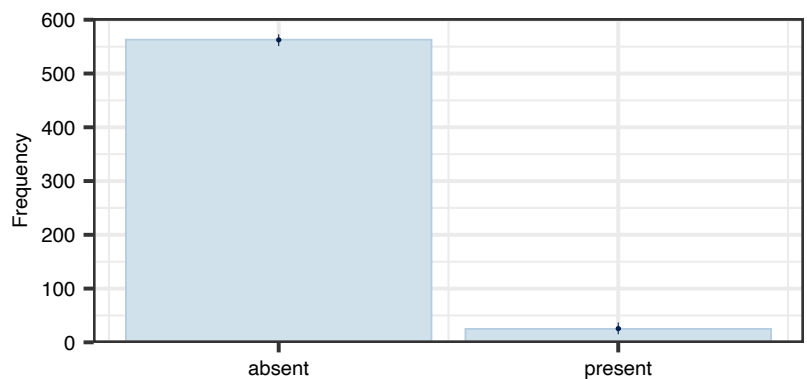

Domain Odds (Grammar)

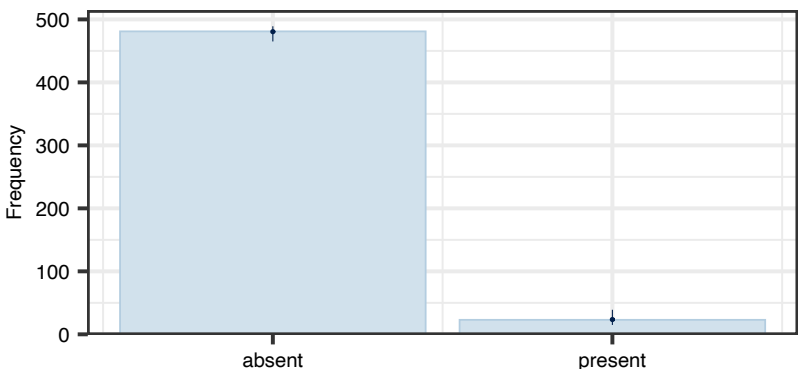

Constraint Odds/Count (Phonology)

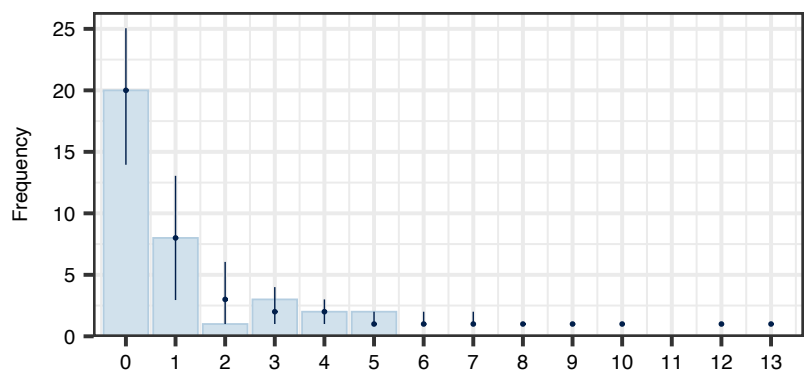

Constraint Odds/Count (Grammar)

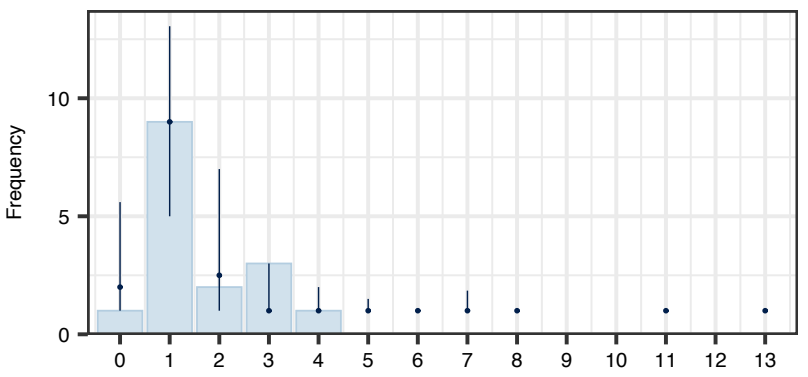

Domain Size (Phonology)
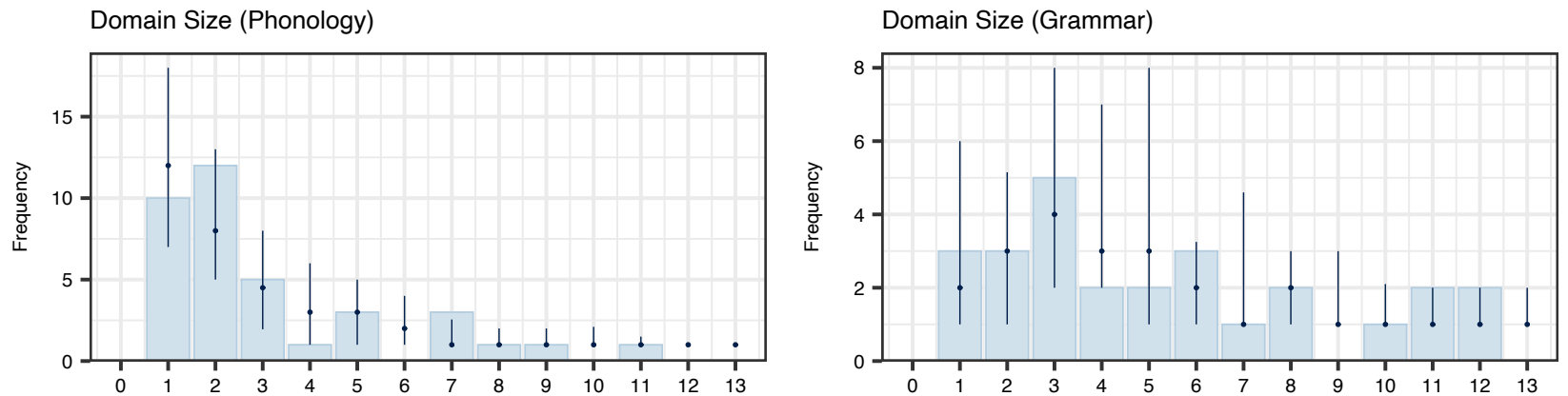

Figure S3: Posterior predictive checks of models without the L2 factor and without varying intercepts. Same plotting conventions as in Figure S2. 


\section{References}

Bürkner, Paul-Christian. 2018. Advanced Bayesian Multilevel Modeling with the R Package brms. The $R$ Journal 10. 395-411.

Carpenter, Bob, Andrew Gelman, Matthew D. Hoffman, Daniel Lee, Ben Goodrich, Michael Betancourt, Marcus Brubaker, Jiqiang Guo, Peter Li \& Allen Riddell. 2017. Stan: A Probabilistic Programming Language. Journal of Statistical Software 76.

Gabry, Jonah, Daniel Simpson, Aki Vehtari, Michael Betancourt \& Andrew Gelman. 2019. Visualization in Bayesian Workflow. J. R. Stat. Soc. A 182. 389-402.

Gelman, Andrew, Aleks Jakulin, Maria Grazia Pittau \& Yu-Sung Su. 2008. A Weakly Informative Default Prior Distribution for Logistic and Other Regression Models. The Annals of Applied Statistics 2. 1360-1383.

Harrison, Xavier A. 2014. Using Observation-Level Random Effects to Model Overdispersion in Count Data in Ecology and Evolution. PeerJ 2. e616.

Lüdecke, Daniel, Dominique Makowski, Philip Waggoner \& Indrajeet Patil. 2020. performance: Assessment of Regression Models Performance.. R Package, https://easystats.github.io/performance.

McElreath, Richard. 2020. Statistical Rethinking (Second Edition). Boca Raton, FL: CRC Press.

Paananen, Topi, Juho Piironen, Paul-Christian Bürkner \& Aki Vehtari. 2019. Implicitly Adaptive Importance Sampling.. ArXiv [https://arxiv.org/pdf/1906.08850.pdf].

Vehtari, Aki, Andrew Gelman \& Jonah Gabry. 2016. Practical Bayesian Model Evaluation Using LeaveOne-Out Cross-Validation and WAIC. Statistics and Computing 27(5). 1413-1432.

Yao, Y, A Vehtari, D. Simpson \& A. Gelman. 2018. Using Stacking to Average Bayesian Predictive Distributions. Bayesian Analysis 10. 10.1214/17-BA1091. 